\title{
Inequality, networks and exclusion : distributive decision making in small-scale societies
}

Citation for published version (APA):

d'Exelle, B. (2008). Inequality, networks and exclusion : distributive decision making in small-scale societies. [Doctoral Thesis, Maastricht University]. Datawyse / Universitaire Pers Maastricht. https://doi.org/10.26481/dis.20080528be

Document status and date:

Published: 01/01/2008

DOI:

10.26481/dis.20080528be

Document Version:

Publisher's PDF, also known as Version of record

\section{Please check the document version of this publication:}

- A submitted manuscript is the version of the article upon submission and before peer-review. There can be important differences between the submitted version and the official published version of record. People interested in the research are advised to contact the author for the final version of the publication, or visit the DOI to the publisher's website.

- The final author version and the galley proof are versions of the publication after peer review.

- The final published version features the final layout of the paper including the volume, issue and page numbers.

Link to publication

\footnotetext{
General rights rights.

- You may freely distribute the URL identifying the publication in the public portal. please follow below link for the End User Agreement:

www.umlib.nl/taverne-license

Take down policy

If you believe that this document breaches copyright please contact us at:

repository@maastrichtuniversity.nl

providing details and we will investigate your claim.
}

Copyright and moral rights for the publications made accessible in the public portal are retained by the authors and/or other copyright owners and it is a condition of accessing publications that users recognise and abide by the legal requirements associated with these

- Users may download and print one copy of any publication from the public portal for the purpose of private study or research.

- You may not further distribute the material or use it for any profit-making activity or commercial gain

If the publication is distributed under the terms of Article $25 \mathrm{fa}$ of the Dutch Copyright Act, indicated by the "Taverne" license above, 


\section{Inequality, Networks and Exclusion:}

Distributive Decision Making in Small-scale Societies 
(C) Ben D’Exelle, 2008

Universitaire Pers Maastricht ISBN 978-90-5278-720-6 


\title{
Inequality, Networks and Exclusion:
}

Distributive Decision Making in Small-scale Societies

\author{
PROEFSCHRIFT
}

ter verkrijging van de graad van doctor

aan de Universiteit Maastricht, op gezag van de Rector Magnificus, prof. mr. G.P.M.F. Mols

volgens het besluit van het College van Decanen,

in het openbaar te verdedigen op

woensdag 28 mei 2008 om 12.00 uur

door

\section{Ben D’Exelle}

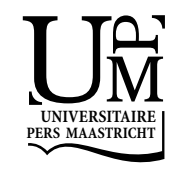




\section{Promotor}

Prof. dr. A.M. Riedl

\section{Copromotor}

Dr. J. Bastiaensen (Universiteit Antwerpen, België)

\section{Beoordelingscommissie}

Prof. dr. F. Palm (voorzitter)

Prof. dr. J.-C. Cardenas (Universidad de los Andes, Colombia)

Prof. dr. J. Sonnemans (Universiteit van Amsterdam, Nederland)

Dr. M. Strobel

Het in dit proefschrift beschreven onderzoek werd mede mogelijk gemaakt door het Instituut voor Ontwikkelingsbeleid en -beheer van de Universiteit Antwerpen. 


\section{Contents}

\section{Acknowledgements v v}

1. Motivation and Outline 1

2. Excluded Again: Village Politics at the Aid Interface 7

1. Introduction ...................................................................... 7

2. Conceptual issues ................................................................. 9

2.1. Encounters at the interface .......................................... 9

2.2. The politics behind aid brokerage .................................. 10

2.3. Political change processes at the interface ....................... 12

3. Empirical review ................................................................ 13

3.1. The use of aid brokerage ............................................... 14

3.2. Brokerage and exclusion from aid ................................. 17

3.3. Brokerage concentration and village access to aid ............. 21

3.4. Perspectives for political change ..................................... 22

4. Conclusion: The role of aid providers ..................................... 26

3. Aid Brokerage, Voice and Exclusion in Heterogeneous Com- 29 munities: A Laboratory Study

1. Introduction ….................................................................... 29

2. Related literature ................................................................ 31

3. Experimental design .............................................................. 34

3.1. A non-cooperative distribution game with voting for pun- 35 ishment

3.2. Experimental procedures and parameters ........................ 39

4. Empirical results .............................................................. 42 


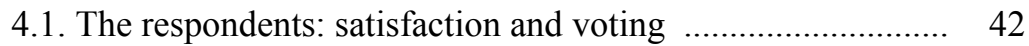

4.2. The representatives ........................................................ 49

4.3. Political change ............................................................ 61

5. Conclusion …......................................................................... 64

Appendix 1: Experimental procedures and instructions ................ 65

Appendix 2: An outcome-based fairness model ......................... 69

Appendix 3: When the low-income player becomes the representa- 76 tive

4. Social Networks and Exclusion: A Field Experiment on 79

Distributive Decision Making in a Poor Rural Community

1. Introduction ........................................................................... 79

2. Literature …..................................................................... 81

3. Research design ................................................................. 82

3.1. Household and social network survey ............................ 82

3.2. Dictator game experiment .............................................. 83

4. Results ..................................................................... 85

4.1. Some descriptive statistics ............................................ 85

a. General socio-economic characteristics of the studied village 85

b. Some descriptive network statistics ................................. 86

4.2. Experimental results ........................................................ 91

4.3. Social link formation ....................................................... 100

5. Conclusion …...................................................................... 102

Appendix 1: Regression results ............................................. 104

Appendix 2: Experimental instructions ......................................... 112

Appendix 3: Procedures of household survey, network survey and 114 experiment

Appendix 4: Post-experimental questionnaire ............................ 117

Appendix 5: Household survey ................................................ 121

Appendix 6: Network survey ................................................... 124

5. Social Capital Formation and Economic Inequality: 125 A Laboratory Study

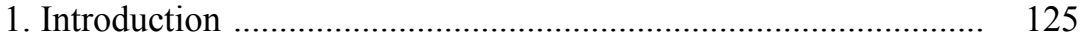


2. Related literature ............................................................ 127

3. Experimental design ................................................................ 131

4. Empirical findings ..................................................................... 133

4.1. The evolution of network density .......................................... 135

4.2. Requesting support …………….................................... 137

4.3. Giving support ........................................................... 141

a. Support-giving and the number of preceding investment $\quad 142$ opportunities

b. Support-giving before first investment opportunity ............... 143

c. Support-giving after first investment opportunity .................. 146

4.4. Explaining differences in group aggregated tie strength $\quad 150$

4.5. Structure of the formed networks of social ties .................. 152

4.6. Final distributive results .................................................... 154

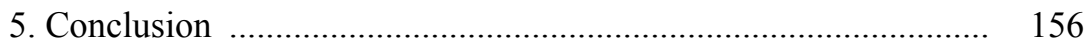

Appendix 1: Experimental procedures and instructions ................... 157

Appendix 2: Personality dimensions ……...................................... 160

$\begin{array}{lll}\text { 6. Conclusion } & 163\end{array}$

$\begin{array}{ll}\text { References } & 167\end{array}$

Nederlandse Samenvatting (Summary in Dutch) 175

$\begin{array}{ll}\text { Short Curriculum Vitae } & 182\end{array}$ 



\section{Acknowledgements}

The trajectory that I followed to come to this work has been rather special. The preparation of this thesis did not start immediately after completing my Master studies. Whereas I officially started my $\mathrm{PhD}$ at Maastricht University in September 2005, there was already a long history before . . .

My journey started ten years ago, in 1998, when I finished the PhD. program of the Faculty of Applied Economics at the University of Antwerp (Belgium). Thereafter, I left for more than three years to work as a resident researcher at Nitlapán, a research and development institute at the Central American University in Nicaragua, where I was able to begin to understand the complexity and challenges of development, inequality and poverty in rural Nicaragua. During this stay, the initial ideas for this thesis were born. As I truly believe that any serious research on poverty, social exclusion and networks in a development context requires a thorough understanding of local culture, norms and attitudes, I am convinced that this experience has been invaluable. Therefore, my first thanks go to my former colleagues in Nicaragua and the rural peasants I have learned so much from. Muchas gracias por la confianza, la amistad y las discusiones interesantes que han contribuido a mi capacidad de entender la realidad Nicaragüense. Es mi deseo y esperanza que podamos continuar nuestra cooperación y que este libro pueda contribuir de alguna manera a un mayor entendimiento de pobreza y exclusión social, y como combatirlas.

When I started at the Institute of Development Policy and Management (IOB - University of Antwerp) in 2002 it was a logical step to do further academic research on the topics I had studied in Nicaragua. When I learned how enormously helpful experimental methods could be for my research, I decided, in September 2004, to establish contact with the Centre for Research in Experimental Economics and Political Decision Making (CREED) at the University of Amsterdam, one of the leading centres in Europe for experimental research in economics and political science.

My first contacts with CREED were made through Prof. Arthur Schram, to whom I am very grateful for giving me the opportunity to come and present my 
research ideas. It was there where I first met my promoter Prof. Arno Riedl, who agreed to support my research. During a full year, I was regularly visiting CREED and benefiting from many interesting discussions with, among others, Jens Großer, Astrid Hopfensitz, Ernesto Rueben, Christian Traxler, Aljaz Ule, Eva Van den Broek and Joep Sonnemans.

In September 2005, Arno moved to Maastricht University (MU) and I, without hesitation, followed. I am very grateful for his dedication to this project, and for his supportive and honest critiques. They have helped me become a better researcher and meet the high standards expected of academic research. I am also grateful to other colleagues at MU who helped me to improve my experimental designs, either through informal discussions, the formal meetings of the Behavioural and Experimental Economics group, or through their participation in experimental pilots. I am also grateful to Martin Strobel for giving me advice on Z-tree programming.

I am highly indebted to my colleagues at the IOB who granted me sufficient freedom to pave my own path and to look for cooperation with researchers at other universities. Given the very different and unique characters of the IOB, a development institute focusing on policy recommendations, and the Faculty of Economics and Business Administration of Maastricht University which undertakes fundamental research, I was fully aware of the high-risk / high-yield potential of such cooperation. I am convinced that I and this project have benefited from this approach, and it is my hope that this document is appreciated by both institutions.

The research documented in this work also benefited from the financial support provided by VLIR-UOS, IOB-UA and the Oesterreichische Nationalbank (project number 11429, title: 'Experimental analysis of the formation, dynamics and economic consequences of social networks').

Last, but not least, I want to thank Katrien, my wife, and our children Xochilt, Leon and Oona, as well as my parents and parents-in-law for their emotional and practical support. During the last months, 'my PhD' became an often-used excuse for why I was less available during the weekends to spend time with my family. As proof of his close concern, my four-year old son invented his own favourite game: 'writing his own PhD'. I am happy that now, once again, I have time to encourage him to play more joyful games. 


\section{Motivation and Outline}

This work studies distributive decision making and exclusion processes in economically unequal small-scale societies. It builds on the increased recognition within economics that economic actors are embedded in social structures, which exert a determinant influence on their decision making and the related performance of markets and organizations (Granovetter, 1985). With small-scale societies, we refer to societies that are characterized by repeated and frequent interactions among their members. Examples range from social relations on the job floor of companies in well-developed economies to social relations in rural villages in countries confronted with extreme poverty.

More specifically, we will study how the embeddedness of economic agents in small-scale societies influences distributive decision making and exclusion processes. We will not only look at the individual decision making of agents who distribute economic resources, but also at the decision making of potential recipients of these resources when they are given the means to react. In other words, we will also examine the political dimensions at work when economic resources are distributed within small-scale societies. Ultimately, taking account of the decision making of both distributors and potential recipients of economic resources, we want to identify and understand the processes responsible for the reproduction of economic inequality.

Although these issues are important in many settings, where possible, we will focus on their relevance for local development and poverty reduction. Recently, economic inequality has received renewed attention within the debate on how to combat global poverty and stimulate economic development. The World Bank concluded in its 2006 World Development Report that correction of economic inequity has the potential to facilitate sustained development and poverty reduction. This justifies why policy makers should pay attention to the equity implications of their policies, and why it may be justified to implement redistributive policies.

This debate is particularly relevant in Latin America, where we conducted field research for this thesis. Income distributions in this continent are among the most unequal in the developing world. As early as 1990, the World Bank 
stated that "nowhere in the developing world are the contrasts between poverty and national wealth more striking than in Latin America and the Caribbean. Despite average per capita incomes that are five to six times those in South Asia and Sub-Saharan Africa, nearly one-fifth of the population still lives in poverty" (World Bank, 1990: 141). Based on recent evidence, the current picture has barely changed as economic inequality in Latin America remains among the highest in the developing world (WDR, 2006). The main question is, therefore, why such inequality can be so persistent.

One of the main reasons relates to the fact that inequity-reducing policies often face a lack of political feasibility (Sen, 1995). The bottom line is, of course, that when designing and implementing redistributive policies, policy makers have to pay attention to voters' preferences and that politically the poorest groups tend to be weakly represented. In the same vein, it has often been documented how programs and policies that are intended to benefit the 'poor' are often of 'poor' quality (Goodin \& Le Grand, 1987), as they lack the support of more powerful sectors.

In this work, we focus on two elements that have received insufficient attention within the policy debate and that might exert an important influence on the political feasibility of redistributive policies. Both are related to the 'social distance' between the agents involved.

First, it is often ignored that those people affected by redistributive policy schemes are embedded in social networks. The importance of social networks, and their influence on the feasibility of redistributive schemes, is well illustrated by the armed peasant resistance against the Nicaraguan government in the early 1980s. Particularly striking is the fact that some of the poor peasants who had previously fought for the Sandinista revolution took up arms against the revolutionary Sandinista government. Among other reasons, their resistance resulted from a reaction against the potentially negative side-effects a national redistribution program, through state-led agrarian reforms, would have on local social networks (Horton, 1998). Many poor peasants had established informal support relationships with large landowners which guaranteed them privileged access to essential resources. The Sandinista agrarian reform, based on the confiscation of large private properties, affected these landowners and thereby endangered peasants' access to these resources. Accordingly, many peasants perceived the government's redistributive program as a serious threat, even if the government had promised them land, employment and social services. This illustrates how social networks have to be seriously considered when implementing redistributive economic policies, as they are an important source of resources and opportunities to the agents involved. 
Second, it is often assumed that the agents who take distributive decisions are socially distant from the potentially benefited and affected. This is the case when the central state is the only agent that takes distributive decisions. However, with policy makers paying increasing attention to decentralization and local participation (World Bank, 2000), this assumption becomes quite unrealistic. To the extent that discriminatory power to (re)distribute is transferred to the local level, social distance decreases between those who distribute resources and those who are potentially benefited or affected.

It is the objective of this work to come to a better understanding of the complex processes behind exclusion and persistent inequality, and the influence social networks and economic inequality exert on them. For this, we look at distributive decision making within small-scale societies using different tools such as surveys, laboratory experiments and field experiments.

This work starts with an empirical field study on the influence community representatives exert on exclusion rates from development aid (chapter 2). Making use of a household survey in 33 Nicaraguan rural villages, we observe that many people rely on community representatives to obtain access to outside aid resources. We also observe that village representation structures can exert a determinant influence on (recurrent) aid exclusion processes. In particular, the more representation is monopolized by a limited number of representatives, the larger becomes the group that is excluded from all aid resources. Since the poorest rely especially on community representatives to facilitate access to aid, they are the most vulnerable to this type of exclusion. As a more decentralized representation structure should lessen this type of exclusion, we have looked at the local politics responsible for the perpetuation and/or transformation of these structures.

Several impediments to political change are identified. First, in villages with more centralized representation fewer political alternatives are identified, and so opportunities for a more decentralized structure are more limited. Second, the most excluded there-in know fewer representatives and have less ability to propose political alternatives. Consequently, if political change is supported from within a community, it is not likely that it will improve representation for the most excluded. We conclude, therefore, that there is a strong case for a more active role of external aid donors.

In the following chapters, we extend this work in two directions - the political economy at work behind distributive decision making in small-scale societies and the importance of social ties and social network positions. In chapter 3, we examine the political economy at work when a permanent group representative distributes economic resources among group members. We study 
the strategies of community members who have the option to protest against the distributive decisions of this local representative, and how they interact with the strategies of the representative. For this, we make use of a laboratory experiment. This experiment consists of a repeated game wherein a permanent group representative; the richest of an economically-heterogeneous group, distributes resources among group members. The latter are given the opportunity to punish the representative by means of simple majority voting. Four different treatments are organized by combining conditions of public and private information on the distribution and voting decisions.

The experimental results show that the lower the share of the resources a respondent receives from the representative, the lower his/her satisfaction about this share. When receiving information on the complete distribution, his/her satisfaction also decreases the more a representative keeps for him/herself, and the less the respondent receives in comparison with other respondents. As expected, lower satisfaction increases the propensity to vote in favour of punishing the representative. In addition, there are important strategic elements behind voting decisions. When voting decisions are made public, respondents are somewhat more reluctant to vote in favour of punishment, but this reluctance decreases with lower satisfaction. Moreover, the more a respondent believes that both other respondents will vote in favour of punishment, the more he/she is inclined to do so as well. Furthermore, it is observed that female or middleendowment respondents are more reluctant to vote in favour of punishment unless information on the distribution is public. This results in significantly higher punishment rates with common information on the distribution decisions.

When punishment rates are high, representatives tend to follow a strategy of keeping all the resources to themselves. This is the case in all treatments except with public voting and private information on the distribution. Under the latter, representatives are able to keep punishment rates down by successfully applying an exclusion strategy, wherein one respondent is completely excluded from the distributed resources. In most of the cases, it is the poorest respondent who is excluded in this way.

To study the influence of political change in favour of the poorest, we organized a second scenario with the poorest player as the permanent representative. We observe that the final distribution of earnings becomes much more equal and that punishment rates are substantially lower for all treatments. This type of political change is thus beneficial in both distributional and efficiency terms.

In chapter 4, we examine the influence of real social networks on distributive decision making. In particular, we study to what extent social network 
positions are taken into account when agents make distributive decisions. For this we conducted a series of dictator game experiments in a rural Nicaraguan village, complemented by a social network survey. The results indicate that social network positions correlate strongly with generosity, but that this correlation is highly contingent upon the type of network we look at. Social proximity in general networks, friendship networks and extended family networks, increases generosity. In addition, generosity increases the more the dictator's friends have relatively few other friends, the denser the support networks of the dictator, the smaller the family networks of the dictator and/or the recipient (if both have a direct family relation), and the larger the recipient's ego network through social public activities. Finally, looking at the determinants of network formation, we found that the poor, the less mobile, women and young people have a lower likelihood of links with other village members. Accordingly, these people are more vulnerable to exclusion because they tend to be more socially isolated from others.

Whereas chapter 4 confirmed the importance of social networks in distributive decision making, in chapter 5 , we look at how networks of social ties are formed and how economic inequality exerts an influence on them. For this, we conducted a laboratory experiment that consists of a repeated 'favour game' with groups of six players. In each round, one player is randomly chosen to have the opportunity to ask one or more of the other five players for support. Each player that is asked for support then decides on the amount of support to give, which is multiplied with an efficiency factor.

The results confirm that both favour requests and favour giving are influenced by direct reciprocity motives and by individual beliefs about future returns. Both expected returns and direct reciprocity are somewhat biased by economic inequality. High-endowment players give more support to lowendowment players than what the latter give to them, and this difference becomes larger, the larger the most recent support they received from lowendowment players. At the same time, low-endowment players are more likely to request support from high-endowment players than from low-endowment players, and if asked for support tend to give more support to high-endowment players than to other low-endowment players. They do so because they (correctly) expect higher returned support from high-endowment players. It is this bias in reciprocity and expectations which lies at the heart of certain centralization in the formed networks of social ties in economically-heterogeneous groups. It also explains why, in such groups, very high levels of support-giving can be obtained if significant support is given between low-endowment players and from low-endowment players to high-endowment players early in the game. 



\section{Excluded Again: Village Politics at the Aid Interface}

\section{Introduction ${ }^{1}$}

By now, it is generally recognized that the romantic view of local communities as homogenous entities - often implicit in community-based or other participatory development approaches - is problematic (Cleaver, 1999; Kothari, 2001; Mosse, 2001; Platteau \& Abraham, 2002). Just as society as a whole, local communities are indeed places where different and often conflicting interests coexist. One can therefore not assume that agents operating as intermediaries at the interface between their community and outside aid donors automatically represent and respond to all community members. All too often, aid resources are captured by local elites (Galasso \& Ravallion, 2001; Conning \& Kevane, 2002; Platteau \& Abraham, 2002; Platteau \& Gaspart, 2003; Ravallion, 2003). It has been less documented, however, how this implies that certain groups of people tend to be excluded from aid resources. To the extent that interface structures remain unchanged, the same group of people may be excluded from each aid donor that arrives at the village. This justifies the need for a study of the possibilities of transforming the aid interface, so that this type of recurrent exclusion is reduced. The following case of a village in rural Nicaragua exemplifies our starting-point:

In this village, a small group of land-rich peasants had historically dominated the interface with aid projects. They organized village meetings when development projects asked for such and they identified village needs. As a result, development

\footnotetext{
${ }^{1}$ I am highly indebted to the Nicaraguan research and development institute Nitlapán-UCA for its cooperation and support, with special thanks to Miguel Alemán Robleto for support on the survey design, the fieldwork and several interesting discussions. Substantial improvements were realized thanks to useful comments on earlier versions by Tekabe Ayalew, Johan Bastiaensen, Tom De Herdt, Renato Flores, Nathalie Holvoet, Wendy Janssens, Nadia Molenaers, Jean-Philippe Platteau, Robrecht Renard, Jos Vaessen and Bjorn Van Campenhout.
} 
actors mainly supported productive activities apt for land-rich peasants, whereas the considerable land-poor part of the village remained neglected.

Important at this interface is the village committee, representing the village to the mayor of the municipality to which the village belongs, which was also dominated by the land-rich elite. About a year before our visit, however, a local assembly managed to replace this committee by a new one that was more representative of the ample landless sector. This change was the result of a clear rejection of the old elitist committee by the landless. According to some informants, the open rejection of the most powerful local broker and president of the village committee by the mayor was instrumental for the coordinated collective action to reject the existing village committee. The new village committee, however, is less experienced and less well connected with aid providers than its predecessor. During a focus group interview, we observed that they did not have many project ideas that could attract the attention of potential aid donors.

Undoubtedly, every development worker at the grassroots could report numerous anecdotes of local elites being highly active at the interface. Far less attention is paid, however, to how such situation may make certain community sectors recurrently excluded from aid flows. In this respect, our case calls several important questions to attention. First, abstracting from local specificities, can we generalize on the importance of interface structures and its influence on exclusion processes? More particularly, does the concentration of intermediation among a limited number of agents increase the proportion of people recurrently excluded from aid resources? Second, if this is the case are the poor more vulnerable to this kind of exclusion? Third, if both previous questions are confirmed, it is important to understand how interface structures are (re)created, and what role local agents can have in political change processes. In particular, to what extent are the recurrently excluded able to change representation structures? Fourth, studying these processes, it is important to examine the potential dangers that political change entails in terms of reducing a community's potential to attract future aid resources. Finally, questions concerning the role policymakers can play in political change processes arise.

Making use of a household survey in 33 rural villages in Nicaragua, our empirical evidence confirms that the concentration of intermediation in a limited number of agents strongly increases the village proportion of households excluded from all aid. In combination with the evidence that it is especially the poor that rely on local intermediation to obtain access to aid, this correlation strongly suggests that the political change in the direction of a more decentralized intermediation structure has the potential to benefit especially the poor.

Several impediments to political change are identified. First, in villages with more centralized representation fewer political alternatives are identified, so that the perspectives for a more decentralized structure are more limited. 
Second, the most excluded know fewer representatives and have less ability to propose political alternatives. Consequently, if political change is supported from within a community, it is not likely that it will improve representation for the most excluded. We conclude, therefore, that there is a strong case for a more active role of external aid donors.

\section{Conceptual issues}

To address the research questions outlined above, we first define some concepts and describe some processes related to the (re)creation of intermediation structures at the interface. In particular, we elaborate in this conceptual section on interface brokerage, the politics behind brokerage and political change processes. In the course of this section, we formulate specific hypotheses that will be tested in the empirical section.

\subsection{Encounters at the interface}

The worlds of the development community and people in local communities tend to be so divergent, that specialised 'interface brokers' are required to bridge both worlds (Bierschenk et al., 2000; Long, 2001). According to Burt (1995) brokers are agents who occupy a bridging function between different social agents. Interface brokers are brokers from local communities who operate at the interface with the outside donor community and therefore occupy a bridging function between agents in both worlds.

Brokerage at the interface may not only be profitable for brokers, who have privileged access to the resources provided by aid donors. It may also be for the other parties involved. For peer community members brokers are useful as they have the capacity to attract external aid flows. Brokers often have valuable assets, such as previously built trust relations with aid providers, the knowledge and understanding of the current development discourse pursued by aid providers as well as the capacity to act on this discourse (Laurent, 1998). For aid donors, brokers are useful as they can facilitate local operations. In this respect, brokers' access to local information, their capacity to contribute to the analysis of local problems, and their ability to convoke and convince local people are important assets.

It should be clear, however, that not all community agents need intermediation by interface brokers to get in contact with external donors. As documented by Bierschenk et al. (2000) the capacity to work at the interface and to make 
contact with aid providers is mainly acquired through experience at the interface. In particular, we expect that the economically better off are in a better position to gain this experience, as they usually also have higher social and geographical mobility. For this reason, we expect them to have more capacity to make direct contact with aid providers, whereas the poorer community members have to rely relatively more on interface brokers to obtain access to the development community and its resources. This will be tested in the empirical section as hypothesis $1 \mathrm{a}$.

Also on the donor side, not all actors may make equal use of interface brokers. Brokers tend to maintain patron-client relations, characterized by rules of loyalty and paternalistic protection, which are difficult to make compatible with the rules of a market-oriented program, such as objective selection procedures and credit repayment under all conditions (Bastiaensen \& D'Exelle, 2002). Market-oriented programs may therefore be reluctant to rely on interface brokers. In contrast, programs that channel resources by means of donations may rely more on the participation of community brokers for the definition and management of their activities. Moreover, brokers themselves may also be more interested in resources with less severe strings attached because such resources can be more easily conditioned on political loyalty (see next section on this). This leads to hypothesis $1 \mathrm{~b}$ : In comparison with other types of projects, it is less likely that market-oriented projects relations are intermediated by interface brokers.

\subsection{The politics behind aid brokerage}

Aid donors, interface brokers and community members are involved in a political game around the attraction and local distribution of aid resources. The power interface brokers can accumulate in this game depends on several elements.

First, as information carriers at the interface, brokers have a privileged position to manipulate information flows to aid providers. This is evident when aid providers entrust brokers the task to identify local needs (and thus implicitly the criteria to select potential beneficiaries). Yet, this is also the case when aid providers rely on potentially more democratic methods for this purpose, like village meetings. Brokers are often the conveners of such meetings and thus influence their composition. Some agents may not be invited to participate in these meetings, so that their interests remain unrepresented. Moreover, even if there are different interests represented in such meetings, it is unclear if these are equally taken account of. To the extent that these meetings are based on public 
discussion and consensus seeking, it is likely that the interests of the dominant are acknowledged whereas the interests of the marginalized are ignored (Mosse, 1994). Brokers may not only control information flows to aid donors on the community needs, they may also control information flows towards the community concerning the arrival and selection criteria of aid resources. By controlling information flows in both directions, brokers can become real gatekeepers to aid flows.

Second, aid donors often ensure that the mandate of the brokers they work with is locally legitimized. For this, they usually rely on informal talks with local informants or sometimes they even organize formal elections. In both cases, the more people politically support a certain representative, the more likely it becomes that external aid providers decide to work with that representative. Representatives, therefore, need sufficient political support to be selected by outside aid donors, and thus to become interface brokers ${ }^{2}$. This, however, does not imply that representatives need the support of the entire community. They do not even require the support of the majority.

This may be due to a lack of political alternatives. But even when there were political alternatives, brokers are not forced to look for the support of the entire community. Brokerage of aid resources often goes hand in hand with clientelism, defined as an interchange of tangible personal benefits (in our case aid resources) in return for intangible resources in the form of loyalty and political support (Wolf, 1977). Clientelism can only be effective if clients receive sufficient amounts of benefits. With a constraint on the resources channelled by each aid donor, representatives are forced to divide resources among a limited group. Dividing the available resources so that all community members would be benefited would dilute political support too much ${ }^{3}$.

Thus, brokers are not stimulated to look for a large group of political supporters. They only represent and are accountable to a limited group of community members. To maintain this political support, brokers have a strong incentive to benefit the same group of community members with every new aid program arriving at the village. Any sign of disregarding the clientelistic reciprocity logic might lead to a rapid disintegration of clientelistic relations, and with it the broker's power basis (Landé, 1977: 508).

\footnotetext{
${ }^{2}$ Note here the explicit difference we make between representatives and interface brokers.

${ }^{3}$ In many cases, dividing the aid resources to benefit the entire community is not even feasible. This is the case when aid donors channel an insufficient amount of resources.

${ }^{4}$ Any broker considering altruistic acts beyond the own client-group is therefore likely to lose political power. We think for instance about fairness-minded brokers who are willing to rotate the group of beneficiaries so that after a certain period all village members have received benefits.
} 
With each broker tied to a limited group of political clients, we expect that the more brokerage is concentrated in a limited number of brokers, the larger the proportion of community agents that is recurrently excluded from aid flows. This is hypothesis 2 that we will test in the empirical section of this paper.

Brokerage concentration, however, may also have certain advantages, such as its contribution to a community's capacity to attract aid resources. Where brokerage is highly concentrated brokers may have large experience and capacity to make contact with aid providers and convince them to start operations in their community. As our case at the beginning of this chapter suggests, replacing current brokers by less experienced representatives may result in a worse outcome, as the latter may have less ability to attract future aid resources. This will be tested as hypothesis 3 in the empirical section.

\subsection{Political change processes at the interface}

To the extent that aid brokerage structures are determinant in processes of recurrent exclusion from aid flows, it is of interest to look at reinforcement mechanisms of brokerage structures and how political change at the interface might eventually occur. In particular, we are interested in possible mechanisms that hamper political change, necessary to improve the perspectives of the recurrently excluded. To investigate this, we borrow from recent theories that suggest that socio-political structures are being continuously re-created by the ongoing interaction between social structure and agency (Cleaver, 1999; Long, 2001). Due to "increasing returns to adoption of a particular institutional form" these structures may eventually become 'locked in' (Bardhan, 2000: 223).

Applied to brokerage, the (re)production of brokerage structures is closely related to the identification of local representatives by community members. Aid providers usually make use of informal talks with local informants or sometimes they even organize formal elections to select community brokers to work with. In both cases, the perspectives for a community agent of being approached by a new aid provider increase with more community members identifying him/her as their potential representative. There are, however, two mechanisms behind the increasing returns to adoption of brokerage structures, which might hamper political change processes ${ }^{5}$, necessary to reduce exclusion.

\footnotetext{
${ }^{5}$ For political change to be realized aid donors have to start cooperating with new interface brokers. Consequently, any political change implies a decentralization of brokerage.
} 
First, as illustrated by Bierschenk et al. (2000), a community representative acquires brokerage capacity through his/her experience at the interface. The more capacity the higher the possible returns of calling upon him/her, not only for aid providers but also for community members. At the same time, the number of aid providers that arrive at a village is limited and potential brokers compete with each other to become the community's spokesperson towards aid providers. With centralized brokerage, a limited number of brokers are highly active at the interface, and thus acquire large experience, capacity and visibility. Consequently, it results difficult for any political alternative to compete. We therefore expect that in villages with higher brokerage concentration fewer political alternatives are identified, which will be tested as hypothesis 4a. If this hypothesis is true, political alternatives are not given the opportunity to acquire the necessary experience, capacity and visibility to challenge the ruling brokers. Consequently, once a village has high brokerage concentration it is hard to escape the 'exclusion trap'.

Second, community members who are benefited by aid brokerage get to know the important key-persons, whereas excluded people often do not know whom to contact to obtain information on aid opportunities, and thus eventually access to aid resources. This also means that the excluded, as being disconnected from the interface, have limited information on the representatives that could replace the elite representatives. In contrast, we expect them to identify relatively more the elite, not necessarily because they hope this increases their chances of getting part of the aid resources, but simply because the elite is most visible to them. We will test this as hypothesis $4 \mathrm{~b}$ in the empirical section. Concomitantly, if political change is supported from within a community, it is not very probable that it improves the representation of the most excluded, so that their exclusion is reduced.

\section{Empirical review}

In this part, we test the hypotheses set out in the conceptual section. We start by studying the importance of brokerage for community agents and aid providers. Thereafter, we investigate the influence of brokerage concentration on recurrent exclusion processes from aid flows and a village's access to aid resources. We close by examining the importance of people's voice in political change processes and how brokerage concentration may hamper political change.

For the empirical analyses, we make use of a household survey in 33 Nicaraguan rural villages. These villages were selected such that they are a representative sample of the socio-economic and geographical variation of the 
Pacific and Interior regions of Nicaragua where the largest part of the population lives. For the definition of the village boundaries and the composition of a village census we triangulated different local information sources. From these censuses, we randomly selected 50 households in each village. As village sizes differ considerably, we weighted observations to correct under-weighing (overweighing) - in the total population - of observations in large (small) villages.

Table 2.1. Descriptive statistics on village characteristics $(N=33)$

\begin{tabular}{lccrr}
\hline & Min. & Max. & Mean & Std. dev. \\
\hline Proportion of households excluded from all aid & 0.029 & 0.626 & 0.212 & 0.141 \\
Community size & 50 & 332 & 141.09 & 57.265 \\
Number of projects & 3 & 14 & 8.33 & 2.814 \\
Household mean number of aid relations & 0.45 & 2.55 & 1.25 & 0.541 \\
Brokerage activity & 0.11 & 0.59 & 0.31 & 0.136 \\
Brokerage concentration & 0.15 & 1.00 & 0.46 & 0.224 \\
Household mean number of identified representatives & 0.85 & 2.28 & 1.61 & 0.380 \\
Number of elite representatives & 1.00 & 8.00 & 4.73 & 1.587 \\
Proportion of landless households & 0.04 & 0.76 & 0.41 & 0.172 \\
Proportion of households dependent on salaried & 0.18 & 0.80 & 0.48 & 0.134 \\
agricultural work & & & & \\
\hline
\end{tabular}

Table 2.1 shows descriptive statistics of the most important variables we will use in our analyses. Each of these variables will be defined and discussed when they are used in the empirical analysis. One variable we want to highlight here already, because it is one of the most important variables, is the village proportion of households excluded from all aid. We observe that in most villages this proportion is considerable, averaging around 0.21 . It also varies a lot. In the most extreme cases, more than half of the village has been excluded from all aid.

\subsection{The use of aid brokerage}

In this subsection, we examine the use of brokers by community members and aid donors. In particular, we will look at possible correlations between the use of brokers on the one hand, and the community members' poverty and donors' market-orientedness on the other hand. To investigate local brokerage and other mediation mechanisms, we asked each household in the sample for details of all 
(governmental and non-governmental) aid providers it received benefits from in recent years ${ }^{6}$. As we are interested in recurrent exclusion processes, we not only asked for currently active donors, but also for recently concluded aid initiatives. For each relation with an aid provider, we asked the respondent how the contact was established. The 'Total' columns of Table 2.2 confirm the importance of local intermediation and brokerage. More than half of the identified aid relations were established through mediation by someone of the community, of which $38.6 \%$ by a community broker and $14.5 \%$ by a community peer ${ }^{7}$.

To test whether the use of brokerage depends on the poverty of community members (hypothesis 1a) we grouped aid relations based on the poverty characteristics of the household. More specifically, we compared landless and nonlandless households, and households dependent on salaried agricultural work and those not. We did so, as being landless or being a salaried agricultural worker are very good proxies for poverty in the areas of study (Maldidier \& Marchetti, 1996).

Table 2.2 demonstrates that percentages of the different categories differ substantially between landless and non-landless households, and between households dependent on salaried agricultural work and those not. Based on a Pearson F-statistic we observe that mediation by a community broker is significantly different between landless and non-landless households, and between households dependent on salaried agricultural work and those not. The percentages indicate that landless households or households engaging in salaried agricultural work tend to rely more on brokerage, which confirms hypothesis 1a. The statistically significant differences of 'own initiative' and 'visit by project staff', and the higher percentages of these categories for non-landless households and households not dependent on salaried agricultural work, indicate that economic strength increases a households' ability to get directly in touch with aid flows.

\footnotetext{
${ }^{6} \mathrm{We}$ did not pose this question in an open way, but used a list with the names of the programs that have been active in each of the respective villages. This reduced the risk of response bias. For instance, some might expect that by claiming not having received aid they might be eligible for more aid (assuming that the information they give to our fieldworkers would in some way or another influence their access to future aid). Asking this question for each of the aid initiatives instead of using one open question makes it more difficult to hide any information on received aid. Another potential response bias (which is reduced in this way) could occur when those participating in almost all aid initiatives forget to mention one of the programs they have worked with.

${ }^{7}$ We define brokers as contact persons identified as community representatives by more than one respondent in the village. Other contact persons in the community are considered community peers.
} 
Table 2.2. Access mechanisms vs. household poverty levels

\begin{tabular}{lcccc}
\hline & \multicolumn{4}{c}{ Landless } \\
& Total & No & Yes & P-value \\
\hline Own initiative & $13.6 \%$ & $16.1 \%$ & $7.4 \%$ & .000 \\
Visit by project staff & $27.9 \%$ & $30.3 \%$ & $22.0 \%$ & .012 \\
Mediation by a community broker & $38.6 \%$ & $34.4 \%$ & $48.9 \%$ & .000 \\
Mediation by a community peer & $14.5 \%$ & $13.5 \%$ & $16.9 \%$ & .173 \\
Mediation by someone from outside the community & $5.4 \%$ & $5.7 \%$ & $4.8 \%$ & .498 \\
\hline & $100.0 \%$ & $100.0 \%$ & $100.0 \%$ & \\
Number of relations with projects & 1674 & 1198 & 476 & \\
\hline
\end{tabular}

Salaried agricultural worker

\begin{tabular}{lcccc} 
& Total & No & Yes & P-value \\
\hline Own initiative & $13.6 \%$ & $15.2 \%$ & $11.2 \%$ & .095 \\
Visit by project staff & $27.9 \%$ & $31.6 \%$ & $22.6 \%$ & .002 \\
Mediation by a community broker & $38.6 \%$ & $34.3 \%$ & $44.9 \%$ & .001 \\
Mediation by a community peer & $14.5 \%$ & $13.9 \%$ & $15.2 \%$ & .529 \\
Mediation by someone from outside the community & $5.4 \%$ & $5.0 \%$ & $6.1 \%$ & .413 \\
\hline & $100.0 \%$ & $100.0 \%$ & $100.0 \%$ & \\
Number of relations with projects & 1679 & 990 & 689 & \\
\hline
\end{tabular}

Notes. P-values (two-sided) are the result of a two-way comparison along the economic categorization of the household and the access mechanism. For each access mechanism we make the comparison with all other access mechanisms. The chi-square test is converted into a Pearson Fstatistic after correcting for dependencies of observations due to multiple observations per household and after applying weights to correct for underestimation of observations in large villages.

The intermediation by community brokers may also depend on the type of aid provider. According to hypothesis $1 \mathrm{~b}$, we expect that relations with marketoriented projects are less likely established through the mediation of community brokers. To test this, we distinguished three categories: 'market-oriented' development programs offering credit at market conditions (aiming for the complete recuperation of operation costs and the resources provided); aid programs offering credit on 'subsidized' terms and conditions (sometimes 
combined with donations); and 'charity-oriented' donors transferring resources exclusively by means of donations ${ }^{8}$.

Table 2.3. Access mechanisms vs. project type

Type of aid provider

\begin{tabular}{lccccc} 
& Charity & $\begin{array}{c}\text { Subs. } \\
\text { finance }\end{array}$ & Market & P-value $^{\mathrm{a}}$ & P-value $^{\mathrm{b}}$ \\
\hline Own initiative & $8.9 \%$ & $8.2 \%$ & $24.7 \%$ & .000 & .000 \\
Visit by project staff & $28.1 \%$ & $28.0 \%$ & $28.2 \%$ & .996 & .936 \\
Mediation by a community broker & $51.8 \%$ & $44.5 \%$ & $20.7 \%$ & .000 & .000 \\
Mediation by a community peer & $8.3 \%$ & $13.5 \%$ & $19.8 \%$ & .000 & .000 \\
Mediation by someone from outside the community & $2.9 \%$ & $5.8 \%$ & $6.6 \%$ & .048 & .125 \\
\hline & $100.0 \%$ & $100.0 \%$ & $100.0 \%$ & & \\
Number of relations with projects & 399 & 741 & 506 & & \\
\hline
\end{tabular}

Notes. P-values (two-sided) are the result of a two-way comparison along the types of aid provider and the access mechanism. For each access mechanism we make the comparison with all other access mechanisms. The chi-square test is converted into a Pearson F-statistic after correcting for dependencies of observations due to multiple observations per household and after applying weights to correct for underestimation of observations in large villages.

${ }^{\mathrm{a}}$ Comparison over all types of aid providers; ${ }^{\mathrm{b}}$ Comparison between market-oriented aid projects and all other types of aid providers.

Table 2.3 shows that brokerage use is significantly different when comparing the three types of aid and when comparing market-oriented aid and the others types of aid. The percentages indicate that relations with market-oriented programs are substantially less likely established through the intermediation by interface brokers, which confirms hypothesis $1 \mathrm{~b}$. We also observe that relations with market-oriented donors are more likely established as a result of the household's own initiative or through mediation by a community peer (who is not a broker).

\subsection{Brokerage and exclusion from aid}

We now examine how village brokerage structures, as part of the aid interface, influence recurrent exclusion from aid flows. Whereas in the previous subsec-

\footnotetext{
${ }^{8}$ Of the 82 development interventions we identified in the survey, 55 projects channeled resources by means of credit. Of this group, 26 projects offered credit at market conditions.
} 
tion we only took account of the established relations with aid providers and examined how they were established, in this subsection we look at all potential links with aid donors and thus also those links that for one reason or another were not established. This allows us to study exclusion processes from aid flows.

To test whether higher brokerage concentration in a village increases the proportion of households recurrently excluded from aid flows (hypothesis 2) we first define exclusion from aid flows. We asked the households in the sample whether they work or have worked with each of the programs we had previously identified in their village. Aggregating all potential relations with aid programs, we observe in Table 2.4 that only less than $20 \%$ of the potential relations with aid providers were established. There are, however, many reasons why people do not work with a particular aid provider, and not all of them are the result of 'exclusion'. Some people simply do not like the project or do not have any necessity. To detect real exclusion we asked each household for the reason of not working with a particular aid provider.

Table 2.4. Do you work or have you worked with the mentioned project?

\begin{tabular}{lcc}
\hline & Frequency & Percent \\
\hline No & 8228 & $82.80 \%$ \\
Yes & 1715 & $17.20 \%$ \\
Total & 9944 & $100.00 \%$ \\
\hline
\end{tabular}

On the basis of their answers, different categories were created (see Table 2.5). We considered the following possible reasons of not working with a particular project as indications of exclusion. First, when people do not know about the presence of the program in their village, as this means in practice that they are cut off from any information on the project. Second, they know about the program but did not manage to get in contact with it. In Table 2.5, we observe that for more than $75 \%$ of the potential but not established relations with development programs this was due to one of these two reasons ${ }^{9}$.

\footnotetext{
${ }^{9}$ People could also be excluded by a project itself. This is the case when a project imposes certain requirements or selection criteria (the two last rows in Table 2.5). However, as we are only interested in exclusion caused by intermediary agents at the interface, we do not include these cases.
} 
Table 2.5. Reasons for not working with the mentioned project

\begin{tabular}{lcc}
\hline & Frequency & Percent \\
\hline Does not know the project & 4316 & $52.78 \%$ \\
Knows the project, but . . & & \\
$\quad$ did not manage to get in contact & 2124 & $25.98 \%$ \\
does not like the project & 576 & $7.04 \%$ \\
does not have any necessity & 140 & $1.71 \%$ \\
other reason why not interested & 527 & $6.45 \%$ \\
does not fulfil project requirements & 380 & $4.65 \%$ \\
fulfils project requirements, but was not selected & 114 & $1.39 \%$ \\
\hline Total & 8177 & $100.00 \%$ \\
\hline
\end{tabular}

We are now able to test hypothesis 2. For this we estimated a standard OLS regression model (Table 2.6). As dependent variable, we use the village proportion of households excluded (as defined above) from all projects that work or have worked in the village. We thus look at the most extreme form of recurrent exclusion. Recall from Table 2.1, that in most villages this proportion is considerable, averaging around 0.21 . We now explain the explanatory variables we used in the regression model. We refer to Table 2.1 for descriptive statistics on these variables.

In a first model, we control for the level of 'brokerage activity' and 'brokerage concentration'. Brokerage activity is defined as the proportion of aid relations established with the help of brokers. Brokerage concentration is measured by the Herfindahl index, that is the sum of the squared shares of each identified broker within the total number of relations intermediated by brokers. Table 2.6 shows the results. We observe that for a given level of brokerage activity, the village proportion of households excluded from all aid substantially and significantly increases with higher brokerage concentration. An increase of brokerage concentration by one standard deviation (i.e. by 0.224 , see Table 2.1 for this) increases the proportion of excluded households with more than half a standard deviation, or 0.076 .

As exclusion is also expected to be highly contingent on the presence of aid at the village level, we control for this in a second model by adding the 'household mean number of aid relations' in the village as explanatory variable. The influence of brokerage concentration is robust to adding this variable, although it decreases somewhat due to its correlation with this variable (see next section where we study the correlation between both variables). The results demonstrate 
that increasing the household mean number of aid relations in the village with one standard deviation (i.e. by 0.541 , see Table 2.1 for this), reduces the village proportion of households excluded from all aid with more than half a standard deviation, or 0.077 .

Table 2.6. OLS on the village proportion of households excluded from all aid $(N=33)$

\begin{tabular}{lccccccc}
\hline & \multicolumn{2}{c}{ Model 1. } & \multicolumn{2}{c}{ Model 2. } & \multicolumn{2}{c}{ Model 3. } \\
& $\begin{array}{r}\text { Stand. } \\
\text { Coef. }\end{array}$ & two- & sided P & $\begin{array}{l}\text { Stand. } \\
\text { Coef. }\end{array}$ & $\begin{array}{l}\text { two- } \\
\text { sided P }\end{array}$ & $\begin{array}{l}\text { Stand. } \\
\text { Coef. }\end{array}$ Two- \\
& sided P \\
\hline Number of projects & - & - & - & - & 0.378 & .007 \\
Household mean number of aid relations & - & - & -0.549 & .000 & -0.732 & .000 \\
Brokerage activity & -0.261 & .081 & -0.076 & .557 & -0.063 & .582 \\
Brokerage concentration & 0.541 & .001 & 0.332 & .016 & 0.407 & .002 \\
\hline Adj. R-squared & 0.333 & & 0.552 & & 0.645 & \\
F & 8.989 & & 14.165 & & 15.510 & \\
Prob > F & 0.001 & & 0.000 & & 0.000 & \\
\hline
\end{tabular}

Finally, we expect that exclusion is not only dependent on brokerage concentration and the quantity of aid resources, but also on the 'number of projects' through which these aid resources are channelled. We control for this in a third model. The effect of brokerage concentration is robust to adding this variable. Despite the high correlation between the number of projects and the household mean number of aid relations, both coefficients remain statistically significant. The results indicate that all other things equal, the more projects are used to establish the same number of aid relations, the larger the excluded sector. This implies that different projects arrive at the same group of people, being it for different reasons (most projects work with the middle-class, the same intermediation structures are used, the same persons meet first with aid programme officers, etc.). To establish a given number of aid relations, it is therefore preferable to use a few larger projects instead of using several smaller projects, as this results in a smaller village proportion of excluded households.

The strong correlation that we identified between brokerage concentration and the proportion of the village that is excluded from all aid, combined with the evidence that it is especially the poorest that rely on brokerage to obtain access to aid, suggests that political change in the direction of more decentralized brokerage would benefit especially the poorest. Decentralizing brokerage 
structures may therefore also be justified by its potential contribution to poverty reduction.

\subsection{Brokerage concentration and village access to aid}

Whereas brokerage concentration tends to increase the proportion of a community that is excluded from all aid resources, it may also positively influence the arrival of aid resources at the village. In particular, as was suggested by our case at the beginning of this chapter, replacing current brokers by less experienced representatives may reduce a community's capacity to attract future aid resources.

Figure 2.1. Correlation between brokerage concentration and aid presence

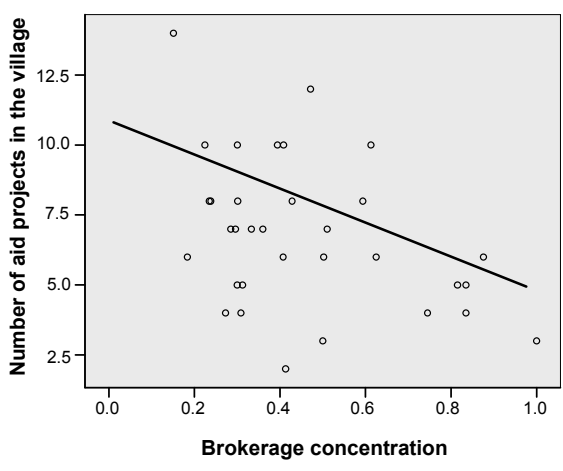

Pearson correlation $=-0.405$ (two-sided $\mathrm{P}=.019)$

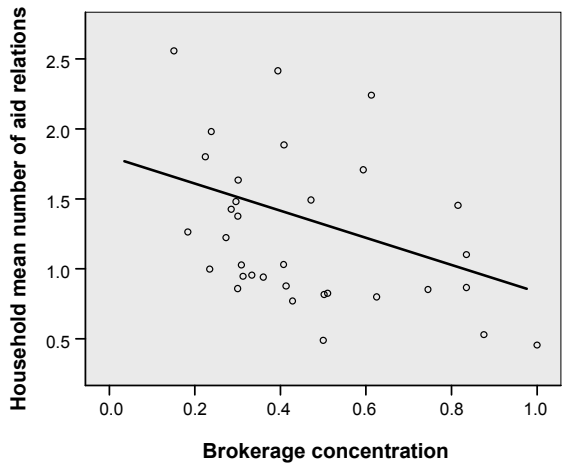

Pearson correlation $=-0.396($ two-sided $P=.022)$

To test this hypothesis, we look at the correlation between brokerage concentration and aid presence. Our data indicate that the correlations with aid presence, as measured by 'number of projects' and 'household mean number of aid relations', are negative and statistically significant at the 5\% level (Figure 2.1). This suggests that villages with more decentralized brokerage have actually a higher capacity to attract aid resources ${ }^{10}$. This is probably due to the higher diversification of social ties with outside aid providers that goes with more decentralized brokerage. A more decentralized brokerage implies that more

\footnotetext{
${ }^{10}$ The causality in the other direction seems little plausible. Given the numerous case-studies of recurrent capture by local elites (even when different projects simultaneously operate at the village), it is little plausible that simply channelling more aid leads to lower brokerage concentration.
} 
brokers are active at the interface. As a result, a higher proportion of the village might be represented and/or more contacts are made with aid donors. This makes it more likely that preferences of aid donors and beneficiaries meet each other, so that at the end more aid providers find their 'niche' and initiate operations in the village.

We should remark, however, that these correlations are based on a crosssectional analysis and do not allow us to look at dynamic processes at play when new and inexperienced brokers would become active at the interface. In particular, although the negative correlation between brokerage concentration and aid access at the village level suggests that decentralizing brokerage does not lower a village's capacity to attract future aid resources, there may be a temporary capacity drop. Replacing elite representatives in a village by inexperienced representatives may temporarily reduce a village's capacity to attract future aid resources.

Here, two remarks are warranted. First, political change is often considerably less drastic than exemplified in the case at the beginning of this chapter. In most cases, the ruling elite remains active at the interface and new actors only gradually acquire prominence at the interface, enabling them to build capacity. Second, even when political change is very drastic a lack of capacity tends to be temporal as capacity is acquired through experience at the interface. This of course assumes that the new brokers are given sufficient time and opportunities to acquire this experience. Where political change is extremely drastic, coordination among donors at the supra-community level may be necessary to give new actors the opportunity to acquire more experience and thus capacity to act at the interface.

\subsection{Perspectives for political change}

In this section, we look at the perspectives for political change, and how this political change may be initiated by community members - i.e. without intervention of external aid providers. In particular, we will show that it is hard to escape the 'exclusion trap' once a village has high brokerage concentration and that if political change is supported from within a community it is not likely that it will improve representation for the most excluded, which is necessary to reduce their exclusion.

New aid donors often rely on informal talks with local informants or organize formal elections to select local representatives to work with. In such a case, the number of community members that identify a particular representative may be crucial for a representative to be selected by aid donors to work with, 
and thus to become an interface broker. Consequently, the identification of representatives by community members when new aid providers arrive at their community, may be a crucial element for the (re)creation of a community's representation structures.

Two particular questions will be studied in this section. First, we study whether brokerage concentration itself hampers political change, through a limitation of the identification of political alternatives. In particular, we expect that with centralized brokerage, political alternatives are relatively less visible and thus less identified by community members. This will be tested as hypothesis $4 \mathrm{a}$.

Second, there may be a correlation between one's exclusion level and the number and type of representatives one identifies. In particular, it may be that the recurrently excluded - as being disconnected from the interface - have limited information on who could be proposed as political alternative (hypothesis $4 b$ ). If this is the case, the excluded may have little capacity to influence political change and improve their perspectives of getting access to future aid flows.

To study these questions, we asked each survey respondent to identify up to three (in their opinion) most important representatives in the village. In each community, we also drew up a list with the most important community representatives by interviewing local informants such as local representatives of the mayor or aid program officers. As this is a very similar approach aid providers follow when they visit a village for the first time, we identified those representatives that are most visible for new aid donors. We call these representatives the elite representatives. Representatives identified by survey respondents that did not appear on these lists were considered non-elite representatives. We consider them to be potential alternatives for the elite representatives. For descriptive statistics on the mean number of representatives identified by the households and the number of elite representatives we identified in each village we refer to Table 2.1.

We are now able to study the first question. For this, we looked at the correlation between brokerage concentration and the household mean number of identified non-elite representatives in a village. For the calculation of the latter variable we divided the total number of non-elite representatives identified by the interviewed households in a village by the number of interviewed households in that village. The correlation between both variables is negative and statistically significant (Pearson correlation $=-0.496$; two-sided $\mathrm{P}=.003$ ). Assuming that the proportion of the village that identifies a certain representative directly influences the probability that this representative is chosen by an 
aid donor to work with, this negative correlation suggests that in villages with highly centralized brokerage, political change is more difficult to attain and thus brokerage tends to remain relatively centralized. This is so because the non-elite representatives are relatively little identified and therefore less visible for external aid providers. This confirms hypothesis $4 \mathrm{a}$.

The correlation with the household mean number of identified elite representatives (Pearson correlation of -0.245 ; two-sided $\mathrm{P}=.169$ ), in contrast, is small and statistically insignificant. Elite representatives are just more visible in general, so that their identification tends to be less influenced by the concentration of brokerage.

To study the second question, we look at possible correlations between the identification of community representatives and the exclusion level of the survey respondents, measured as the proportion of aid projects in the village from which they had been excluded. For this we created three different classes of households according to their exclusion level. We defined the range of the classes so that they contain a similar amount of households. A class of low exclusion consists of all households with exclusion levels lower or equal than 0.5 . Households face moderate exclusion if they have exclusion levels higher than 0.5 and lower or equal than 0.8 . Highly excluded households have exclusion levels higher than 0.8 . We then compared the identification of community representatives across the different classes of households. Table 2.7 shows the results.

Table 2.7 shows that on average the highly excluded group identified 1.494 representatives, whereas the moderately excluded group and the group of low exclusion identified respectively 1.635 and 1.875 representatives. Applying a Mann-Whitney test, we observe that all pair-wise comparisons result in significant differences. Thus, there is a clear relation between being excluded and identifying representatives. A household that is frequently excluded from aid resources has less information on who acts as community representative.

When doing the same analysis for elite and non-elite representatives separately, we obtain similar results for non-elite representatives. The higher a household's exclusion from aid resources the fewer non-elite representatives the household identifies. Comparing the absolute number of identified elite representatives differences are smaller. According to a Mann-Whitney test, differences are only significant between the group of high exclusion and low exclusion. Elite representatives are more visible in general, so that their identification in absolute terms tends to be somewhat less influenced by a household's exclusion. 
Table 2.7. Influence of exclusion on the identification of community representatives

\begin{tabular}{|c|c|c|c|c|c|c|}
\hline & \multicolumn{3}{|c|}{ Exclusion $^{\mathrm{a}}$} & \multicolumn{3}{|c|}{ 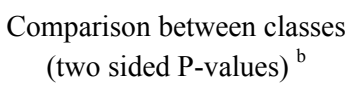 } \\
\hline & low & moderate & high & $\begin{array}{c}\text { low }- \\
\text { mod }\end{array}$ & $\begin{array}{c}\text { mod - } \\
\text { high }\end{array}$ & $\begin{array}{l}\text { low - } \\
\text { high }\end{array}$ \\
\hline \multicolumn{7}{|l|}{ Elite representatives } \\
\hline absolute number (class average) & 1.242 & 1.181 & 1.105 & .540 & .201 & .049 \\
\hline relative number ${ }^{\mathrm{c}}$ (class average) & 0.678 & 0.720 & 0.738 & .075 & .225 & .001 \\
\hline percentage that identified none & $28.6 \%$ & $30.9 \%$ & $36.8 \%$ & .431 & .051 & .004 \\
\hline \multicolumn{7}{|l|}{ Non-elite representatives } \\
\hline absolute number (class average) & 0.664 & 0.469 & 0.397 & .003 & .019 & .000 \\
\hline relative number ${ }^{\mathrm{c}}$ (class average) & 0.346 & 0.295 & 0.267 & .074 & .167 & .001 \\
\hline proportion that identified none & $54.1 \%$ & $64.8 \%$ & $70.4 \%$ & .001 & .061 & .000 \\
\hline \multicolumn{7}{|l|}{ Elite + non-elite representatives } \\
\hline absolute number (class average) & 1.875 & 1.635 & 1.494 & .002 & .014 & .000 \\
\hline proportion that identified none & $15.0 \%$ & $17.0 \%$ & $25.0 \%$ & .413 & .002 & .000 \\
\hline
\end{tabular}

Number of households

$529 \quad 445$

509

\footnotetext{
${ }^{a}$ Low exclusion: $\mathrm{x} \leq 0.5$; Moderate exclusion: $0.5<\mathrm{x} \leq 0.8$; High exclusion: $\mathrm{x}>0.8$; with $\mathrm{x}=$ number of exclusions over total number of projects in the village.

${ }^{\mathrm{b}}$ A Mann-Whitney test is used to compare means between classes, whereas a chi-square test to compare percentages between classes.

${ }^{\mathrm{c}}$ In comparison with the total number of identified representatives (elite + non-elite).
}

Looking at the relative number of identified elite and non-elite representatives (second and fifth row in Table 2.7) we observe that these are significantly different between highly and lowly excluded groups. In particular, the highly excluded group identifies relatively more elite representatives and relatively less non-elite representatives. Moreover, in the sixth row of Table 2.7 we observe that more than $70 \%$ of the highly excluded households do not identify any nonelite representative, which is a significantly higher percentage compared with each of the other classes of households. These results confirm hypothesis $4 \mathrm{~b}$. They suggest that the highly excluded have limited information on who could be proposed as political alternative.

Based on the empirical evidence in this section, we come to the following conclusions regarding the perspectives for political change. First, in villages with more centralized brokerage fewer non-elite representatives are identified, so that the perspectives for political change are more limited. Second, highly 
excluded households exert less influence on any political change process, as they identify fewer representatives and they identify relatively more elite representatives. If political change is supported from within a community, it is therefore not very likely that it will improve representation for the most excluded, which is necessary to reduce their exclusion.

\section{Conclusion: The role of aid providers}

We now summarize our empirical results and then turn to the role of aid providers within political change processes. Our results have demonstrated that village brokerage structures, as part of the interface with aid providers, exert a determinant influence on recurrent exclusion processes from aid flows. The more brokerage is monopolised by a limited number of brokers, the larger becomes the group that is excluded from all aid resources. As it is especially the poorest that rely relatively more on brokerage to get access to aid, brokerage concentration and complete exclusion from aid flows tend to affect especially the poorest. Given the benefits of a more decentralized brokerage, we have looked upon some mechanisms that are responsible for the perpetuation or transformation of brokerage structures.

To the extent that new outside aid donors rely on informal talks with local informants or organize formal elections to select the local representative to work with, the probability of a certain representative to be selected by an outside aid donor increases with the number of community members that identify that representative. Consequently, the identification of community representatives is a crucial element for the (re)creation of representation structures when new aid providers arrive at the village. In particular, we assume that the perspectives for political change are closely related with the identification of non-elite representatives.

We identified several impediments to political change, which result from an insufficient identification of non-elite representatives. First, in villages with more centralized brokerage fewer political alternatives are identified, which reduces the perspectives for a more decentralized brokerage structure. Second, we observed that the most excluded, as being disconnected from the interface, have little capacity to propose political alternatives. This implies that if political change is supported from within a community, it is not very likely that it will improve representation for the most excluded, which is necessary to reduce their exclusion.

This leaves aid donors that are really engaged with combating recurrent exclusion processes, with no other option than to follow a more interventionist 
logic. In particular, it is not impossible for aid donors to find new political actors that represent the most excluded even if they are not very intensively identified by community members. Because of the lower identification by community members, however, it increases search and operation costs, and requires more time and energy than aid donors usually invest in such activities.

Here an important remark is warranted on the ability of aid donors to support political change processes. We have seen that relations with marketoriented donors are less mediated by interface brokers. Consequently, marketoriented aid donors have less capacity to change brokerage structures. Other aid donors make more use of local brokerage, so they may have more potential to change local brokerage structures. However, their higher reliance on local brokerage necessary to facilitate their local operations makes them at the same time also vulnerable to local resistance from the ruling brokers and their clientele, especially when brokerage power is concentrated in the hands of a limited number of brokers. This constitutes a real dilemma, which hampers donors to make an effort to expand their outreach beyond the networks of the ruling brokers. Yet, given the demonstrated benefits of a more decentralized brokerage this does not free them from that responsibility. 



\section{Aid Brokerage, Voice and Exclusion in Heterogeneous Communities: A Laboratory Study}

\section{Introduction}

As demonstrated in the previous chapter, community representatives tend to exert an important influence on the local distribution of aid. This is particularly true where donors give them a formal mandate to distribute resources among community members, as is the case with the growing number of government and non-government donors that follow a community-based approach (Mansuri \& Rao, 2004).

It is, however, all but evident that these local representatives - generally among the better-off community members - have similar interests as the aid donors who are interested in supporting the poorest classes. In contrast to aid donors, local representatives may also be motivated by individual profit seeking. The 'social preferences' of these representatives may not be strong enough to outweigh individual profit-seeking, not to mention to give similar shares to the poorest classes as the aid donor would do. The delegation of distribution tasks to local representatives is, therefore, bound to increase social exclusion.

At the same time, however, potential beneficiaries are not passive agents. Very often they have the ability to influence the representative's distributive decision-making by making use of a political voice and control institution. The workings of such an institution, however, may be dependent on certain information conditions. In particular, local communities are often not small enough for information flows to reach all members. In many cases, respondents only receive information on their own share without knowing the share received by other community members. The information received on the distribution of resources might influence their satisfaction and eventually their use of the political control institution. Information on who disagrees with the proposed 
distribution and who makes use of the political control institution, however, might also matter. In local communities, information on who disagrees with the representative's distribution decision may be made public (e.g. through a quick hand raising procedure), or it may remain secret (e.g. through an anonymous voting procedure). If this information is public, representatives may take account of this information when making their distribution decision. In particular, it is plausible that community members who express dissatisfaction may receive less from the representative and thus eventually become worse-off in comparison with those who remain silent.

To comprehend the complex interaction between the distribution of aid by community representatives and the voice of community members as potential beneficiaries of these resources, we organized a laboratory experiment. In subsequent rounds, a permanent representative, being the richest of an economically-heterogeneous group, is asked to distribute a fixed quantity of resources among group members ${ }^{11}$. After each distribution decision, the other members have the ability to punish the representative if a majority of them vote in favour of doing so.

To examine the influence of information on the distribution decisions made by the representative, and of information on the use of the political control institution by the respondents, we constructed four treatments, by combining two information conditions. The first condition relates to information on the distribution of the aid. We compare a situation with public information on the complete distribution of the resources with one where the respondents only know their individual shares. The second condition relates to information on the respondents' voting decisions. We compare a situation where this information is kept secret with a situation where both the representative and the other respondents obtain complete information on individual voting.

Not only can aid donors influence these information conditions ${ }^{12}$, they can also resort to a drastic political change in favour of the poorest, if they are not satisfied with the representative's decisions. To study the implications of such

\footnotetext{
${ }^{11}$ Note the following two assumptions. First, it is the richest player who acts as representative. We justify this by the observation that most community representatives tend to be among the better-off. Second, the representative cannot be replaced. In most communities, the local 'elite', although contested, remain firmly in power. For empirical evidence that supports both assumptions, we refer to the previous chapter.

${ }^{12}$ Although aid programs transfer distributive-decision power to local representatives, they do not completely give up their agency. As providers of aid they may still influence some rules of the game related to information access on the distribution of the resources and on the use of the political control institution by the community members.
} 
an externally-imposed political change, we organized a second part of the same experimental game, but with the poorest player as the permanent representative.

The experimental results show that the lower the share of the resources a respondent receives from the representative, the lower his/her satisfaction about this share. When receiving information on the complete distribution, his/her satisfaction also decreases the more a representative keeps for him/herself, and the less the respondent receives in comparison with the other respondents. As expected, lower satisfaction increases the propensity to vote in favour of punishing the representative. In addition, there are important strategic elements behind voting decisions. When voting decisions are made public, respondents are somewhat more reluctant to vote in favour of punishment, but this reluctance is lower with lower satisfaction. Moreover, the more a respondent believes that both other respondents will vote in favour of punishment, the more he/she is inclined to do as well. Furthermore, it is observed that female or richer respondents are more reluctant to vote in favour of punishment unless information on the distribution is public. Consequently, with common information on the distribution decisions punishment rates are significantly higher.

We also observe that being punished induces representatives to keep all resources to themselves. Only with public voting and private information on the distribution are representatives able to keep punishment rates down. They do so by successfully applying an exclusion strategy, where one respondent is completely excluded from the distributed resources. Poorer respondents have a higher likelihood of becoming the victims of this type of exclusion. When the poorest player becomes the permanent representative, the final distribution of the net earnings becomes much more equal and punishment rates substantially decrease.

\section{Related literature}

An increasing number of government and non-government aid programs follow a community-based development approach. According to conservative calculations, the World Bank's portfolio of projects that follow such an approach has increased from \$325 million in 1996 to \$2 billion in 2003 (Mansuri \& Rao, 2004). In practice, this approach amounts to donors giving community representatives a formal mandate to distribute aid resources among community members. In comparison with the officers of aid programs, local representatives tend to have important advantages such as their superior screening capacity and lower information and operation costs, which might increase the efficiency and effectiveness of such programmes. 'Moral hazard', however, in the form of 
distributions that conflict with the interests of the donor, such as resource misappropriation by these representatives, or the complete exclusion of certain agents, might outweigh the advantages of relying on local representatives (Alderman, 2001; Galasso \& Ravallion, 2001; Conning \& Kevane, 2002; Platteau \& Gaspart, 2003; Mansuri \& Rao, 2004).

To reduce such a bias in the distribution of resources, aid donors may apply control mechanisms that reduce such moral hazards. Platteau \& Gaspart (2003), for instance, discuss the feasibility of a political control mechanism that consists of incremental resource transfers by the donor, conditional on the agreement of the community. Two assumptions, which are implicit in their model as well as in most aid donors' conceptualization of local communities, should be reconsidered, however.

First, the assumption that a community acts as one decision maker is not evident. This is important as community representatives may take advantage of this. In particular, they may strategically undermine any political coalition that obliges them to retain fewer resources. They can do so by favouring some of the potential beneficiaries while excluding others. Second, communities can hardly be considered as economically-homogenous entities. In most communities, no matter how poor they are, economic inequality is the rule rather than the exception. Consequently, community members may have very different and, perhaps, even competing interests, with possible behavioural implications for community representatives who distribute aid and for community members as potential beneficiaries.

It is the aim of this research to consider these realities. As we will make use of a laboratory experiment, it is interesting to look at the experimental literature and the insights it has produced related to these assumptions. An important experimental game that bears a considerable resemblance to ours is the ultimatum game. We will look briefly at three extensions that make this basic bargaining setting more resemble the small societies we study: repeated play with fixed partners, economic inequality and multiple respondents.

In the ultimatum game (Güth et al., 1982), one player (the proposer) receives a fixed amount of money that he/she has to distribute between him/herself and another player, the respondent. The respondent can accept or reject the proposal, but if he/she rejects it, both players receive nothing. Experimental results typically show that the mean of the proposals is around $30-40 \%$ of the available amount and the mode is the equal split. At the same time, most offers of less than $20 \%$ are rejected by the respondent (Camerer \& Thaler, 1995). 
This strongly contrasts with standard economic theory that predicts that profit-maximizing respondents would not make use of the rejection possibility if this would make them worse off. By backward induction, knowing that respondents would never reject a proposal, distributors would, therefore, keep everything. However, as ample evidence of ultimatum game experiments indicates, respondents reject very unequal distributions, even if this means that they would end up with nothing. This is behaviourally rationalized as a reaction to unfair distributions.

Comparing these results with proposals made in dictator game experiments, where the respondent can only accept, distributors do give more to the respondent when the latter has a punishment option (Hoffman et al., 1994). These results confirm that distributors pay more attention to the will of potential recipient-respondents when the latter have the means to punish the distributor in the form of reducing their pay-off, even if this can only be done at a positive cost for the respondent.

Many extensions have been made to this basic setting. In contrast with the bulk of repeated ultimatum game experiments where players are rematched each round, keeping the players fixed adds reputation considerations and may reduce the relative importance of fairness concerns. Slembeck (1999) has demonstrated that in such a setting representatives demand more and rejection rates are higher than in the standard ultimatum game. He attributes this to the super game strategies of income-maximizing representatives who try to obtain a reputation as a tough player in the early rounds in order to increase future earnings.

Other extensions have allowed for economic heterogeneity of the participants. Introducing endowment inequality increases the number of focal points, which may increase punishment rates. In particular, when assessing the fairness of a distribution people may compare with the equal split of the distributed resources, but they may equally well compare with the equal split of the final pay-offs. It may also be plausible that 'rich' representatives (i.e. with large endowments), instead of being motivated by fairness concerns and giving more to poorer respondents, actually play more selfishly as their higher endowments give them more bargaining power (Armantier, 2006).

A third avenue of extensions to the ultimatum game have allowed for multiple respondents. They provide behavioural evidence about more complex interpersonal comparisons. Knez \& Camerer (1995) let a proposer simultaneously play two independent ultimatum games. Their results indicated that half of the respondents demand more when they know that the other respondent receives more. Proposers, however, do not anticipate that respondents make such social comparisons, so that rejection rates tend to be higher than in the 
standard ultimatum game. Riedl \& Vyrastekova (2004) have studied a setting where respondents are involved in the same distribution game, so that their acceptance or rejection decision may have consequences for the pay-off of other respondents. In their three-player ultimatum game, each of the two respondents has to decide whether or not to reject the proposal. They observed that half of the respondents, when deliberating about such a decision, consider the pay-off of the other respondent.

In contrast with two-player ultimatum games where there is a one-to-one link between the respondent's decision and his/her final pay-off, with multiple respondents there are different procedures possible that link the respondents' rejection decisions with the final outcome. In contrast with Riedl \& Vyrastekova (2004), where each respondent has veto power, with larger respondent groups majority voting may be more common. Extensions that allow for such voting procedures within a bargaining setting are new. They are one of the main contributions of this research. The following possible behavioural implications of such voting procedures are important to consider. First, as distributors do not require the support of all respondents, they may strategically distribute resources in a way that the minimum required support is obtained, while excluding the respondents whose votes are not required, i.e. they try to obtain the 'smallest coalition'. This allows them to maximize their share of resources without being punished. Second, some distributors may also take account of the cost to obtain support form such a coalition (i.e. the resources they need to transfer to the coalition to safeguard its political support). Profit-seeking representatives may explicitly look for the respondents who are satisfied with a smaller share of the pie. It may, therefore, be a profit-maximizing strategy to exclude the poorest respondents if they are believed to have higher acceptance thresholds (see also Abbink \& Ellman (2005) who tested a similar hypothesis).

\section{Experimental design}

In this section, we start with a description of the game that was used in our experiment, which consists of a distribution game followed by a voting stage for punishment. We identify possible equilibria of the voting subgame under standard and social preferences and the resulting optimal strategies of the representative. Thereafter, we explain the procedures and parameters that were used to implement this game in an experimental setting. The treatment conditions are explained as well as possible hypotheses on the influence of these conditions on the experimental results. 


\subsection{A non-cooperative distribution game with voting for punishment}

The game implemented in the laboratory consists of a four-player dictator game, followed by a voting stage that determines whether or not the dictatorrepresentative is punished (see Figure 3.1. for the game tree). The four players are labelled A, B, C and D, and player A assumes the role of representative. The game proceeds as follows:

(1) The representative A distributes a fixed amount of resources $\mathrm{M}$ among a group of four players, him/herself included, such that

$$
x_{A}+x_{B}+x_{C}+x_{D}=M
$$

(2) The respondents simultaneously decide whether or not to vote in favour of punishing the representative.

\section{Figure 3.1 Game tree}

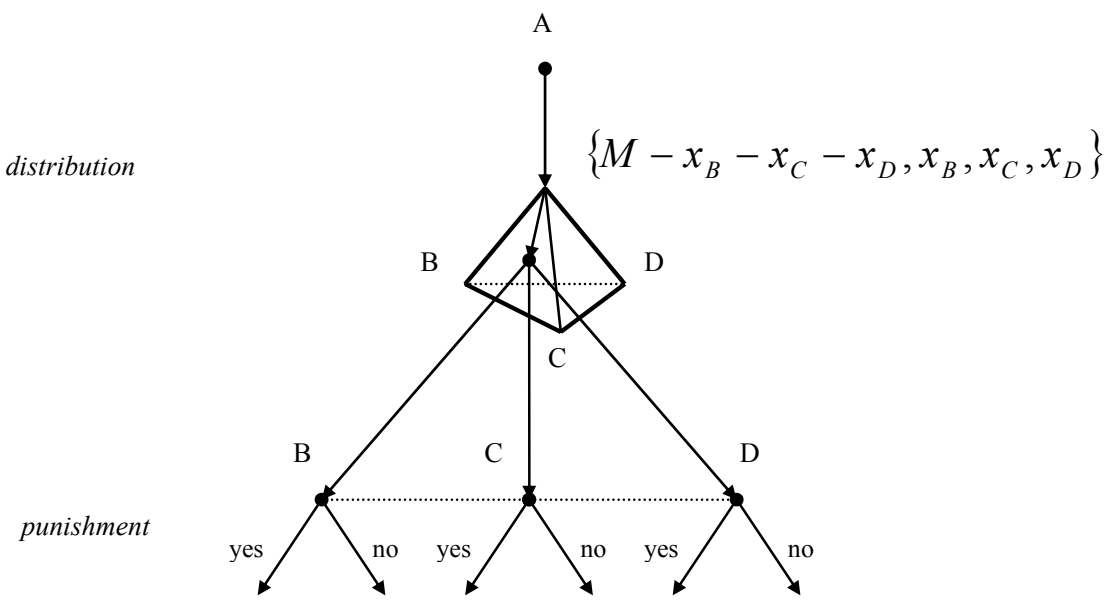

The pay-offs of the players are determined in the following way. If less then two respondents vote in favour of punishment, the distribution will be implemented as proposed by the representative. In any other case, these pay-offs will be reduced by $\mathrm{k}$ for each respondent and by $\mathrm{K}$ for the representative, whereby $\mathrm{K}$ is much larger than $\mathrm{k}^{13}$. This might be conceived as a control and punishment procedure implemented by the aid donor if a majority of respondents votes in

\footnotetext{
${ }^{13}$ This cost scheme is different from the one used in the classical ultimatum game. In particular, the cost of punishment does not depend on the proposed distribution, and thus the foregone profits.
} 
favour of this. In such a case, the aid donor interprets this as a collective action from the community, and charges the costs of this procedure to the entire community, also those who did not vote in favour of punishment.

It is important to stress that we opted for three instead of two respondents because of our interest in potential exclusionary dynamics induced by majority voting systems. In particular, with three respondents it is possible that one respondent is excluded by the representative who only needs a majority to avoid punishment.

We now characterize the pure strategy equilibria of the voting subgame. According to standard economic theory, the respondents when taking a voting decision only look at the effect of their voting decision on their final income. As costly punishment would make respondents worse off, respondents prefer that the representative is not punished. However, whether the representative is punished also depends on the other respondents' voting decision. When two other respondents vote in favour of punishment, the third respondent cannot change the voting outcome and is therefore indifferent between voting in favour of or against punishment. When he/she votes in favour of punishment we obtain strategy combination $(y, y, y)$, which is an equilibrium as no one can increase his/her utility by changing his/her individual strategy. However, when he/she votes against punishment, it becomes better for the other respondents to vote against punishment. Consequently, a voting outcome with exactly two respondents voting in favour of punishment cannot be an equilibrium. When exactly one or zero respondents vote in favour of punishment, $(y, n, n),(n, y, n),(n, n, y)$, $(n, n, n)$, the representative is not punished and no respondent can improve his/her pay-off by changing his/her voting decision. These strategy combinations are thus also equilibria. As all identified equilibria are not dependent on the distribution decision made by the representative, the optimal strategy for the representative will always be to keep all resources.

Up to now, we assumed that respondents and representatives only take account of their final income and not how their income compares with the income of the other players. However, according to the extensive literature on ultimatum game experiments, respondents do take account of how their income compares with the others' income and many representatives in an attempt to avoid rejection give substantial amounts to the respondents. Recent theoretical models have rationalized this by including an inequality term in the utility function (e.g. Fehr \& Schmidt, 1999; Bolton \& Ockenfels, 2000).

In contrast with standard preferences where punishment reduces the utility of each of the respondents, with social preferences this might be different, as individual utility also depends on the social comparison with the representative. 
In contrast with standard preferences where the voting equilibria are independent from the representative's distribution decision, we will show that with social preferences some of the voting equilibria depend on the representative's distribution decision. In particular, we will look at the impact of assuming that the players in our game have Fehr-Schmidt social preferences (Fehr \& Schmidt, 1999) instead of standard preferences. Due to the majority voting rule, $(y, y, y)$ and $(n, n, n)$ remain equilibria. If all respondents take the same voting decision, no respondent can increase his/her utility by changing his/her strategy as he/she cannot change the voting outcome.

For the other strategy combinations, $(y, n, n),(n, y, n),(n, n, y)$, which were equilibria with standard preferences and resulted in non-punishment, we study under what conditions they are not longer equilibria with social preferences. For this to be the case it is needed that at least two respondents are better-off when the representative is punished (and thus the representative is punished). As shown in appendix 2 (proposition 1), this is the case when the envy parameters of the respondents are above a certain threshold. The new equilibria under these conditions are $(y, y, n),(y, n, y),(n, y, y)$ and $(y, y, y)$. These equilibria exist irrespective of the distribution of the representative.

It is also shown that if envy parameters are below this threshold, the best response of the respondents becomes dependent on the distribution decision made by the representative. At least two respondents are better-off when the representative is punished, if their final income remains below a certain 'acceptance threshold'. Under these conditions $(y, y, y)$ is always an equilibrium, and also $(y, y, n),(y, n, y)$ or $(n, y, y)$ may be equilibria in dependence of which respondent has his/her final income remaining below the acceptance threshold.

Regarding the representative's optimal strategy, we make a distinction between the voting equilibria that are dependent on and those that are independent from the representative's distribution. If the representative believes that the respondents will play one of the equilibria that are independent from his/her distribution decision, the representative will keep all resources if his/her guilt parameter is not higher than $3 / 4$, otherwise he/she will distribute the resources such that the final income of all players is equalized (for a proof of this proposition 2 see appendix 2).

If the representative believes that the respondents will play one of the equilibria that are dependent on his/her distribution, he/she may be interested in 
avoiding punishment ${ }^{14}$. He/she may achieve this by giving at least two respondents more than their acceptance threshold so that they prefer non-punishment. As he/she only needs two respondents to abstain from voting for punishment to avoid punishment, he/she may increase his/her income by excluding the third respondent. Moreover, as $E_{D}<E_{B}=E_{C}$, respondent $\mathrm{D}$ has a higher acceptance threshold, so that the representative can increase his/her income even more without being punished by excluding respondent $\mathrm{D}$ instead of one of the other respondents. As indicated by the calculations of proposition 2 (appendix 2), following such an exclusion-strategy would only increase the representative's utility if his/her guilt parameter is lower than $3 / 4$. Otherwise he/she will prefer to equalize the final income of all players. According to the distribution of envy and guilt parameters assumed by Fehr \& Schmidt (1999), guilt parameters higher than $3 / 4$ are very rare. Consequently, with Fehr-Schmidt social preferences it is predicted that most representatives will opt for the exclusion strategy by forming a coalition with the middle-income players.

None of these models, however, satisfactorily explain why respondents in our experiment should take account of the share the other respondents receive. As each respondent pays the same punishment cost, punishing the representative leaves inequalities among respondents unaffected. Consequently, a vote for punishment cannot be rationalized as an attempt to reduce inequality among the respondents. Intention-based models are more promising in this respect. A reciprocal action by a respondent towards the representative through votes for punishment is determined by the perceived kindness of the action of the representative. It is the representative who is responsible for possible unkind treatments and this does not only depend on how outcomes compare between the representative and the respondent, but also on differences between the outcomes of the respondents. If a respondent is given less in comparison with other respondents, he/she might interpret this as unkind behaviour from the part of the representative.

Moreover, perceived kindness might also depend on the relative income positions (Falk \& Fischbacher, 2006). Richer respondents might not perceive it unkind to receive lower shares in comparison with poorer respondents whereas poorer respondents might perceive it very unkind if they receive lower shares in comparison with richer respondents. Such model would predict that respondents' behaviour is correlated with the differences between their received share

\footnotetext{
${ }^{14}$ The representative will only be interested in avoiding punishment if the cost of punishment is sufficiently high so that the utility of any non-punishment outcome is equal or higher than the maximum attainable utility with punishment.
} 
and the shares of the other respondents, which would not be the case in our model with standard and social preferences.

Finally, when taking a voting decision respondents may also be influenced by their expectations on the voting decisions of the other respondents. Some respondents may act as conditional cooperators (Fischbacher et al., 2001) and therefore vote in favour of punishment the more respondents they believe will do as well. This would make $(y, y, y)$ a likely outcome. However, as this strategy combination is also an equilibrium with standard and social preferences, empirical observation of this strategy combination does not allow us to draw any conclusions on its behavioural foundations. For this, we also need to test for a correlation between a respondent's propensity to vote in favour of punishment and his/her beliefs that the two other respondents will do as well. With standard or social preferences such a correlation is absent as the respondent is indifferent between voting in favour of or against punishment in case he/she expects the two other respondents will vote in favour of punishment.

\subsection{Experimental procedures and parameters}

At the beginning of the experiment, participants are told that the experiment consists of three independent parts, in the sense that the earnings in one part will not be influenced by their decisions in subsequent parts of the experiment. Moreover, each part is explained after the previous part has finished. The first part is a one-shot dictator game ${ }^{15}$. In the second and third part of the experiment, participants are matched in groups of four. Group composition remains unchanged in these parts of the experiment. In each part, participants play the previously described game for 10 rounds. At the beginning of each round, all players receive a fixed endowment. To study the influence of economic inequality in this game we let the players receive different endowments. One person receives 200 'francs' (=1 Euro) each round, two players receive each 150 and one player receives 100 . We call them respectively high-endowment, middleendowment and low-endowment players. Inequality is introduced before the start of the first round in a purely arbitrary way ${ }^{16}$. The endowment each player

\footnotetext{
${ }^{15}$ We changed this somewhat to allow for the possibility of destroying (see Bardsley (2005) on this). This makes that keeping everything is not a corner solution anymore, so that more players would choose this option. By doing so, selfish agents reluctant to choose a corner solution are more likely to be detected.

${ }^{16}$ Thus, inequality is difficult to justify morally. In reality, however, it is common that economic inequality is justified by certain actors, which would reduce the effect of inequality.
} 
receives at the beginning of each round is publicly known. The accumulated earnings of each participant are private knowledge throughout the experiment.

One participant is a permanent representative who each round is asked to distribute an additional (publicly known) pie of 200 'francs' between all members. Whereas in the second part it is the high-endowment player who is the permanent representative, in the third part this role is assumed by the lowendowment player. After each distribution decision of the representative, respondents are asked for their satisfaction (on a 9-point scale) about their share received $^{17}$ and they decide whether or not to vote in favour of punishing the representative. In case of punishment the pay-off of the representative is reduced with 200 'francs ${ }^{18}$, whereas the cost of punishment is 20 'francs' for each of the respondents (also for those who did not vote in favour of punishment). Player roles do not change during the 10 rounds.

To be able to study the influence of strategic elements more thoroughly, we asked participants after each decision for their beliefs about the voting decisions of the respondents. In particular, whereas each respondent is asked for the likelihood that exactly two, one or none other respondents vote in favour of punishment, the representative is asked for the likelihood that a specific respondent votes in favour of punishment and this for each of the respondents. To induce sincere estimates we used the quadratic scoring rule for belief elicitation (see e.g. Offerman, 1997). In brief, the amount they earn with these estimates depends on the reported likelihood estimates and the actual voting decisions of the other members ${ }^{19}$.

\footnotetext{
${ }^{17}$ This helps us to disentangle psychological elements from strategic elements.

${ }^{18}$ Note that this is exactly the same amount as the resources to be distributed. As a consequence, keeping all resources but being punished results in a status-quo for the representative. Compared with this benchmark, representatives have a strong incentive to try to avoid punishment by giving more resources to the others, as this could lead to positive net earnings. If they fail to avoid punishment, however, not keeping all resources leads to negative net earnings.

${ }^{19}$ The additional earnings for a respondent are equal to $3+6 p_{j}-3\left(\left(p_{0}\right)^{2}+\left(p_{1}\right)^{2}+\left(p_{2}\right)^{2}\right)$ if $\mathrm{j}$ respondents vote in favor of punishment (with $j=0,1,2$ ). $p_{j}=P_{j} / 100$, with the reported percentages $P_{j}$ representing the percentage that $\mathrm{j}$ respondents vote in favor of punishment. The additional earnings for the representative are $\sum^{3}\left[1+2 p_{j}-\left(\left(p_{y a}\right)^{2}+\left(p_{m o}\right)^{2}\right)\right]$, with $\mathrm{p}_{\mathrm{j}}=\mathrm{P}_{\mathrm{j}} / 100$. The reported percentages $\mathrm{P}_{\mathrm{j}}(\mathrm{j}=$ yes, no)

represent the probability that a specific respondent votes in favor of punishment. Consequently, both the representative and the respondents can earn an additional earning of maximum 6 'francs' in case their likelihood estimates are completely correct. The participants got to see the formulas in the instructions, but they were told that it was not important to understand them exactly and it was sufficient that they realized that their expected earnings were maximized if they indicated their true likelihood estimates.
} 
We organized four different treatments (Table 3.1), by combining two information conditions. The first information condition relates to the information on the distribution decision made by the representative. We compare a setting wherein information about the distribution remains private for the respondents with a setting with common information on the distribution. Only when respondents have full information on the distribution, they are able to compare their share with the share of the other group members and social comparison may enter their subsequent voting decisions. Representatives may anticipate that respondents engage in social comparison and therefore adapt their distribution decisions.

The second information condition relates to information on the voting decisions of the respondents. We distinguish between a setting wherein voting decisions remain secret and a setting wherein voting decisions are made public. The difference might be crucial as our game is a repeated game with fixed partners. In particular, the voting decision of a respondent may influence subsequent distribution decisions of the representative. If multiple respondents have to vote about punishment and voting is public (and thus the representative knows who has been dissatisfied with his/her distribution decision) the representative also obtains information about the relative acceptance thresholds of the respondents. Representatives may use this information to shift resources away from those agents that are more difficult to satisfy. Such an exclusion-strategy allows them to increase their personal share and remain unpunished. Respondents who actually disagree with the current distribution, however, may anticipate this and therefore refrain from voting in favour of punishment if voting is public.

Table 3.1. Treatments

\begin{tabular}{lcc}
\hline & $\begin{array}{c}\text { Secret } \\
\text { voting }\end{array}$ & $\begin{array}{c}\text { Public vot- } \\
\text { ing }\end{array}$ \\
\hline Private information on the distribution & 8 groups & 8 groups \\
Common information on the distribution & 7 groups & 8 groups \\
\hline
\end{tabular}

The experiment was conducted in the computer lab of Maastricht University in the second half of 2006. It was computerized using Z-tree software (Fischbacher, 2007). In total 124 students participated in 31 groups, most of them students in economics and business administration, all from Maastricht University. $52.4 \%$ of the participants were male and average age was 21.8 with a minimum of 18 and maximum of 31 . None of the students had participated in a similar experiment before. Each session took between 90 and 120 minutes, and 
average earnings were 22.2 Euros, with the highest earnings 31.7 Euros and lowest earnings 10.7 Euros. More detailed experimental procedures and the instructions can be found in Appendix 1.

\section{Empirical results}

In this section we look at the representatives' distribution decisions and the respondents' voting decisions, and how they interact with each other. We first look at the determinants of the satisfaction of the respondents about their received share and their subsequent voting decisions. Thereafter, we study the strategies of the representatives and their relation with punishment and exclusion. Treatment effects will be identified and discussed while analyzing the decision-making of both respondents and representatives.

\subsection{The respondents: satisfaction and voting}

The respondents' voting decisions might depend on both psychological and strategic elements. To disentangle both behavioural motives, we measured the respondents' satisfaction with their received share. We expect their voting decision to be highly correlated with their satisfaction. It seems intuitive that respondents are more inclined to vote in favour of punishment the less satisfied they are with the resources they receive from the representative. Before studying the respondents' voting decision we therefore start with an analysis of the determinants of their satisfaction.

We asked the respondents about their satisfaction level with the share they received, on a 9 point scale with range [-4, 4], and used this measure as dependent variable in a regression model. We expect that the less a respondent receives from the representative, the lower his/her satisfaction. As the satisfaction level for a given received share might differ between low and middle-endowment respondents we add a dummy variable to control for the endowment of the respondent. As the influence of the received share might also differ between low and middle-endowment players, we add an interaction variable between the received share and the endowment dummy variable. In addition, to study whether female respondents have different satisfaction levels for a given received share we control for the sex of the respondent. Finally, we add two dummies to control for the information conditions on the voting and distribution decisions, and we control for the round number to test whether there exists any time trend. 
Table 3.2 shows the results. Pooling the data of all treatments in the first model we observe that the received share is a very strong determinant of the satisfaction about that share. We also observe that it is the only significant variable in this model.

Table 3.2. Satisfaction with the received share

\begin{tabular}{|c|c|c|c|c|c|c|}
\hline & \multicolumn{2}{|c|}{$\begin{array}{l}\text { Model } 1 . \\
\text { Pooled }\end{array}$} & \multicolumn{2}{|c|}{$\begin{array}{c}\text { Model } 2 . \\
\text { Private } \\
\text { information }\end{array}$} & \multicolumn{2}{|c|}{$\begin{array}{c}\text { Model } 3 . \\
\text { Common } \\
\text { information }\end{array}$} \\
\hline & Coef. & S.E. & Coef. & S.E. & Coef. & S.E. \\
\hline Own share & 0.090 & $0.008 * * *$ & 0.100 & $0.008 * * *$ & 0.084 & $0.013 * * *$ \\
\hline Middle-endowment player (dummy) & 0.314 & 0.272 & 0.438 & 0.310 & 0.188 & 0.470 \\
\hline Own share $\mathrm{x}$ middle-endowment player & 0.001 & 0.010 & -0.013 & 0.011 & 0.014 & 0.016 \\
\hline Share representative & - & - & - & - & 0.001 & 0.004 \\
\hline $\operatorname{Sex}(1=$ male; $0=$ female $)$ & -0.343 & 0.289 & -0.404 & 0.387 & -0.332 & 0.433 \\
\hline Public voting (dummy) & 0.230 & 0.348 & 0.476 & 0.412 & -0.039 & 0.581 \\
\hline Common information (dummy) & 0.045 & 0.328 & - & - & - & - \\
\hline Round & 0.016 & 0.024 & -0.018 & 0.025 & 0.050 & 0.042 \\
\hline Constant & -4.008 & $0.424 * * *$ & -4.008 & $0.383^{* * *}$ & -4.145 & $0.975^{* * *}$ \\
\hline $\mathrm{N}$ & 930 & & 480 & & 450 & \\
\hline R-squared & 0.5730 & & 0.6181 & & 0.5443 & \\
\hline Prob $>F$ & 0.0000 & & 0.0000 & & 0.0000 & \\
\hline F & 68.20 & & 200.22 & & 40.17 & \\
\hline
\end{tabular}

Notes. OLS regression with robust standard errors to correct for intra-group correlations. We ran separate regressions for public and secret voting, but results were not very different, so that we decided to pool observations under public and secret voting. Significance levels (two-sided): $*=$ $10 \%, * *=5 \%, * * *=1 \%$.

Pooling data of both private and common information treatments, however, might conceal influences that are specific to one of both treatment conditions. In particular, when information on the distribution is common social comparison might become important. Therefore, we estimate separate models for private and common information on the distribution. In the model with data from the common information treatments we also controlled for the share the representatives keep for themselves. In these models too the received share results the only significant explanatory variable.

In case of common information on the distribution decisions the following modifications make sense. First, if respondents engage in social comparison, their relative position vis-à-vis the person of comparison might be an important 
determinant. More specifically, it might matter if the inequality is advantageous (in the sense that the received share is larger than the share of the person of comparison) or disadvantageous (Fehr \& Schmidt, 1999). Second, social comparison might be very different between low and middle-endowment respondents. In particular, whereas low-endowment respondents are only able to compare with high and middle-endowment players, middle-endowment respondents are able to compare with high, middle and low-endowment players. Thus, it is necessary to estimate separate models for both types of respondents.

Table 3.3 reports the estimation results for low- and middle-endowment respondents separately. In both models we observe that once we control for relative standing the received share does not exert any significant direct influence on the satisfaction of the respondents. The relative positions vis-à-vis the other group members, in contrast, are important determinants of a respondent's satisfaction. We observe that disadvantageous inequality (envy) towards the high-endowment player (the representative) exerts a significant negative influence on the satisfaction level of the respondent. The higher the inequality in favour of the representative, the less satisfied the respondent becomes with his/her own share. The coefficient is similar for both types of respondents. Advantageous inequality (guilt) increases the satisfaction of the middleendowment respondents. For low-endowment respondents we do not observe such effect.

Respondents also compare with the middle-endowment players. Coefficients of advantageous inequality are positive whereas coefficients of disadvantageous inequality are negative. As indicated by the size of the coefficients, for middle-endowment players advantageous inequality with respect to other middle-endowment respondents weighs more than advantageous inequality towards the representative $(\mathrm{F}(1,14)=5.77$; two-sided $\mathrm{P}=.031)$. This suggests a group reference effect. The fact that respondents find themselves in a similar position seems to make them focus on the differences between them. Regarding disadvantageous inequality we do not find such effect $(\mathrm{F}(1,14)=3.00$; twosided $\mathrm{P}=.105)$.

Low-endowment players are less satisfied if they receive less than the average of both middle-endowment players and their satisfaction becomes lower the larger this difference. In case inequality is advantageous for the lowendowment player we do not observe any influence on his/her satisfaction level. 
Table 3.3. Satisfaction with the received share (common information)

\begin{tabular}{|c|c|c|c|c|}
\hline & \multicolumn{2}{|c|}{$\begin{array}{c}\text { Model } 1 . \\
\text { Middle-endowment } \\
\text { respondents (players 2-3) }\end{array}$} & \multicolumn{2}{|c|}{$\begin{array}{l}\text { Model } 2 . \\
\text { Low-endowment } \\
\text { respondents (player 4) }\end{array}$} \\
\hline & Coef. & S.E. & Coef. & S.E. \\
\hline Own share & 0.019 & 0.016 & 0.026 & 0.022 \\
\hline Max $\{$ own share - share high-endow, 0$\}$ & 0.018 & $0.010^{*}$ & -0.025 & 0.021 \\
\hline Max $\{$ share high-endow - own share, 0$\}$ & -0.021 & $0.003 * * *$ & -0.017 & $0.006^{* *}$ \\
\hline Max $\{$ own share - share middle-endow, 0$\}$ & 0.022 & $0.010^{* *}$ & 0.031 & 0.034 \\
\hline Max $\{$ share middle-endow - own share, 0$\}$ & -0.037 & $0.009 * * *$ & -0.042 & $0.013 * * *$ \\
\hline Max $\{$ own share - share low-endow, 0$\}$ & -0.004 & 0.012 & - & - \\
\hline Max $\{$ share low-endow - own share, 0$\}$ & -0.019 & $0.006^{* *}$ & - & - \\
\hline $\operatorname{Sex}(1=$ male; $0=$ female $)$ & -0.106 & 0.527 & -0.719 & 0.977 \\
\hline Public voting & 0.583 & 0.521 & -1.128 & 0.943 \\
\hline Round & 0.061 & 0.064 & 0.091 & 0.072 \\
\hline $\mathrm{N}$ & 300 & & 150 & \\
\hline Prob $>F$ & 0.0000 & & 0.0000 & \\
\hline $\mathrm{F}$ & 135.75 & & 113.03 & \\
\hline
\end{tabular}

${ }^{\text {a }}$ In the first model the respondent compares with the other middle-endowment player, whereas in the second model we let the low-endowment respondent compare with the average of both middleendowment players.

Notes. OLS regression with robust standard errors to correct for intra-group correlations. As all shares sum up to a constant, we estimate a model without constant to avoid complete collinearity. $\mathrm{R}$-squared is not included as it is overestimated in models without a constant term. Significance levels (two-sided): $*=10 \%, * *=5 \%, * * *=1 \%$.

Middle-endowment players are also able to compare with the low-endowment respondents. We observe that advantageous inequality does not influence their satisfaction level. Disadvantageous inequality, in contrast matters. In case a middle-endowment player receives less than the low-endowment respondent, the former will be more dissatisfied the larger this difference. Based on an F-test, we find that the influence of disadvantageous inequality with the lowendowment respondents is not statistically different from the influence of disadvantageous inequality with other middle-endowment respondents $(\mathrm{F}(1,14)$ $=2.21$; two-sided $\mathrm{P}=.160$ ). Moreover, it is also not statistically different from the influence of disadvantageous inequality with the high-endowment player $(F(1,14)=0.10$; two-sided $P=.756)$. The latter suggests that in their satisfaction levels with their share middle-endowment players do not recognize the less favorable and unfair position of low-endowment respondents in comparison with the high-endowment representative. Finally, the sex of the respondent does 
not exert a significant effect on the satisfaction with the received share. We summarize the findings discussed so far in our first result.

\section{Result 1 Satisfaction with the received share}

When information is private, satisfaction with the received share increases with the share, which is the only statistically significant determinant. With common information on the distribution, a respondent is less satisfied if the representative keeps more than what he/she gives to the respondent, and the more so the larger this difference. Respondents also compare with the other respondents. Disadvantageous inequality lowers the satisfaction of respondents irrespective of their endowment, whereas advantageous inequality only increases satisfaction for middle-endowment respondents comparing with each other.

After having studied the determinants of the respondents' satisfaction with their received share, we now estimate an explanatory model on the voting decisions of the respondents. Next to their satisfaction level, there are more strategic elements that might influence respondents' voting decisions. These may influence voting decisions in different ways.

First, we expect that it matters whether voting is public or secret. When voting is public, representatives receive information about who wants to punish him/her. This makes it possible for representatives to retaliate against 'protesting' respondents when making new distribution decisions in subsequent rounds. Anticipating such behaviour, respondents may be more reluctant to vote in favour of punishment when voting is public. However, there might be an interaction effect with the respondent's satisfaction. More dissatisfied respondents may care less about the consequences of their voting decision on future earnings. This may be due to an emotional reaction that outweighs strategic behaviour. Another reason for this might be that they already receive low shares from the representative. Potential profit losses as a result of representatives lowering their shares in response to their protest votes are therefore limited as well.

Second, the beliefs about the voting decisions of the other respondents may be important. Respondents may be conditional voters. Considering punishment a public good, respondents may cast a vote in favour of punishment only if they expect the other respondents to do the same (Fischbacher et al., 2001). To control for such conditional voter effect, we add the respondent's likelihood estimates that one other respondent votes in favour of punishment and the likelihood estimates that both other respondents vote in favour of punishment. 
Furthermore, we control for the information condition on the distribution decisions and the sex and the endowment of the respondent.

The results of model 1 in Table 3.4 show that the satisfaction level with the received share exerts a significant negative influence on a respondent's likelihood of voting in favour of punishment. The results also show that with public voting the respondents are more reluctant to vote in favour of punishment. At the same time, as indicated by the significant interaction effect, this reluctance reduces with lower satisfaction levels.

As hypothesized, when taking a voting decision, respondents are also influenced by their beliefs about what the other respondents would do. The higher their likelihood estimates that both other respondents will vote in favour of punishing the representative, the more they are inclined to do as well. This conditional voter effect is not different between private and public voting as indicated by the insignificant coefficient of the interaction term with the voting condition. The influence of the beliefs that exactly one other respondent votes in favour of punishment is very small and insignificant.

Interestingly, we observe a large influence of the sex of the respondents. Female respondents have a $14.7 \%$ lower probability of voting in favour of punishment in comparison with male respondents. A similar effect exists with the endowment of the respondents. Middle-endowment players have a $13.6 \%$ lower probability of voting in favour of punishment in comparison with lowendowment players. We also observe that with common information on the distribution decisions, the respondents' propensity to vote in favour of punishment increases with $11.7 \%$.

A relevant question to ask, however, is whether the sex and endowment effects are equally present under both private and common information on the representative's distribution decisions. It might be the case that with common information respondents do not only take account of their relative position vis-àvis the other players (which is captured by the satisfaction with the received share as confirmed by previous regression results); but also of the distribution in general, which tends to be very unfair (see next section on this) with most representatives trying to keep as much as possible. If middle-endowment or female respondents are more sensitive to this than low-income or male respondents respectively, their lower propensity to vote in favour of punishment might then disappear once information on the distribution is public. 


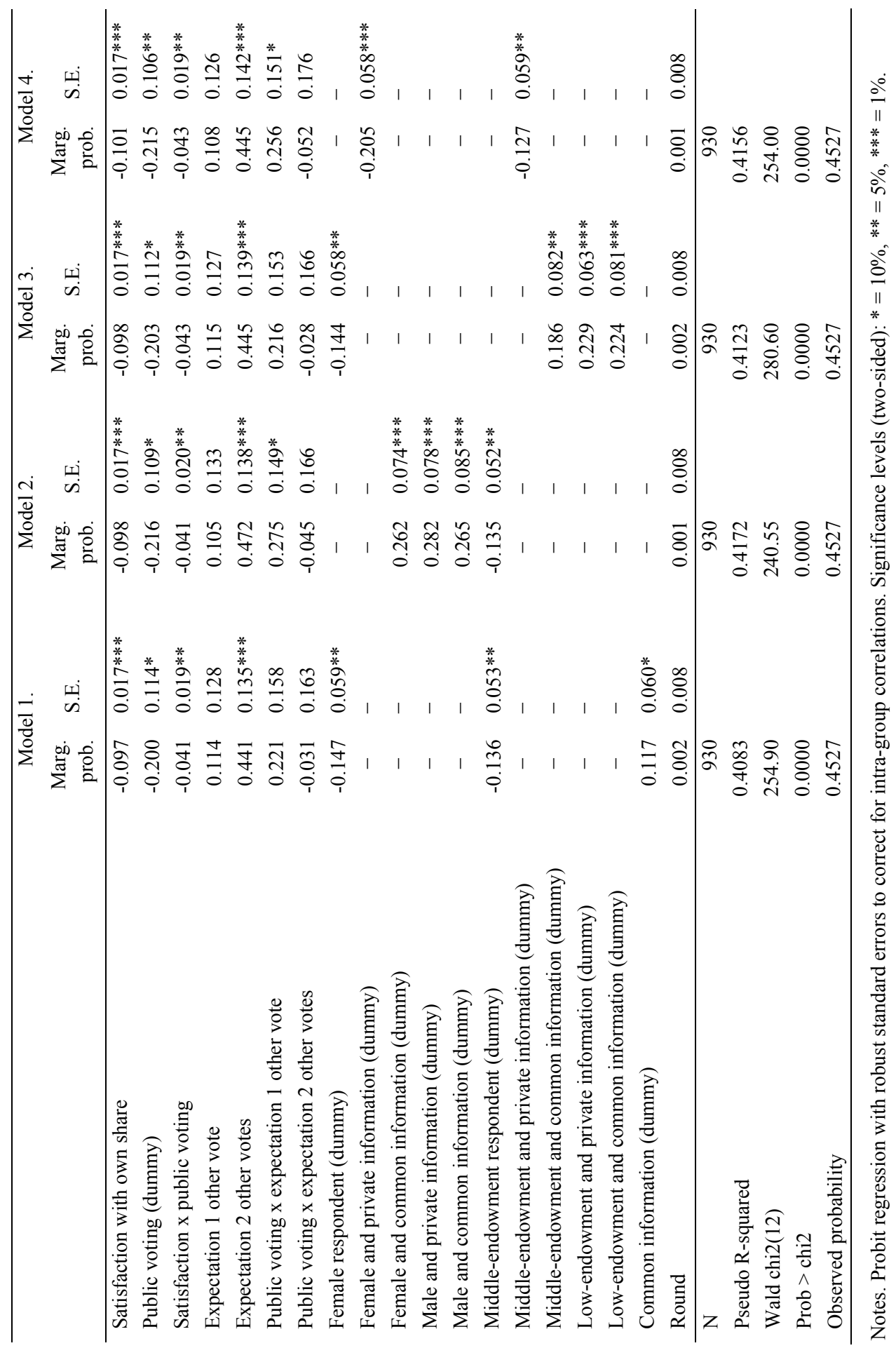


To study these possible interaction effects, we control in model 2 for the different combinations of the respondents' sex and the information condition on the distribution decisions. In model 3, we do the same for the respondents' endowment. The regression results in models 2 and 3 indicate that middleincome or female respondents only have a lower propensity to vote in favour of punishment when information on the distribution is private. Once information on the distribution is made public, differences between male and female respondents disappear. According to a chi-squared test both dummy coefficients are not significantly different $(\operatorname{chi} 2(1)=0.00$; two-sided $\mathrm{P}=.965)$. The same applies to differences between low-endowment and high-endowment respondents ( chi2 $(1)=0.22$; two-sided $\mathrm{P}=.641)$. Building on these results we are able to combine models 2 and 3 into a model 4 . Our findings on the respondents' likelihood of voting in favour of punishment are summarized in a second result.

\section{Result 2 Propensity to vote in favour of punishment}

A respondent's propensity to vote in favour of punishment decreases with higher satisfaction with the received share. It also decreases when voting is public, although this effect becomes weaker with lower satisfaction. A respondent's propensity to vote in favour of punishment also decreases the less he/she believes that both other respondents will vote in favour of punishment. Female or middle-endowment respondents have a lower propensity to vote in favour of punishment unless information on the distribution is common.

\subsection{The representatives}

In this section we study the representatives' decision making when the highendowment player is the representative, i.e. the first 10 rounds of the experiment. We start with some descriptive statistics on the representatives' distribution decisions. We then elaborate a classification of strategies and look at the relative frequency of the strategies under the different treatment conditions. After this static analysis, we examine the dynamics of strategy choice and its relation with punishment.

Two focal ways of allocating the additional resources might be interpreted as 'fair'. First, the additional resources can be distributed in an equal way, i.e. 50 'francs' for each of the four players. Second, resources may be distributed so that the final distribution among the respondents is equalized. This is obtained if the representative gives 100 'francs' to the low-endowment players, 50 'francs' 
to each of the middle-endowment players and keeps nothing to him/herself, so that each player would end up with 200 'francs'.

Table 3.5. Descriptive statistics of distributive decisions

Mean share of ...

\begin{tabular}{|c|c|c|c|c|c|}
\hline & & Player 1 & Player 2 & Player 3 & Player 4 \\
\hline & 1. Secret voting - private information & $\begin{array}{c}106.88 \\
(56.67)^{a}\end{array}$ & $\begin{array}{c}28.68 \\
(27.00)\end{array}$ & $\begin{array}{c}34.13 \\
(26.06)\end{array}$ & $\begin{array}{c}30.33 \\
(25.06)\end{array}$ \\
\hline छ̈ & 2. Public voting - private information & $\begin{array}{c}98.25 \\
(46.88)\end{array}$ & $\begin{array}{c}38.26 \\
(21.66)\end{array}$ & $\begin{array}{c}32.59 \\
(25.21)\end{array}$ & $\begin{array}{c}30.90 \\
(28.76)\end{array}$ \\
\hline 怘 & 3. Secret voting - common information & $\begin{array}{l}102.33 \\
(63.60)\end{array}$ & $\begin{array}{c}29.64 \\
(26.02)\end{array}$ & $\begin{array}{c}35.81 \\
(25.65)\end{array}$ & $\begin{array}{c}32.21 \\
(29.50)\end{array}$ \\
\hline & 4. Public voting - common information & $\begin{array}{c}88.49 \\
(61.43)\end{array}$ & $\begin{array}{c}38.59 \\
(25.67)\end{array}$ & $\begin{array}{c}39.96 \\
(23.97)\end{array}$ & $\begin{array}{c}32.96 \\
(27.09)\end{array}$ \\
\hline & Total & $\begin{array}{c}98.88 \\
(57.71)\end{array}$ & $\begin{array}{c}33.93 \\
(25.57)\end{array}$ & $\begin{array}{c}35.62 \\
(25.38)\end{array}$ & $\begin{array}{c}31.58 \\
(27.61)\end{array}$ \\
\hline
\end{tabular}

${ }^{a}$ Standard deviation between parentheses. Group averages over all rounds.

Notes. Taking group averages over all rounds the shares are not significantly different over the four treatments. Based on a Kruskal-Wallis test two-sided P-values for the respective shares are .799; $.513 ; .809$ and .998 .

In the experiment, however, representatives keep much more for themselves than dictated by any of both 'fair' ways of allocating resources. In Table 3.5, which shows some descriptive statistics on the representatives' distribution decisions, we observe that on average the share representatives keep is almost three times as much as what they give to each of the respondents. In other words, they only give around $50 \%$ to the three respondents in total, although their endowment is already 50\% higher than the middle-endowment players or even $100 \%$ compared with the low-endowment players. This suggests that to a large extent profit-maximization outweighs concerns for fairness.

For representatives to maximize profits, they should not only consider the share they keep for themselves. It also matters whether or not they manage to avoid punishment as punishment costs are considerable. Recall that the punishment cost for representatives equals the maximum profit they could make by keeping all resources.

Punishment is quite frequent as indicated by Table 3.6., which shows the average punishment frequency after pooling all rounds over all groups by treatment. At the same time, there are considerable differences between the treatments. Given the information condition, punishment rates are higher when voting is secret, and for a given voting condition, when information on the 
distribution is common. This is consistent with the regression results in the previous section on the respondents' propensity to vote in favour of punishment. Using group averages over all rounds as units of observation, differences are significant between public voting/private information and secret voting/common information (Mann-Whitney $\mathrm{U}=4.50$; two-sided $\mathrm{P}=.004$ ). For all other pairwise treatment comparisons differences are not statistically significant (twosided P-values are larger than .200).

Table 3.6. Average punishment frequency by treatment

\begin{tabular}{lcc}
\hline & $\begin{array}{c}\text { Private } \\
\text { information }\end{array}$ & $\begin{array}{c}\text { Common } \\
\text { information }\end{array}$ \\
\hline Secret voting & $42.50 \%$ & $60.00 \%$ \\
Public voting & $26.25 \%$ & $42.25 \%$ \\
\hline
\end{tabular}

Note. All rounds and groups pooled.

Based on the observation that punishment rates differ between the treatments, we also expect that the strategy that leads to the highest profit differs across the treatments. Profit-maximizing representatives may take this into account when choosing their strategy. Before looking at this, we first classify the representatives' strategies.

For this classification, we use the following two dimensions. First, we take account of the share representatives keep. We distinguish between distributions where the representative keeps more than 50 'francs' and distributions where he/she keeps less or equal than 50 'francs'. We do so, because distributions with the representative's share being higher than 50 'francs' cannot be justified by any of both - above described - 'fair' ways of allocating resources. Second, when taking a distribution decision, we also expect representatives to consider the number of respondents to exclude from the resources, where exclusion means not giving any resources. Combining both variables we have eight possible classes of strategies. However, as Table 3.7 shows, two of them are empty and another two have such low percentages that we can ignore them in the remaining analysis. As a result four classes of strategies remain.

A first strategy consists of keeping the entire pie and thus excluding all respondents from the resources. This strategy is followed in $17.74 \%$ of the cases. We will refer to this strategy as the 'exclude-all'-strategy. A second strategy consists of excluding exactly one respondent. This is a very common strategy, as in more than one third of the cases this strategy is chosen. The representatives who follow this strategy seem to try to build a minimum 
coalition. In an attempt to maximize their earnings, they exclude one respondent while trying to obtain the support of the other two respondents. The conjecture that they do so in an attempt to maximize their earnings is supported by the fact that this strategy is in almost all of the cases combined with the representative keeping shares higher than 50 'francs'. We will refer to this strategy as the 'exclude-one'-strategy.

Table 3.7. Classification of strategies

\begin{tabular}{cccc}
\hline & & \multicolumn{2}{c}{ Share of representative $>50$ 'francs' } \\
& & no & yes \\
\hline \multirow{3}{*}{ Excluded } & 0 & $\mathbf{2 6 . 1 3 \%}$ & $\mathbf{1 9 . 6 8 \%}$ \\
respondents & 1 & $2.90 \%$ & $\mathbf{3 2 . 9 0 \%}$ \\
& 2 & $0.00 \%$ & $0.65 \%$ \\
& 3 & $0.00 \%$ & $\mathbf{1 7 . 7 4 \%}$ \\
\hline
\end{tabular}

Notes. $\mathrm{N}=1240$. Pooled over all rounds, groups and treatments

In a third and fourth strategy representatives do not exclude any respondent. The difference between both strategies relates to the share representatives keep. Whereas in the third strategy they keep less or equal than 50 'francs', in the fourth strategy they keep more than 50 'francs'. We will refer to these strategies as the 'no-exclusion-low-share'-strategy and 'no-exclusion-high-share'-strategy, respectively. Under the 'no-exclusion-low-share'-strategy also fall the distributions where the representative does not keep any resources (3.23\% of the cases) or distributes the resources equally among all players (12.8\% of the cases).

Also note that a strategy of excluding two respondents is almost never followed. This makes sense, because to avoid punishment a representative needs at least two respondents satisfied with their received share. It is very improbable that punishment can be avoided by excluding two respondents. Consequently, to the extent that excluding two respondents leads to similar punishment rates as excluding all respondents, the latter is preferred as it leads to a higher expected profit.

We now study whether the strategy choice is related to the treatment conditions. Figure 3.2 shows the relative frequencies of each strategy in each treatment. To test whether the relative frequencies of each of the strategies are significantly different between the treatments we calculate for each treatment the relative frequency of each strategy over all rounds and groups. For each strategy we applied a Mann-Whitney test to each treatment pair. 
Figure 3.2. Representatives' strategy choice by treatment

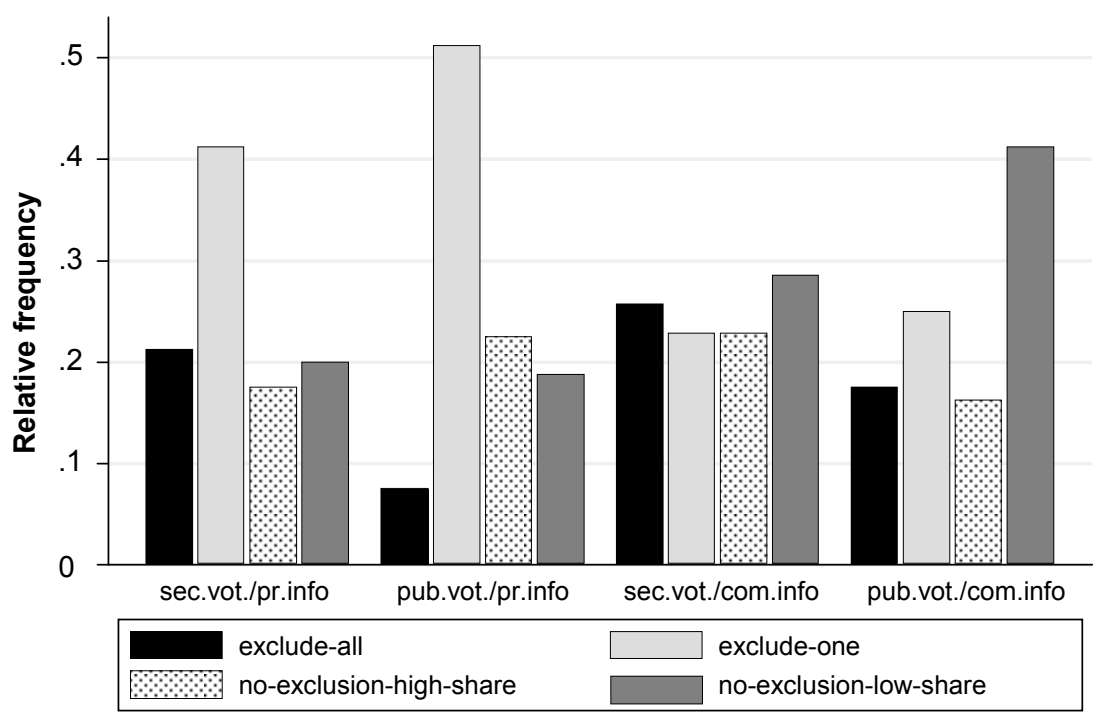

Note. All rounds and groups pooled.

As to the 'exclude-all'-strategy, the relative frequencies of this strategy are significantly different between public voting/private information and secret voting/common information (Mann-Whitney $\mathrm{U}=13.00$; two-sided $\mathrm{P}=.071$ ). For all other pair-wise treatment comparisons, differences are not statistically significant (two-sided P-values $>$.150). The significant difference between public voting/private information and secret voting/common information is attributed to the voting condition, as the relative frequency of this strategy is significantly different between public voting and secret voting (Mann-Whitney $\mathrm{U}=77.00$; two-sided $\mathrm{P}=.079)$ and not between common information and private information (Mann-Whitney $\mathrm{U}=107.00$; two-sided $\mathrm{P}=.545$ ).

Regarding the 'exclude-one'-strategy, the relative frequencies are significantly different between public voting/private information and secret voting/common information (Mann-Whitney $\mathrm{U}=11.50$; two-sided $\mathrm{P}=.054$ ) or public voting/common information (Mann-Whitney $\mathrm{U}=13.50$; two-sided $\mathrm{P}=$ .050). For all other pair-wise treatment comparisons differences are not statistically significant (two-sided P-values $>.350$ ). These significant differences are the result of the information condition (comparison between common information and private information leads to Mann-Whitney $\mathrm{U}=70.00$; two-sided $\mathrm{P}=$ .049 ) and not of the voting condition (Mann-Whitney $\mathrm{U}=102.00$; two-sided $\mathrm{P}=$ $.495)$. 
Finally, the relative frequencies of the 'no-exclusion-low-share'-strategy and the 'no-exclusion-high-share'-strategy do not show any significant difference when compared between treatments, between secret voting and public voting, or between private information and common information.

We now examine whether the strategy choice is related to the punishment frequencies and the average earnings over the different treatment conditions. Punishment reduces the final earnings, and thus may change the optimal strategy for profit-maximizing representatives. For this, we examine whether the above observed differences in strategy choice are consistent with differences in punishment frequency and average earnings. We limit this analysis to the 'exclude-all'-strategy and the 'exclude-one'-strategy, as for the other strategies we did not find significant differences in relative frequency across treatments.

Table 3.8 shows the punishment frequencies and the resulting average earnings by treatment and strategy choice. We observe that the 'exclude-all'strategy almost always results in punishment, with small differences between the treatments. However, in case the representative is not punished earnings are very high, which makes average earnings positive for all treatments. In comparison with the average earnings of the other strategies within a given treatment, this strategy leads to the highest average earnings when information on the distribution is common (third and fourth row in Table 3.8b).

To test this statistically, we estimate a regression on the earnings of the representative controlling for the 'exclude-all'-strategy. According to the estimated coefficient of the control variable, following the 'exclude-all'-strategy in the secret voting/common information treatment increases the average earnings with 53.70 (two-sided $\mathrm{P}=.041, \mathrm{~N}=70$; applying robust standard errors to correct for intra-group correlations) in comparison with the other strategies. Following this strategy in the public voting/common information treatment increases the average earnings with 44.69 (two-sided $\mathrm{P}=.050, \mathrm{~N}=80$; applying robust standard errors to correct for intra-group correlations) in comparison with the other strategies. In both treatments with private information this coefficient is not significantly different from zero (two-sided P-values $>.400$ ). This is consistent with the above observed significant difference of the relative frequencies of this strategy between the public voting/private information treatment and the secret voting/common information treatment.

Regarding the 'exclude-one'-strategy, Table 3.8a shows that punishment frequencies with this strategy differ considerably across the treatments. When information on the distribution is common, punishment rates with this strategy are substantially higher in comparison with private information on the distribution decisions. Based on a probit regression with only a control for the informa- 
tion on the distribution, this difference is statistically significant (two-sided $\mathrm{P}$ of the coefficient of the information dummy $=.006 ; \mathrm{N}=102$; applying robust standard errors to correct for intra-group correlations). The higher punishment frequency with this strategy when information is common is consistent with the significantly lower frequencies of this strategy when information is common.

Table 3.8. Relative frequency of punishment and average earnings

a. Relative frequency of punishment

Strategies

\begin{tabular}{|c|c|c|c|c|c|c|}
\hline & & 1 & 2 & 3 & 4 & Total \\
\hline \multirow{4}{*}{ 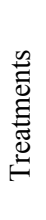 } & Sec.vot./pr.info & $94.12 \%$ & $30.77 \%$ & $64.29 \%$ & $0.00 \%$ & $42.50 \%$ \\
\hline & Pub.vot./pr.info & $83.33 \%$ & $25.00 \%$ & $22.22 \%$ & $7.14 \%$ & $26.25 \%$ \\
\hline & Sec.vot./com.info & $88.88 \%$ & $50.00 \%$ & $93.75 \%$ & $15.00 \%$ & $60.00 \%$ \\
\hline & Pub.vot./com.info & $78.57 \%$ & $45.00 \%$ & $46.15 \%$ & $16.13 \%$ & $42.25 \%$ \\
\hline & Total & $87.27 \%$ & $34.31 \%$ & $55.74 \%$ & $11.11 \%$ & $41.94 \%$ \\
\hline
\end{tabular}

b. Average earnings (after punishment and exclusive endowments)

Strategies

\begin{tabular}{|c|c|c|c|c|c|c|}
\hline & & 1 & 2 & 3 & 4 & Total \\
\hline \multirow{5}{*}{ 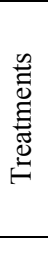 } & Sec.vot./pr.info & 11.77 & 37.89 & -23.21 & 46.88 & 21.88 \\
\hline & Pub.vot./pr.info & 33.33 & 50.13 & 63.61 & 23.57 & 45.75 \\
\hline & Sec.vot./com.info & 22.22 & -28.25 & -88.75 & 11.75 & -17.67 \\
\hline & Pub.vot./com.info & 42.86 & 4.25 & -6.54 & 3.19 & 5.99 \\
\hline & Total & 25.46 & 25.72 & -11.23 & 17.46 & 15.01 \\
\hline
\end{tabular}

Notes. Strategies: 1 = 'exclude-all'-strategy; 2 = 'exclude-one'-strategy; 3 = 'no-exclusion-highshare'-strategy; 4 = 'no-exclusion-low-share'-strategy. All rounds and groups pooled.

Looking at the average earnings, we observe that with private information on the distribution this strategy is among the most profitable. To test whether the earnings with this strategy are also significantly higher in comparison with all other strategies, we estimate a regression on the earnings of the representative controlling for the 'exclude-one'-strategy. According to the estimated coefficient of the control variable, following the 'exclude-one'-strategy does not significantly change the earnings of the representative (two-sided P-values in each of the four treatments $>.250$ ) in comparison with the other strategies. Thus, the observed differences in relative frequency of this strategy across treatments 
are consistent with differences in punishment frequency, but are not supported by any evidence based on the average earnings.

As there are middle-endowment and low-endowment respondents, a further question relates to which respondents are more likely to be excluded when the representative follows the 'exclude-one'-strategy. For this, we estimated a probit regression where we only consider the observations with the 'exclude-one'strategy and we only control for the endowment of the respondent. Pooling both secret voting treatments, the estimated coefficient is not statistically significant from zero (two-sided $\mathrm{P}=.780 ; \mathrm{N}=126$; applying robust standard errors to correct for intra-group correlations). With public voting, however, lowendowment respondent have a $40.00 \%$ higher probability to be excluded (twosided $\mathrm{P}=.015 ; \mathrm{N}=180$; applying robust standard errors to correct for intragroup correlations).

This is consistent with our previous analysis on the voting decisions of the respondents, where we found that low-endowment respondents have a higher propensity to vote in favour of punishment than middle-endowment respondents. With public voting, representatives obtain information on individual voting decisions and are able to make inferences about the respondents' propensity to vote in favour of punishment. Observing that low-endowment respondents have a higher propensity to vote in favour of punishment, representatives may be more inclined to exclude low-endowment respondents than middle-endowment respondents.

\section{Result 3 Strategy choice and punishment (static view)}

a. Making voting public reduces the relative frequency of the 'exclude-all'strategy. It does not change the punishment frequency with this strategy.

b. Making information on the distribution common increases the punishment frequency with the 'exclude-one'-strategy and reduces the relative frequency of this strategy.

c. When the representative follows the 'exclude-one'-strategy, the lowendowment respondent has a 40\% higher probability of being excluded when voting is public.

We have observed how punishment frequencies and average earnings differ across treatments and to what extent this is related to the relative frequencies of the different strategies. Our static analysis has shown that profit-maximization does not satisfactorily explain the representative's strategy choice. This is not too surprising, because representatives do not know in advance which strategy 
would maximize their profits, as they can only imperfectly anticipate the decisions of the respondents. Their strategy choice is conditional on their expectations about punishment. Being punished may change these expectations and make representatives change their strategy choice. This justifies a closer look at the dynamics of strategy choice. For this, we first look at the general evolution of the different strategies over time in the different treatments. Thereafter we look at the influence of punishment and expected earnings on individual strategy choice.

Table 3.9. Correlations between round number and the relative frequencies of strategies and punishment

\begin{tabular}{lccccc}
\hline & \multicolumn{5}{c}{ Strategies } \\
Treatments & 1 & 2 & 3 & 4 & punishment \\
\hline \multirow{2}{*}{ Sec.vot./pr.info } & 0.833 & -0.634 & -0.463 & 0.439 & \multirow{2}{*}{$0.514(.128)$} \\
& $(.003)$ & $(.049)$ & $(.178)$ & $(.205)$ & \\
Pub.vot./pr.info & -0.275 & 0.303 & 0.120 & -0.199 & $-0.222(.538)$ \\
& $(.441)$ & $(.396)$ & $(.742)$ & $(.581)$ & \\
Sec.vot./com.info & 0.749 & 0.342 & -0.619 & 0.178 & $-0.044(.903)$ \\
& $(.013)$ & $(.334)$ & $(.056)$ & $(.624)$ & \\
Pub.vot./com.info & 0.818 & 0.199 & -0.824 & 0.386 & $0.161(.657)$ \\
& $(.004)$ & $(.582)$ & $(.003)$ & $(.270)$ & \\
\hline
\end{tabular}

Notes. Strategies: 1 = 'exclude-all'-strategy; 2 = 'exclude-one'-strategy; 3 = 'no-exclusion-highshare'-strategy; 4 = 'no-exclusion-low-share'-strategy. All groups pooled. Two-sided P-values between parentheses.

Table 3.9 shows for each treatment the Spearman correlation coefficient between the round number and the relative frequency of the different strategies and the relative frequency of punishment (taking together all groups within a treatment). We observe that the frequency of the 'exclude-all'-strategy tends to increase with time in all but the public voting/private information treatment.

In the secret voting/private information treatment this increase is combined with a decrease of the 'exclude-one'-strategy over time as shown by the statistically significant Spearman correlation. When information on the distribution is common, this increase is combined with a statistically significant decrease in the 'no-exclusion-high-share'-strategy. We also observe that the 'no-exclusion-lowshare'-strategy remains constant with time.

In the treatments where the frequency of the 'exclude-all'-strategy increases with time punishment rates are considerable (see Table 3.8 above). One would expect that the increasing frequencies of the 'exclude-all'-strategy results in 
increasing punishment frequencies. However, as confirmed by the insignificant Spearman correlation coefficients in the last column of Table 3.9, punishment rates remain constant with time and thus have been high from the start. This suggests that the causality goes in the other direction, i.e. being unsuccessful in avoiding punishment induces representatives to switch to the 'exclude-all'strategy. For representatives who face serious difficulties with avoiding punishment, it may be a profit-maximizing strategy to exclude all respondents. Keeping less than 200 'francs' and being punished (which deducts 200 'francs' from their earnings) leads to a lower pay-off than keeping everything to themselves and being punished.

To find stronger evidence for this hypothesis, we estimate a probit regression on the probability that a representative changes his/her strategy into the 'exclude-all'-strategy, controlling for being punished in the previous round and only considering the rounds where the strategy in the previous round was not the 'exclude-all'-strategy. According to the estimated coefficient of the control variable, representatives who did not follow the 'exclude-all'-strategy in the previous round have a $32.97 \%$ higher likelihood of changing their strategy into the 'exclude-all'-strategy if they were punished in the previous round (two-sided $\mathrm{P}=.000 ; \mathrm{N}=222$; applying robust standard to correct for intra-group correlations).

When representatives change their strategy into the 'exclude-all'-strategy, an interesting question becomes whether they insist on this strategy thereafter. Considering only the cases where in the previous round the representative followed the 'exclude-all'-strategy and was punished, in 17 out of the 38 cases the representative did not insist on this strategy. As for the representative punishment costs are equal to the resources he/she has to distribute each round, keeping a non-zero share and avoiding punishment is always preferred over following the 'exclude-all'-strategy and being punished. Such a strategy change will of course only be realized if the representative expects that with the new strategy he/she will be able to avoid punishment. If not, keeping all resources remains preferable.

To better understand the importance of a representative's expectations about the respondents' voting decisions for his/her strategy choice, we calculate the expected earnings and compare them across strategies. Recall that we asked the representative for the likelihood that a specific respondent votes in favour of punishment and this for each of the respondents. With this information we calculated the probability that two or more respondents vote in favour of punishment. We multiplied this probability with the punishment cost and 
deducted this from the share the representative keeps. In this way we obtained the expected earnings.

Figure 3.3 shows the distribution of the expected earnings by strategy. We observe that when the representative chooses the 'exclude-all'-strategy, in more than $80 \%$ of the cases he/she expects that he/she will be punished, which implies that his/her expected earnings are equal to zero. This percentage is very similar to the observed punishment frequencies with this strategy (see Table 3.8 above), which indicates that representatives have very realistic expectations. In all strategies except the 'no-exclusion-low-share'-strategy, are expected earnings significantly larger than zero.

Figure 3.3. Expected earnings of the representative by strategy (rounds 1-10)

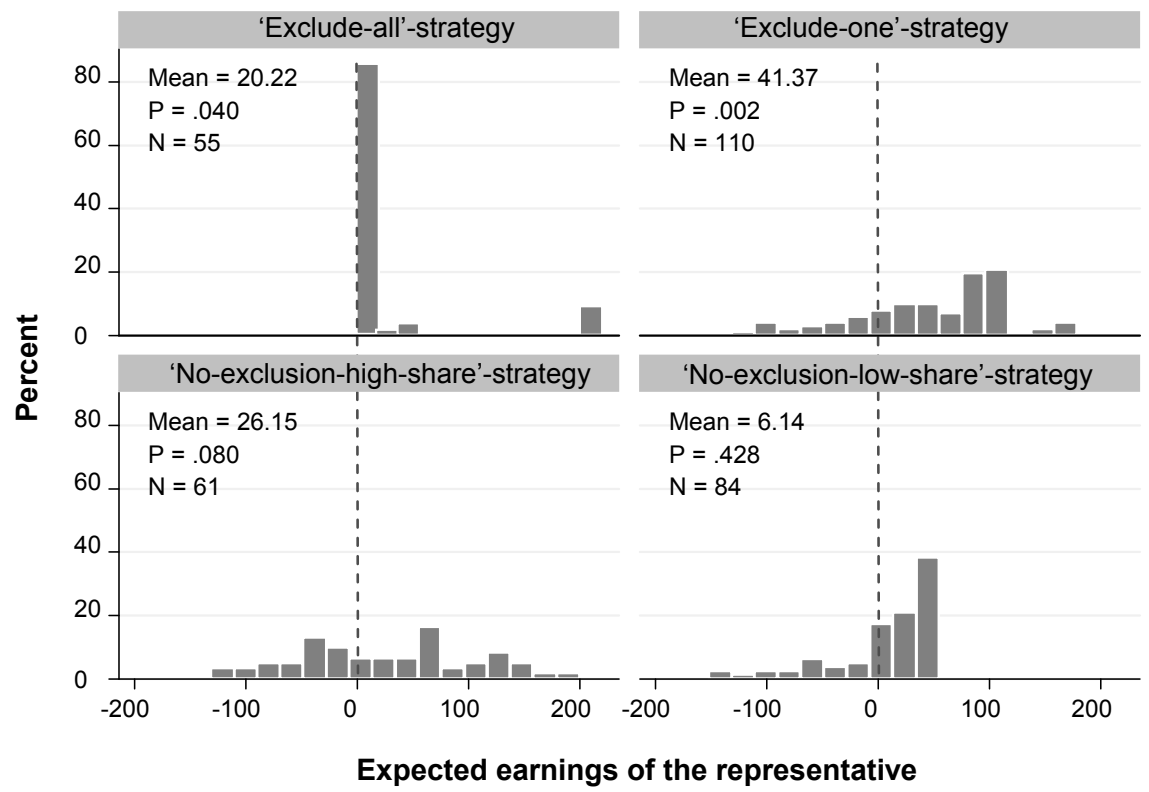

Notes. All rounds and treatments pooled. Two-sided P-values were calculated by estimating an OLS regression with only a constant term and applying robust standard errors to correct for intragroup correlations

To find further evidence on the importance of the expected earnings for representatives' strategy choice, we look at the difference between their expected earnings in the current round and their earnings in the previous round. Figure 3.4 shows the distribution of this difference and distinguishes between strategy choices that are different from those in the previous round and strategy choices 
that are the same as in the previous round. We observe that when representatives do not change their strategy they expect to obtain similar earnings as in the previous round. When they change their strategy they expect to receive significantly higher earnings than they obtained with the strategy in the previous round. This confirms that representatives follow a profit-maximizing logic taking account of their expectations on the respondents' voting decisions.

Figure 3.4. Expected earnings round $t$ - earnings round t-1 (rounds 1-10)

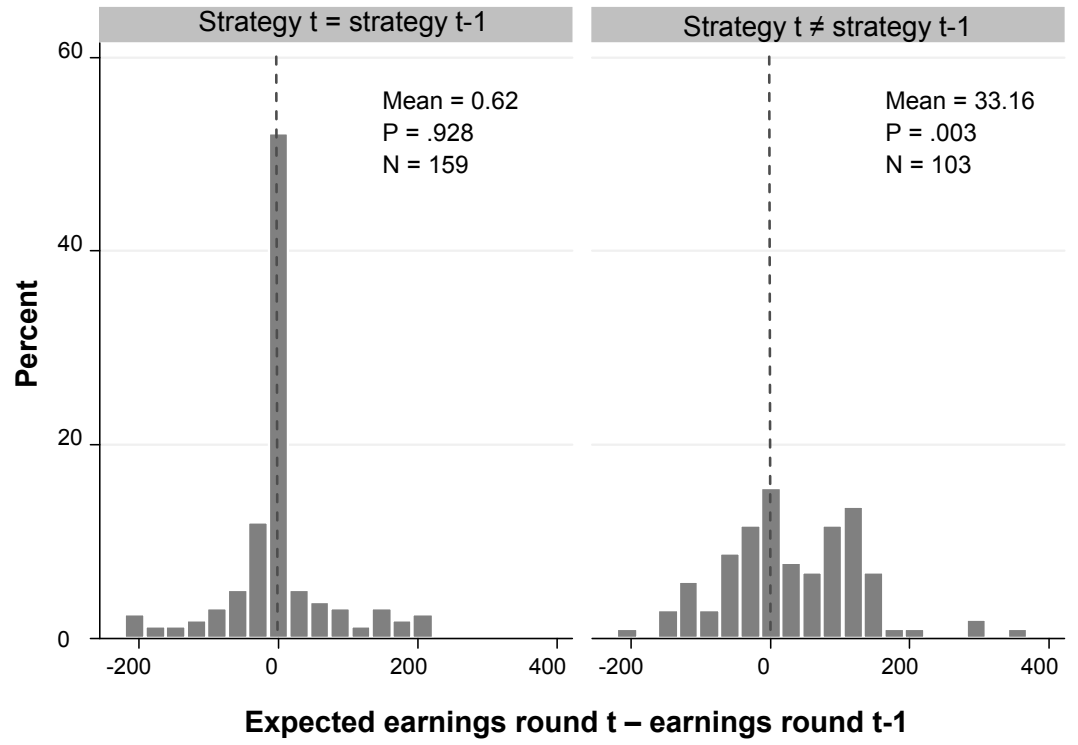

Notes. All rounds and treatments pooled. Two-sided P-values were calculated by estimating an OLS regression with only a constant term and applying robust standard errors to correct for intragroup correlations

A final note is required on the stability of strategy choice in the public voting/private information treatment, as confirmed by the insignificant Spearman correlations in Table 3.9. As shown by Table 3.8, in this treatment punishment rates are relatively low, so that the representative faces little incentives to revise his/her strategy. Receiving information on the respondents' votes enables representatives to infer about the respondents' acceptance thresholds, which helps them to avoid punishment. It also enables them to successfully apply the 'exclude-one'-strategy, which represents more than half of the strategy choices in this treatment. At the same time, respondents anticipating such behaviour of the representative are more reluctant to vote in favour of punishment, which is 
even more the case when information on the distributed resources is private, as confirmed by our regression results in the previous section. We now summarize our results on the dynamics of strategy choice in a fourth result.

\section{Result 4 Strategy choice and punishment (dynamic view)}

Being punished induces representatives to switch to the 'exclude-all'-strategy. Many representatives, however, do not persist in this strategy but switch to another strategy which they expect to be more profitable. In the public voting/private information treatment however, punishment frequency is limited and there is not any trend in strategy choice. Many representatives follow the 'exclude-one'-strategy in this treatment, which results successful in avoiding punishment and thus leads to high earnings.

\subsection{Political change}

We now look at the experimental results after implementing a political change, i.e. after giving the role of permanent representative to another group member. Given the observation that the endowment differences of the respondents do not drive high-endowment representatives to give higher shares to low-endowment players in comparison with middle-endowment players - when voting is public they may even be the target of exclusion -, we look at a political change where the low-endowment player becomes the representative. For this, we organized 10 additional rounds with the same distribution game.

Figures $3.5 \mathrm{a}$ and $3.5 \mathrm{~b}$ show the distribution of the final earnings (inclusive endowments and after deduction of punishment costs) of each player over all groups by treatment. They also show the distribution of the endowments. Comparing the distribution of the final earnings with the distribution of the endowment allows us to detect whether the distribution of the additional resources makes the final distribution more equal. Whereas the results are mixed when the high-endowment player is the representative, with the low-endowment player as representative in all treatments we observe that the final distributions are more equal than the distribution of the endowments. 
Figure 3.5. Distribution of the final earnings by treatment
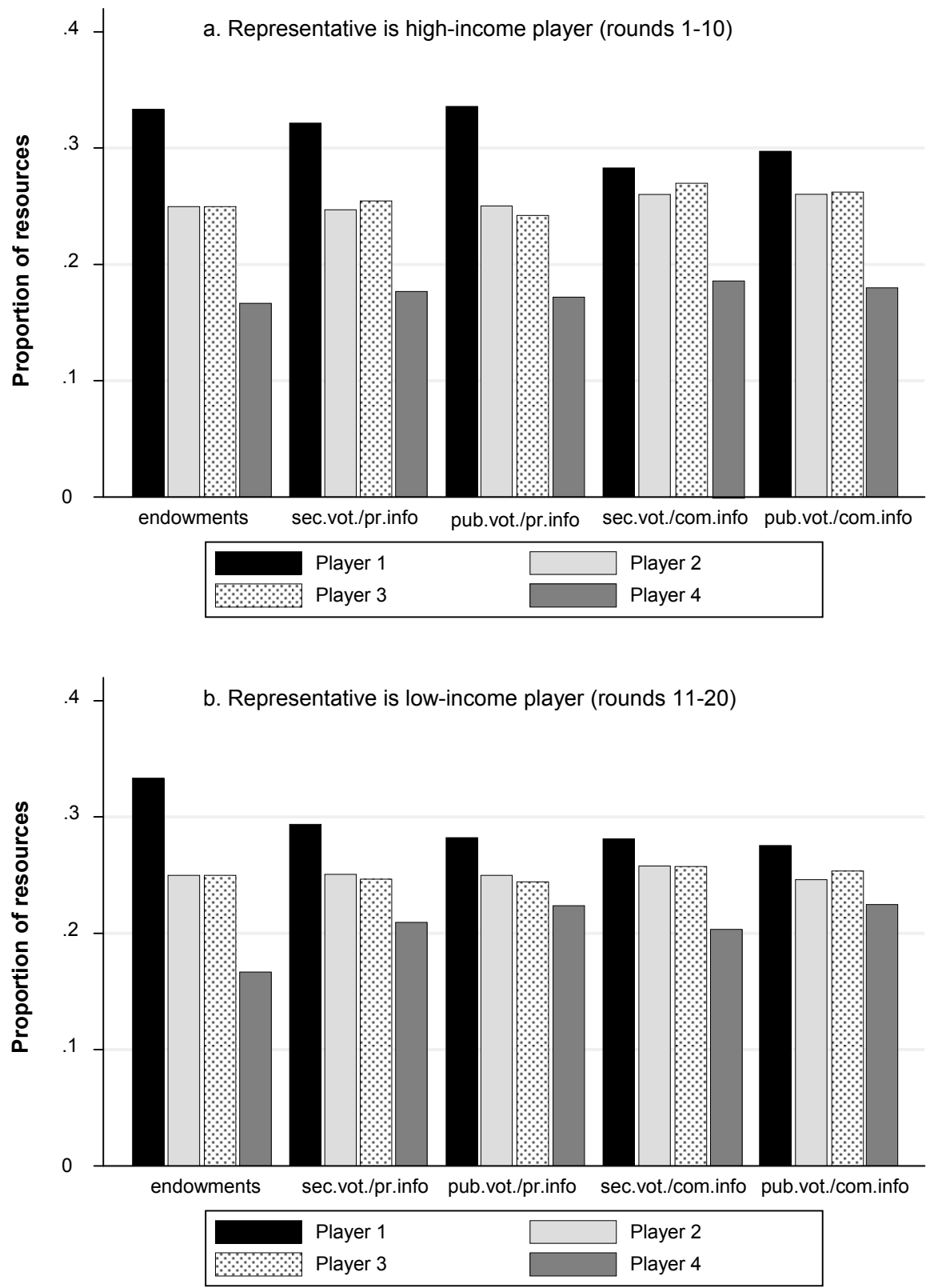

Note. All rounds and groups pooled 
To test whether the distributions of the final earnings in the second part are more equal than in the first part, we used the following procedure. After calculating the average final earnings of each player over all rounds, we calculate the standard deviation of these earnings within each group. We then test whether these standard deviations are significantly different between the first and the second part of the experiment by treatment. According to a Wilcoxon signed ranks test standard deviations are significantly different in the public voting/private information treatment $(Z=-2.380$; two-sided $\mathrm{P}=.017)$ and the public voting/common information treatment $(Z=-2.380$; two-sided $P=.017)$, but not in the secret voting/private information treatment $(Z=-1.540$; two-sided $\mathrm{P}=.123)$ or the secret voting/common information treatment $(\mathrm{Z}=-0.845$; twosided $\mathrm{P}=.398$ ).

In most of the cases the low-endowment representative keeps a very high share of the resources to be distributed. In $99.68 \%$ of the decisions the representative keeps equal or more than 50 'francs', in $73.87 \%$ even more or equal than 100 'francs'. This also entails that the 'exclude-one'-strategy is much more common. Percentages for the private information treatments are $82.5 \%$ and $72.5 \%$, when voting is secret and public respectively. For the common information treatments these percentages are somewhat lower: $50.0 \%$ and $58.8 \%$ when voting is secret and public respectively.

Moreover, when this strategy is followed, in many cases it is the highendowment player who is excluded. Percentages for the private information treatments are $47.5 \%$ and $52.5 \%$ when voting is secret and public respectively. For the common information treatments these percentages are $50.0 \%$ and $51.25 \%$ when voting is secret and public respectively. A large proportion of these exclusion-decisions (30.0\% over all treatments) are the result of a 0-50-50100 proposal, which is of course also a focal point as it results in an equal distribution of the final pay-offs. Other strategies are less common. In $9.68 \%$ of the decisions exactly one of the middle-endowment players is excluded. In $6.77 \%$ of the decisions the representative keeps everything and thus all respondents are excluded.

Punishment rates are substantially lower with the low-endowment player as representative $e^{20}$. In only between $20 \%$ and $27 \%$ of the distribution decisions is the low-endowment representative punished, with little differences between the treatments. To test whether this decrease is statistically significant, we take the punishment frequency of each group over all rounds before and after the

\footnotetext{
${ }^{20}$ For regression results on the satisfaction level and the voting decisions of the respondents in this part of the experiment we refer to appendix 3.
} 
political change. Pooling all treatments we apply a Wilcoxon signed ranks test, which indicates that the decrease in punishment rates is highly significant $(\mathrm{Z}=$ -3.038; two-sided $\mathrm{P}=.002$ ). We attribute this to the fact that, in contrast with the high-endowment player as representative, profit-maximization of the representative and fairness considerations go in the same direction, i.e. towards a more equal distribution.

Thus, political change in favour of the poorest player is not only beneficial in distributional terms. It also increases efficiency, measured as the sum of all incomes after punishment over the sum of all incomes before punishment. As punishment costs are constant irrespective of the distribution, there is a direct inverse relation between punishment rates and efficiency. Consequently, as punishment rates are considerably lower when the low-endowment player becomes the permanent representative, efficiency is considerably higher.

\section{Result 5 Political change}

Once the low-endowment player is the permanent representative, the distribution of the final earnings becomes more equal. In most of the cases the representative keeps equal or more than half of the pie. The 'exclude-one'-strategy becomes more common and when it is followed in most of the cases it is the high-endowment player who is excluded. Moreover, punishment rates become substantially lower and thus efficiency higher.

\section{Conclusion}

In this chapter, we studied the political dimensions at play when external economic resources are channelled to a small group of economically-unequal agents through a permanent group representative. For this, we made use of a laboratory experiment where, in subsequent rounds, a permanent representative was asked to distribute a fixed quantity of resources among a group of four agents. After each distribution decision, the other members had the ability to punish the representative through simple majority voting. We organized four different treatments by combining conditions of public and private information on the distribution and voting decisions.

The experimental results showed that the lower the share of resources a respondent receives from the representative, the lower his/her satisfaction about this share. When receiving information on the complete distribution, his/her satisfaction about this share also decreases the more a representative keeps for $\mathrm{him} /$ herself, and, the less the respondent receives in comparison with the other 
respondents. As expected, lower satisfaction increases the propensity to vote in favor of punishing the representative. In addition, there are important strategic elements behind voting decisions. When voting decisions are made public, respondents are somewhat more reluctant to vote in favour of punishment, but this reluctance is lower with lower satisfaction. Moreover, the more a respondent believes that the other respondents will vote in favour of punishment, the more he/she is inclined to do as well. Furthermore, it is observed that female or middle-endowment respondents are more reluctant to vote in favour of punishment unless information on the distribution is public. This results in higher punishment rates with common information on the distribution decisions.

Regarding the distribution decisions of the representative, punishment induces representatives to switch to a strategy of keeping all resources to themselves. Only with public voting and private information on the distribution are representatives able to keep punishment rates down. They do so by applying an exclusion strategy, wherein one respondent is completely excluded from the distributed resources. When voting is public, low-endowment respondents have a significantly larger probability of being excluded in this way in comparison with middle-endowment respondents. This is the result of their higher propensity to vote in favour of punishment.

Political change, in the direction of making the low-endowment player the permanent representative, is beneficial in distributional terms, as the distribution of the final earnings becomes more equal. In most cases, the representative keeps equal or more than half of the pie. The 'exclude one'-strategy becomes more common, and, when it is followed, in most of the cases it is the highendowment player who is excluded. Political change is also beneficial in efficiency terms, as punishment rates become substantially lower.

\section{Appendix 1: Experimental procedures and instructions}

\section{Experimental procedures}

Several measures were taken to guarantee anonymity. To exclude the possibility that participants could make inferences about the group to which they belonged each session was organized with at least two groups. Moreover, participants were seated randomly in the computer lab with isolated cubicles. It was explained that computer numbers were used to recognize participants during the experiment and the data analysis afterwards, but could not be linked to the 
participants' names. In addition, during the experiment no communication was allowed, mobile phones were switched off and no participants could leave the lab. If participants had a question they were asked to raise their hand so that one of the experimenters could come and answer the question in private.

After reading the instructions, the participants had to go through some control questions. The experiment did not start before all participants had correctly answered these questions. At the end of the experiment, participants were asked to fill in a short questionnaire. After all had completed this questionnaire, they were paid out confidentially in cash.

\section{Instructions}

In this experiment, you can earn money. The experiment consists of three unrelated parts. That is, your earnings in one part are independent from your earnings in other parts. In each part you can earn 'francs'. The 'francs' you earn will be converted to Euro according to the conversion rate $\mathbf{2 0 0}$ ' francs' $^{=1} \mathbf{1}$ Euro and paid out to you privately and confidentially after the experiment.

During the whole experiment, you are not allowed to communicate with the other participants in any other way than described in these instructions.

\section{Instructions for part 1}

In part 1 of the experiment, all participants have an endowment of 400 'francs'. In this part you have the opportunity to give all, part or none of your endowment (400 'francs') to one randomly chosen other participant, or to destroy - at costs for yourself - all, part or none of the endowment ( 400 'francs') of this other participant.

You will not get to know the identity of this other participant, nor will this other participant get to know your identity.

At the same time, another participant will have to make a similar decision on an allocation between him/her and you. This other participant, however, will not be the one you are making your decision about. 


\section{Instructions for part 2}

The second part of the experiment consists of 10 rounds.

Before the start:

You will be randomly assigned to a group of 4 participants. Group compositions do not change throughout the 10 rounds. The composition of your group is anonymous.

Each group member receives randomly one of the letters A, B, C or D as 'ID'. Each letter corresponds to the same person during all 10 rounds.

\section{During the experiment :}

At the beginning of each round, you and all other members in your group receive a fixed amount of 'francs'. This is called your 'endowment'. This endowment is not the same for everyone but depends on the letter ID. In each round, member A receives 200 'francs', members B and C receive 150 'francs' each, and member D receives 100 'francs'.

In each round, participant A will also receive 200 additional 'francs' at his/her free disposal. Of these additional 'francs' member A can keep as much as he/she wants for him/herself and give as much as he/she wants to each of the other three participants in the group. We call member A a 'type I' participant, whereas we call the other participants 'type II' participants.

After A has made his/her decision about the distribution of the additional 200 'francs', each type II participant (members B, C, and D) will get to know his/her own received amount but not what the others received or what $\mathrm{A} \mathrm{kept}^{21}$.

Thereafter, the type II participants (members B, C and D) are asked to vote whether or not to deduct 'francs' from A's income. In case a strict majority (that is, at least two out of the three) votes in favour of deduction, 200 'francs' are deducted from A's earnings. In this case, all type II members (also those who did not vote in favour of deduction!) have to bear costs of 20 'francs' each.

\footnotetext{
${ }^{21}$ With common information treatments this phrase was replaced by: "After A has made his/her decision, each member $\mathrm{B}, \mathrm{C}$, and $\mathrm{D}$ will get to know his/her own received amount, how much $\mathrm{A}$ kept, and the amounts received by the other two members."
} 
Voting is secret. This means that nobody will get to know anyone's voting decision $^{22}$.

Before taking any decision in a specific round, you can review all information you received in all past rounds.

After taking their respective decision, type I and type II participants are asked to give likelihood estimates about the voting decisions of the other participants. The amount they earn with these estimates depends on the reported likelihood estimates and the actual voting decisions of the other members. For your interest, we show here the mathematical formula used to calculate these additional earnings for a type II participant (The earnings calculated for a type I participant are calculated in a similar way).

The reported percentages $P_{j}(\mathrm{j}=0,1,2)$ where $P_{j}$ is the percentage that $\mathrm{j}$ number of type II members vote in favour of deducting 'francs' from A's income. Calculate $p_{j}=P_{j} / 100$ for all $\mathrm{j}=0,1,2$. If $\mathrm{j}$ type II members vote in favour of deducting 'francs' from A's income (with $\mathrm{j}=0,1,2$ ), then the additional earnings are equal to: $3+6 p_{j}-3\left(\left(p_{0}\right)^{2}+\left(p_{1}\right)^{2}+\left(p_{2}\right)^{2}\right)$

Once again, it is not important that you exactly understand this formula. It is sufficient that you realize that your expected earnings are maximized if you indicate your true estimation of the likelihood.

\section{Instructions for part 3}

You now continue during an additional 10 rounds. Groups remain the same, so you remain with the same participants in your group.

A round in this part is precisely the same as before except that now member D has become the type I participant and member A has become a type II participant. This means that now it is member D who receives 200 additional 'francs' to his/her free disposal in each round. In addition, in each round participants A,

\footnotetext{
${ }^{22}$ With public voting treatments this phrase was replaced by: "Voting is public. This means that everybody will get to know everyone's voting decision."
} 
B and C will be given the opportunity to vote in favour of deducting 'francs' from the income of participant $\mathrm{D}$.

\section{Appendix 2: an outcome-based fairness model}

In this appendix we calculate important equilibria of our model using a FehrSchmidt utility function (Fehr \& Schmidt, 1999). This utility function allows for self-centred fairness and has been shown to lead to more realistic predictions in diverse settings. Preferences are represented by a utility function for player i (= $1, \ldots, \mathrm{n})$ of the following form:

$$
U_{i}(y)=y_{i}-\alpha_{i} \frac{1}{n-1} \sum_{j} \max \left\{y_{j}-y_{i}, 0\right\}-\beta_{i} \frac{1}{n-1} \sum_{j} \max \left\{y_{i}-y_{j}, 0\right\}
$$

with $\alpha_{i}, \beta_{i}$ being respectively the envy and guilt parameters of player i, which determine the utility loss due to disadvantageous and advantageous inequality aversion respectively. It is assumed that $\beta_{i} \leq \alpha_{i}$ and $0 \leq \beta_{i}<1$. Applying this utility function to our experimental game we obtain the following results.

\section{Proposition 1}

Assuming that envy and guilt parameters are the same for all respondents ${ }^{23}$, strategy combinations with exactly one respondent voting in favour of punishment (which lead to non-punishment), which were an equilibrium with standard preferences, are not longer an equilibrium with Fehr-Schmidt preferences if:

a. $\alpha \geq 3 \frac{k}{K-k}$;

possible equilibria are $(y, y, n),(y, n, y),(n, y, y)$ and $(y, y, y)$

b. $\alpha \leq 3 \frac{k}{K-k}$, and

i) $y_{B} \leq y_{A}-\lambda ; y_{C} \leq y_{A}-\lambda ; y_{D} \geq y_{A}-\lambda$ :

possible equilibria are $(y, y, n)$ and $(y, y, y)$

ii) $y_{B} \leq y_{A}-\lambda ; \quad y_{C} \geq y_{A}-\lambda ; y_{D} \leq y_{A}-\lambda$ :

possible equilibria are $(y, n, y)$ and $(y, y, y)$

\footnotetext{
${ }^{23}$ This is a not unrealistic assumption as the representative cannot make any inference about these parameters before having interacted with the respondents, and thus does not have any reason to assume that these differ between the respondents
} 
iii) $y_{B} \geq y_{A}-\lambda ; y_{C} \leq y_{A}-\lambda ; y_{D} \leq y_{A}-\lambda$ :

possible equilibria are $(n, y, y)$ and $(y, y, y)$

iv) $y_{B} \leq y_{A}-\lambda ; y_{C} \leq y_{A}-\lambda ; y_{D} \leq y_{A}-\lambda$ :

possible equilibria are $(y, y, n),(y, n, y),(n, y, y),(y, y, y)$

with $\lambda=\frac{3 k+\beta(K-k)}{(\alpha+\beta)}$

\section{Proof}

Strategy combinations with exactly one respondent voting in favour of punishment (which thus lead to non-punishment) are not an equilibrium if at least two respondents are better-off when the representative is punished (and thus the representative is punished).

We assume that $E_{i}$ is the endowment that player $i$ receives before the distribution of the additional resources M. $x_{i}$ is the share of the additional resources $\mathrm{M}$ player $\mathrm{i}$ obtains and $y_{i}=E_{i}+x_{i}$. Suppose that the representative $\mathrm{A}$ proposes the distribution $\left(x_{A}, x_{B}, x_{C}, x_{D}\right)$, with $x_{A}+x_{B}+x_{C}+x_{D}=M$, and $0 \leq x_{i} \leq M,(i=A, B, C, D)$. We now look at the conditions that make a respondent's utility higher with punishment than without punishment.

The utility of respondent B without punishment would then $\mathrm{be}^{24}$ :

$$
\begin{aligned}
U_{B}^{P 0}= & y_{B}-\alpha \frac{1}{3}\left[\max \left\{y_{A}-y_{B}, 0\right\}+\max \left\{y_{C}-y_{B}, 0\right\}+\max \left\{y_{D}-y_{B}, 0\right\}\right] \\
& -\beta \frac{1}{3}\left[\max \left\{y_{B}-y_{A}, 0\right\}+\max \left\{y_{B}-y_{C}, 0\right\}+\max \left\{y_{B}-y_{D}, 0\right\}\right]
\end{aligned}
$$

The utility of respondent B with punishment would be:

\footnotetext{
${ }^{24} \mathrm{We}$ elaborate here the more general case, where people include their endowment $E_{A}, E_{B}, E_{C}$ or $E_{D}$ in their utility function. However, it might also be that players only take account of the amount to be distributed and not of the final pay-offs. In such a case the endowment parameters must be removed from all expressions.
} 


$$
\begin{aligned}
U_{B}^{P 1}= & y_{B}-k \\
& -\alpha \frac{1}{3}\left[\max \left\{y_{A}-K-y_{B}+k, 0\right\}+\max \left\{y_{C}-k-y_{B}+k, 0\right\}+\max \left\{y_{D}-k-y_{B}+k, 0\right\}\right] \\
& -\beta \frac{1}{3}\left[\max \left\{y_{B}-k-y_{A}+K, 0\right\}+\max \left\{y_{B}-k-y_{C}+k, 0\right\}+\max \left\{y_{B}-k-y_{D}+k, 0\right\}\right]
\end{aligned}
$$

We have the following possible situations ${ }^{25}$ :

(a) $y_{B} \geq y_{A}$ and $y_{B}-k \geq y_{A}-K$

(b) $y_{B} \geq y_{A}$ and $y_{B}-k \leq y_{A}-K$

(c) $y_{B} \leq y_{A}$ and $y_{B}-k \geq y_{A}-K$

(d) $y_{B} \leq y_{A}$ and $y_{B}-k \leq y_{A}-K$

Case (a) $U_{B}^{P 1} \geq U_{B}^{P 0}$ if $-k-\beta \frac{1}{3}\left(-k+y_{B}+K-y_{A}\right) \geq-\beta \frac{1}{3}\left(y_{B}-y_{A}\right)$

$$
\Leftrightarrow \beta \frac{1}{3}(K-k) \leq-k
$$

this condition is infeasible as $K>k>0$ and $\beta \geq 0$; in this case the utility with punishment will always be lower than the utility without punishment.

Case (b) this is infeasible because $k<K$

$$
\text { Case (c) } \begin{aligned}
& U_{B}^{P 1} \geq U_{B}^{P 0} \text { if }-k-\beta \frac{1}{3}\left(-k+y_{B}+K-y_{A}\right) \geq-\alpha \frac{1}{3}\left(y_{A}-y_{B}\right) \\
& \Leftrightarrow-3 k-\beta\left(-k+y_{B}+K-y_{A}\right) \geq-\alpha\left(y_{A}-y_{B}\right) \\
\Leftrightarrow & 3 k+\beta(-k+K)+\beta\left(y_{B}-y_{A}\right)-\alpha\left(y_{A}-y_{B}\right) \leq 0 \\
\Leftrightarrow & \beta\left(y_{B}-y_{A}\right)+\alpha\left(y_{B}-y_{A}\right) \leq-3 k-\beta(-k+K)
\end{aligned}
$$

\footnotetext{
${ }^{25}$ Note that a respondent's preference for punishment does not depend on the inequality vis-à-vis the other respondents, as punishment costs are the same for all respondents, and consequently punishment does not have any impact on the inequality between respondents. The respondent's utility depends on whether he/she faces advantageous or disadvantageous inequality towards the representative before and after punishment. This implies that the conditions as elaborated for respondent $\mathrm{B}$ equally apply for respondents $\mathrm{C}$ and $\mathrm{D}$, who might have different endowments.
} 


$$
\begin{aligned}
& \Leftrightarrow(\alpha+\beta) \cdot\left(y_{B}-y_{A}\right) \leq-3 k-\beta(-k+K) \\
& \Leftrightarrow y_{B} \leq y_{A}-\lambda \text { with } \lambda=\frac{3 k+\beta(K-k)}{(\alpha+\beta)}
\end{aligned}
$$

As for respondents $\mathrm{C}$ and $\mathrm{D}$ this condition becomes $y_{C} \leq y_{A}-\lambda$ and $y_{D} \leq y_{A}-\lambda$ respectively, we have the following four cases where at least two respondents are better-off when the representative is punished:

i) if $y_{B} \leq y_{A}-\lambda ; y_{C} \leq y_{A}-\lambda ; y_{D} \geq y_{A}-\lambda$ :

$(y, y, n)$ and $(y, y, y)$ become possible equilibria

ii) if $y_{B} \leq y_{A}-\lambda ; y_{C} \geq y_{A}-\lambda ; y_{D} \leq y_{A}-\lambda$ :

$(y, n, y)$ and $(y, y, y)$ become possible equilibria

iii) if $y_{B} \geq y_{A}-\lambda ; y_{C} \leq y_{A}-\lambda ; y_{D} \leq y_{A}-\lambda$ :

$(n, y, y)$ and $(y, y, y)$ become possible equilibria

iv) if $y_{B} \leq y_{A}-\lambda ; y_{C} \leq y_{A}-\lambda ; y_{D} \leq y_{A}-\lambda$ :

$(y, y, n),(y, n, y),(n, y, y),(y, y, y)$ become possible equilibria

Case (d) $U_{B}^{P 1} \geq U_{B}^{P 0}$ if $-k-\alpha \frac{1}{3}\left(-K+y_{A}+k-y_{B}\right) \geq-\alpha \frac{1}{3}\left(y_{A}-y_{B}\right)$

$$
\begin{aligned}
& \Leftrightarrow-k-\alpha \frac{1}{3}(-K+k) \geq 0 \\
& \Leftrightarrow \alpha \geq 3 \frac{k}{K-k}
\end{aligned}
$$

The same condition applies to respondents $\mathrm{C}$ and D. Thus, if $\alpha \geq 3 \frac{k}{K-k}$ all respondents prefer that the representative is punished, so that $(y, y, n),(y, n, y),(n, y, y),(y, y, y)$ become possible equilibria. 


\section{Proposition 2}

If the representative believes that he/she cannot influence the punishment outcome with his/her distribution decision, his/her optimal distribution decision will be:

a) keep all resources if $\beta_{A}<\frac{3}{4}$

b) distribute the resources so that the final income of all players is equalized, if $\beta_{A}>\frac{3}{4}$

\section{Proof}

The utility of the representative without punishment would be:

$$
\begin{aligned}
& U_{A}^{P 0}=y_{A}-\alpha_{A} \frac{1}{3}[\left.\max \left\{y_{B}-y_{A}, 0\right\}+\max \left\{y_{C}-y_{A}, 0\right\}+\max \left\{y_{D}-y_{A}, 0\right\}\right] \\
&-\beta_{A} \frac{1}{3}\left[\max \left\{y_{A}-y_{B}, 0\right\}+\max \left\{y_{A}-y_{C}, 0\right\}+\max \left\{y_{A}-y_{D}, 0\right\}\right]
\end{aligned}
$$

The utility of the representative with punishment would be:

$$
\begin{aligned}
U_{A}^{P 1}= & y_{A}-K \\
& -\alpha_{A} \frac{1}{3}\left[\max \left\{y_{B}-y_{A}-k+K, 0\right\}+\max \left\{y_{C}-y_{A}-k+K, 0\right\}+\max \left\{y_{D}-y_{A}-k+K, 0\right\}\right] \\
& -\beta_{A} \frac{1}{3}\left[\max \left\{y_{A}-y_{B}+k-K, 0\right\}+\max \left\{y_{A}-y_{C}+k-K, 0\right\}+\max \left\{y_{A}-y_{D}+k-K, 0\right\}\right]
\end{aligned}
$$

We will show the case where the representative is punished. The nonpunishment case is similar as marginal utilities of changing the shares of the players are the same without punishment $(\mathrm{K}$ and $\mathrm{k}$ are not dependent on the shares of the players).

Case a) all respondents receive an equal or lower share than the representative after punishment

$$
U_{A}^{P 1}=y_{A}-K-\beta_{A} \frac{1}{3}\left(3 y_{A}+3 k-3 K-y_{B}-y_{C}-y_{D}\right)
$$




$$
\begin{aligned}
& \frac{\partial U_{A}}{\partial y_{A}}=1-\beta_{A}>0 ; \frac{\partial U_{A}}{\partial y_{B}}=\frac{\partial U_{A}}{\partial y_{C}}=\frac{\partial U_{A}}{\partial y_{D}}=\beta_{A} \frac{1}{3}>0 \\
& \frac{\partial U_{A}}{\partial y_{A}}>\frac{\partial U_{A}}{\partial y_{B}} \text { if } \beta_{A}<\frac{3}{4}
\end{aligned}
$$

i) If $\beta_{A}>\frac{3}{4}$ the representative will maximize the income of the respondents.

Therefore,

$$
\begin{aligned}
& y_{A}-K=y_{B}-k=y_{C}-k=y_{D}-k=\frac{1}{4}\left(M+E_{A}+E_{B}+E_{C}+E_{D}-3 k-K\right), \text { and, } \\
& U_{A}^{P 1}=\frac{1}{4}\left(M+E_{A}+E_{B}+E_{C}+E_{D}-3 k-K\right)
\end{aligned}
$$

ii) If $\beta_{A}<\frac{3}{4}$ the representative will maximize his/her income by excluding all respondents from the resources.

Consequently, $U_{A}^{P 1}=M+E_{A}-K-\beta_{A} \frac{1}{3}\left(3 E_{A}+3 M-3 K-E_{B}-E_{C}-E_{D}+3 k\right)$

Case b) two respondents receive an equal or lower share, one respondent an equal or higher share than the representative after punishment

$$
\begin{aligned}
& U_{A}^{P 1}=y_{A}-K-\alpha_{A} \frac{1}{3}\left(y_{B}-y_{A}-k+K\right)-\beta_{A} \frac{1}{3}\left(2 y_{A}-2 K-y_{C}-y_{D}+2 k\right) \\
& \frac{\partial U_{A}}{\partial y_{A}}=1+\frac{1}{3} \alpha_{A}-\frac{2}{3} \beta_{A}>0 ; \frac{\partial U_{A}}{\partial y_{B}}=-\alpha_{A} \frac{1}{3}<0 ; \frac{\partial U_{A}}{\partial y_{C}}=\frac{\partial U_{A}}{\partial y_{D}}=\beta_{A} \frac{1}{3}>0 \\
& \frac{\partial U_{A}}{\partial y_{B}}>\frac{\partial U_{A}}{\partial y_{C}}=\frac{\partial U_{A}}{\partial y_{D}} \text { if } 1+\frac{1}{3} \alpha_{A}>\beta_{A}, \text { which is always the case as } \beta_{A}<1 \text { and } \\
& \alpha_{A} \geq 0
\end{aligned}
$$

Consequently the resources will be distributed such that

$$
\begin{aligned}
& y_{A}-K=y_{B}-k=\frac{1}{2}\left(M+E_{A}-K+E_{B}-k\right), y_{C}=E_{C} ; y_{D}=E_{D} ; \\
& U_{A}^{P 1}=\frac{\left(M+E_{A}-K+E_{B}-k\right)}{2}-\beta_{A} \frac{1}{3}\left(M+E_{A}-K+k+E_{B}-E_{C}-E_{D}\right) .
\end{aligned}
$$

Case c) one respondent receives an equal or lower share, two respondents an equal or higher share than the representative after punishment 
$U_{A}^{P 1}=y_{A}-K-\alpha_{A} \frac{1}{3}\left(-2 y_{A}+y_{B}+y_{C}-2 k+2 K\right)-\beta_{A} \frac{1}{3}\left(y_{A}-y_{D}+k-K\right)$

$\frac{\partial U_{A}}{\partial y_{A}}=1+\frac{2}{3} \alpha_{A}-\frac{1}{3} \beta_{A}>0 ; \frac{\partial U_{A}}{\partial y_{B}}=\frac{\partial U_{A}}{\partial y_{C}}=-\alpha_{A} \frac{1}{3}<0 ; \frac{\partial U_{A}}{\partial y_{D}}=\beta_{A} \frac{1}{3}>0$

$\frac{\partial U_{A}}{\partial y_{B}}>\frac{\partial U_{A}}{\partial y_{D}}$ if $1+\frac{2}{3}\left(\alpha_{A}-\beta_{A}\right)>0$, which is always the case as $\alpha_{A} \geq \beta_{A}$

Consequently the resources will be distributed such that

$$
\begin{aligned}
& y_{A}-K=y_{B}-k=y_{C}-k=\frac{1}{3}\left(M+E_{A}-K+E_{B}+E_{C}-2 k\right) ; y_{D}=E_{D} ; \\
& U_{A}^{P 1}=\frac{\left(M+E_{A}-K+E_{B}+E_{C}-2 k\right)}{3}-\beta_{A} \frac{1}{3}\left[\frac{\left(M+E_{A}-K+E_{B}+E_{C}-2 k\right)}{3}-E_{D}+k\right]
\end{aligned}
$$

Case d) all respondents receive an equal or higher share than the representative after punishment

$$
\begin{aligned}
& U_{A}^{P 1}=y_{A}-K-\alpha_{A} \frac{1}{3}\left(-3 y_{A}-3 k+3 K+y_{B}+y_{C}+y_{D}\right) \\
& \frac{\partial U_{A}}{\partial y_{A}}=1+\alpha_{A}>0 ; \quad \frac{\partial U_{A}}{\partial y_{B}}=\frac{\partial U_{A}}{\partial y_{C}}=\frac{\partial U_{A}}{\partial y_{D}}=-\alpha_{A} \frac{1}{3}<0 ; \text { consequently, the repre- }
\end{aligned}
$$
sentative will keep as much as possible, leading to a share of

$$
\begin{aligned}
& y_{A}-K=y_{B}-k=y_{c}-k=y_{D}-k=\frac{1}{4}\left(M+E_{A}+E_{B}+E_{C}+E_{D}-3 k-K\right), \text { so that, } \\
& U_{A}^{P 1}=\frac{1}{4}\left(M+E_{A}+E_{B}+E_{C}+E_{D}-3 k-K\right)
\end{aligned}
$$

Comparing the utilities between the different cases,

If $\beta_{A}<\frac{3}{4}: \mathrm{U}($ case a-ii $)>\mathrm{U}($ case $\mathrm{b})>\mathrm{U}($ case $\mathrm{c})>\mathrm{U}($ case $\mathrm{d})$. Thus, keeping all resources maximizes the representative's utility

If $\beta_{A}>\frac{3}{4}: \mathrm{U}($ case $\mathrm{a}-\mathrm{i})=\mathrm{U}($ case $\mathrm{d})>\mathrm{U}($ case $\mathrm{c})>\mathrm{U}($ case $\mathrm{b})$. Thus, distributing resources so that each player has the same final income maximizes the representative's utility. 


\section{Appendix 3: When the low-income player becomes the representative}

Table 3.9. Satisfaction with own share (common information)

\begin{tabular}{lrlrl}
\hline & \multicolumn{2}{c}{ Model 1. } & \multicolumn{2}{c}{ Model 2. } \\
& $\begin{array}{c}\text { Middle-endowment } \\
\text { respondents (players 2-3) }\end{array}$ & $\begin{array}{c}\text { High-endowment } \\
\text { respondent (player 1) }\end{array}$ \\
& Coef. & S.E. & Coef. & S.E. \\
\hline Own share & 0.027 & 0.026 & 0.080 & $0.041^{*}$ \\
Max \{own share - share high-endow, 0\} & 0.042 & $0.023^{*}$ & - & - \\
Max \{share high-endow - own share, 0$\}$ & -0.004 & 0.016 & - & - \\
Max \{own share - share middle-endow, 0$\}$ & 0.013 & 0.027 & -0.051 & 0.064 \\
Max \{share middle-endow - own share, 0$\}$ & -0.049 & $0.011^{* * *}$ & -0.032 & 0.022 \\
Max \{own share - share low-endow, 0\} & -0.061 & 0.037 & 0.052 & 0.043 \\
Max \{share low-endow - own share, 0$\}$ & -0.018 & $0.006^{* * *}$ & -0.001 & 0.012 \\
Sex (1 = male; 0 = female) & 0.257 & 0.508 & 0.501 & 1.075 \\
Public voting & 0.889 & 0.566 & -0.644 & 1.131 \\
Round & -0.039 & 0.052 & -0.016 & 0.092 \\
\hline N & 300 & & 150 & \\
Prob > F & 0.0000 & & - & \\
F & 12409.82 & & - & \\
\hline
\end{tabular}

${ }^{a}$ In the first model the respondent compares with the other middle-endowment player, whereas in the second model we let the high-endowment respondent compare with the average of both middleendowment players.

Notes. OLS regression with robust standard errors to correct for intra-group correlations. As all shares sum up to a constant, we estimate a model without constant to avoid complete collinearity. $\mathrm{R}$-squared is not included as it is overestimated in models without a constant term. Significance levels (two-sided): $*=10 \%, * *=5 \%, * * *=1 \%$. 
Table 3.10. Voting decision-making (probit)

\begin{tabular}{|c|c|c|}
\hline & $\begin{array}{c}\text { Marg. } \\
\text { prob. }\end{array}$ & S.E. \\
\hline Public voting $(1=$ public; $0=$ secret $)$ & -0.071 & 0.138 \\
\hline Satisfaction with own share & -0.091 & $0.015^{* * *}$ \\
\hline Expectation 1 other vote & -0.079 & 0.172 \\
\hline Expectation 2 other votes & 0.326 & $0.164^{* *}$ \\
\hline Satisfaction $\mathrm{x}$ public voting & -0.020 & 0.022 \\
\hline Public voting $\mathrm{x}$ expectation 1 other vote & 0.111 & 0.208 \\
\hline Public voting $\mathrm{x}$ expectation 2 other votes & -0.509 & $0.218^{* *}$ \\
\hline Female and private information (dummy) & -0.037 & 0.089 \\
\hline Middle income and private information (dummy) & -0.023 & 0.073 \\
\hline Round & -0.005 & 0.008 \\
\hline $\mathrm{N}$ & 930 & \\
\hline Pseudo R-squared & 0.3725 & \\
\hline Wald chi2(12) & 238.98 & \\
\hline Prob $>$ chi 2 & 0.0000 & \\
\hline
\end{tabular}

Note. Probit regression with robust standard errors to correct for intra-group correlations. Significance levels (two-sided): $*=10 \%, * *=5 \%, * * *=1 \%$. 



\section{Social Networks and Exclusion:}

\section{A Field Experiment on Distributive Decision Making in a Poor Rural Community}

\section{Introduction ${ }^{26}$}

More than seventy per cent of the world's poor live in rural areas (World Bank, 2003). They live with less than one dollar a day and their situation has barely changed over the past decades. Whereas the rest of the world has benefited from increasing trade and specialization at the global level, rural areas face severe limitations to economic development, such as their unfavourable access to public services, infrastructure and markets, and the pro-urban bias of most public policies.

Facing these limitations, people living in poor rural communities rely highly on social networks within their livelihood strategies (Dercon \& de Weerdt, 2002; Krishnan \& Sciubba, 2004; Fafchamps \& Gubert, 2007). In poor areas these networks are mainly local. According to Woolcock (1998), it is only with increased development through specialization and more complex economic exchange that linkages with people outside the community become increasingly

${ }^{26}$ I thank Guy Delmelle, Ligia Gómez, Miguel Alemán, Francisco Pérez, Selmira Flores and Alfredo Ruíz for interesting methodological discussions; Tania Paz Mena, Leonardo Matute, Francisco Paiz Salgado, Edna García Flores, Fátima Guevara, Silvia Martinez Arróliga and Will Tellez for support in the field work; Vanessa Castrillo and Jazmina Andino for their help in the search for sufficient coins of money; Elizabeth Campos and Manuel Bermudez for offering a safe in one of their local banking offices; the local support of community leader Francisco Varela; colleagues at MU and IOB-UA for comments on the experimental design; participants of the sixth workshop on 'Dynamic Networks' at Utrecht School of Economics, ESA 2007 (Rome), ECINEQ 2007 (Berlin), a seminar at CIDIN (Radboud University) and the Young Talent Day of the Maastricht Graduate School of Governance for comments on earlier versions of this chapter. I also benefited from comments of Rebecca Blank and Michael Woolcock. 
important, whereas intra-community social links are relatively more important with lower levels of economic development. This, however, does not imply that all members in poor communities are intensely connected with each other resulting in high levels of cooperation, as is sometimes believed by policy makers (Cleaver, 1999; Kothari, 2001; Mosse, 2001; Platteau \& Abraham, 2002). Heterogeneity in economic and social capital tends to be considerable.

Given the limited availability of economic opportunities and the pervasive inequality in rural areas, a justified policy direction is to look at the most excluded groups and to look for the reasons behind their exclusion. As intense use is made of local social networks in rural communities, it is warranted to study how these networks influence access to (and thus exclusion from) these limited economic opportunities. In particular, what network characteristics are important in this respect? Are agents with a central position in networks favoured as they have more power (Burt, 1992; 2005)? Or, is the density of social networks important as - according to Coleman (1990) - it favours a respect for social norms? Finally, to know who tends to be most affected by the effects of social networks, we should turn to the determinants behind social network formation. Are certain people more likely to have less favourable network positions, and therefore face more limited opportunities to improve their living conditions?

When looking for answers to these questions, we should not overlook an important and necessary additional question: "what networks?" Rural societies are characterized by pluriform networks. People are not only connected through friendship relations, they may also be connected because they support each other economically or engage in economic transactions. Others may be connected through kinship or because they go to the same church, or they meet each other at the village school when picking up their children, etc. Consequently, to assess the importance of social networks for the distribution of limited economic opportunities, and, indirectly, what groups are put at a disadvantage by these social networks, it will matter what networks we look at.

To address these research questions, we organized a series of dictator game experiments in a rural Nicaraguan village. In particular, we asked village participants ('dictators') to distribute a fixed sum of money to a particular village 'recipient'. We supplemented experimental data with information on the complete village network, and with those individual characteristics that we expect to influence dictator giving, directly or indirectly through their influence on social network formation.

Our results clearly confirm that it matters what networks we look at. Lower social distance between dictator and recipient on general networks (i.e. irrespec- 
tive of its type), friendship networks and extended family networks favour dictator generosity. Network positions and structures are also important for dictator giving. In particular, generosity increases the more the dictator's friends have relatively few other friends. It also increases with denser support networks of the dictator. Moreover, generosity increases the smaller the family networks of the dictator or the recipient (if both have a direct family relation), or the smaller the recipient's network through social public activities. Finally, our results indicate that economic relations do not exert any influence on generosity.

Taking account of the demonstrated importance of social distance for dictator giving and the determinants behind link formation, we conclude that the poor, the less mobile, women and young people are most vulnerable to exclusion because they tend to be socially more distant from other people in their village, and thus the persons who distribute economic resources. The same applies for people who are very distant neighbours of those who distribute economic resources. As we do not find any evidence of dictators taking account of the individual characteristics of the disadvantaged that might weaken these social network effects, these people might face a real poverty trap.

\section{Literature}

Studying the influence of social networks on distributive decision making complements the growing literature that looks at the social roots of generosity. An interesting starting point in this literature is Bohnet \& Frey (1999) who showed that dictator offers increase when participants present themselves before the experiment. A similar result is obtained when the family name of the participants is told before the dictator game (Charness \& Gneezy, forthcoming). Recent work has extended this focus in the direction of self-reported social distance. An important study by Leider et al. (2007) demonstrated that dictators give $50 \%$ more to friends than to strangers. Goeree et al. (2006) organized a dictator game experiment with teenage girls, complemented with social network data captured through a survey. They show that giving decreases with larger social distances in teenage girl networks. Brañas-Garza et al. (2006) showed how the individual centrality in networks under the form of 'betweenness centrality ${ }^{27}$ increases dictator giving.

\footnotetext{
${ }^{27}$ The 'betweenness centrality' of an individual is equal to the proportion of all shortest paths connecting any pair of subjects in the network that pass through that particular individual.
} 
Our dictator game experiment differs from this literature in several ways. First, we conducted our experiment in the field, where heterogeneity of human agents tends to be much larger than in student populations and on multiple dimensions (e.g. sex, age, education, economic variables, etc.). Second, in real life people may be connected with each other by means of multiple networks. This is especially characteristic for small-scale societies (such as the rural village of our study) where everybody knows each other and where social linking with the outside is limited. An important implication of this pluriformity of social networks is that when explaining giving behaviour it might matter what networks we look at. Third, we conducted our experiment in a rural society that differs substantially from Western student populations in socio-economic and cultural terms. As demonstrated by Henrich et al. (2004), who conducted field experiments in different socio-economic and cultural settings, this might be an important element to consider when studying distributive decision making.

\section{Research design}

In this section, we briefly describe the main features of our research design. For the questionnaires, the experimental instructions or procedural details, we refer to appendices 2 to 6 .

\subsection{Household and social network survey}

Before the experiment we carried out a household survey to capture general socio-economic data and a network survey at the level of individual household heads. With the household survey we gathered data on income, economic assets, economic activities, family composition, education, age, etc. (see appendix 5 for the questionnaire). To gather data on individual networks, we used small cards, each card representing a household in the village. On each card we put the names of the household heads. We asked for each of these cards whether the interviewed person knew the household and whether he/she had a social relation of any kind with one of its members. If a social relation was identified we asked for details on the type of social relation. This method enabled us to capture individual networks on multiple dimensions, such as friendship, family, neighbours, etc. (see appendix 6 for questionnaire). 


\subsection{Dictator game experiment ${ }^{28}$}

Each participant was explained that he/she would be sequentially given six small cylinder-boxes with 20 coins of 1 Córdoba (the Nicaraguan currency) each and be free to divide the coins of each box with one other person. The first recipient was always an unknown person from another village in the region. The five other recipients were randomly selected village members. The random selection involved the dictator drawing cards out of a bag containing all 123 household heads. The dictator got to know the names of the recipient sequentially, i.e. the name of the next recipient was drawn after having finished the previous distribution decision. Thus, before their first decision, dictators knew that their maximum possible earnings were $120 \mathrm{c} \$$ (6.7 US\$, i.e. more than two days average income). We tried to conduct the experiment with as many households as possible, but with only one household head per household. In case of a twoheaded household it was randomly determined who was asked to participate.

In contrast with most experiments conducted in small-scale societies where participants gather on one public spot (Henrich et al., 2004; Cardenas et al., 2000), we organized our field experiment in a decentralized way. For the experiment, we employed five Nicaraguan assistants. Each visited a randomly selected participant at his/her home. This has several advantages. First, it allows us to avoid self-selection. Some people are more inclined to participate in public events. By random selection of the participants we avoid any bias due to selfselection. Second, it avoids that participants are 'watched' by other village members, which could influence behaviour by perceived peer pressure. Third, at the moment of taking decisions participants cannot discuss or communicate in any way with other participants. This is important because a joke or an opinion expressed by for instance a local authoritative actor may substantially influence behaviour.

To minimize the influence of behavioural motives based on direct reciprocity, social prestige or social pressure, we implemented a one-way anonymity design. Only the dictator knows the identity of the recipient, and the recipient does not get to know who has distributed these resources ${ }^{29}$. Dictators were

\footnotetext{
${ }^{28}$ For detailed instructions and procedures see appendices 2 and 3.

${ }^{29} \mathrm{We}$ did not reveal the identity of the dictators to the recipients, nor did we explain them how many dictators had participated. We did not tell how much the others earned in total. In this way, the influence of direct reciprocity is minimized, though it is not completely excluded. Note that, as argued by Camerer \& Thaler (1995), people may bring to the lab certain manners, which may have been shaped under influence of reciprocity outside the lab. We also implemented this one-way anonymity design because of ethical considerations.
} 
informed about this. To reduce the possibility that participants' decisions were influenced by the assistant's presence ${ }^{30}$, the experimental procedures included the following three elements. First, decisions were made in full privacy. Whenever possible, participants went inside their house or a separate room to take a decision. Otherwise, the assistant turned his/her back when the dictator was handling the coins. The assistant also asked them not to make any comments about their decisions. Second, after taking a decision, the assistant asked dictators to fill up the box with metal rings, so that the final weight of the boxes would remain constant irrespective of the amount of coins they left in the box. Third, the boxes were sealed with tape, so that the assistants could not open the boxes. The decisions were recorded by the supervisor who does not have any interaction with the participants.

Furthermore, we were aware that participants' decisions might be influenced by their trust towards the assistant. Whereas the part they keep for themselves might be considered safe earnings, they might have doubts whether the share they leave to recipients is really transferred to them by the assistant. This is an important element as the region is characterized by low trust levels vis-à-vis strangers and people had not participated in experiments before. To build trust with local people, we started with the household and social network survey. The support of the local well-respected community leader was crucial at this moment, as he presented our team to each household and asked people to cooperate.

After finishing the network survey (which took four days), we immediately organized the experiment. By conducting the experiment in only one day we minimized contagion. $94.5 \%$ of the participants told us they had not talked about the experiment with other village members who had already participated before. The assistants also made a subjective evaluation about the participant's dedication, trust and understanding of the experiment. We did not notice any serious problems that could have affected the dictators' decisions. After the experiment the participants were asked to answer some post-experimental questions (see appendix 4).

\footnotetext{
${ }^{30}$ Hoffman et al. (1996) showed how anonymity between the dictator and the experimenter lowers the offers made by the dictator.
} 


\section{Results}

We start the empirical section with some descriptive statistics on the studied village. In particular, we present some important socio-economic household data and we look at important network measures of different types of networks separately as well as the overlap between the different types of networks. Thereafter, we use network data and the individual characteristics of dictators and recipients to explain dictator giving. In a final subsection, we look at network formation, since some variables although not directly important when explaining dictator giving might have an indirect influence through their effect on network formation.

\subsection{Some descriptive statistics}

\section{a. General socio-economic characteristics of the studied village}

We conducted our study in a rural village in the Northern part of the Pacific region of Nicaragua, close to the border with Honduras. The difficult agroecological conditions (dry season, irregular rainfall, low fertility of soils, etc.) make agricultural activities little profitable. Cattle-breeding is one of the most interesting economic activities in the region, as it is both an income source and an important savings instrument that enables local people to bridge the long and harsh dry season. During the dry season, economic activity drops drastically in the region and many people temporally migrate to Costa Rica, El Salvador or Guatemala, where they work in the construction, agricultural or cattle-breeding sector.

Table 4.1 shows some descriptive statistics on data gathered with the household survey. There are 66 households in the studied village, of which 9 single-headed households and 57 two-headed households. As a result the village has 123 household heads in total. We gathered household data on 58 of the 66 households (87.9\%) in the village. In Table 4.1 we observe that more than $60 \%$ of the households in the village are landless and more than half of them do not possess any cattle. Moreover, average education levels of the household heads, measured in the number of years of schooling, are lower than 5 years. At the same time, we observe that there is much heterogeneity in this village. First, economic inequality regarding cattle and land property (the two most important economic assets in the region) is extreme, with standard deviations higher than 2 
times the mean. $53 \%$ of the households do not have any cattle and $65 \%$ are landless, whereas cattle and land property have an average of 3.55 cows and 8.22 hectares respectively. Heterogeneity regarding education, age, number of years of residence and contact with urban centre (measured by the number of visits made last month to the urban centre) is somewhat lower, but still considerable.

Table 4.1. Village level descriptive statistics

\begin{tabular}{lrrrrr}
\hline & Min & Max & Mean & St. dev. & N \\
& & & & & \\
\hline Land (in ha.) of household & 0 & 84 & 8.22 & 17.33 & 58 \\
Land (dummy; 1 = has land) & 0 & 1 & 0.35 & 0.48 & 58 \\
Cattle (number of cows) of household & 0 & 50 & 3.55 & 9.44 & 58 \\
Cattle (dummy; 1 = has cattle) & 0 & 1 & 0.47 & 0.50 & 58 \\
Sex (1 = male; 0 = female) of household head & 0 & 1 & 0.50 & 0.50 & 107 \\
Education of household head & 0 & 13 & 4.19 & 3.60 & 107 \\
Age of household head & 21 & 86 & 45.86 & 14.55 & 107 \\
Number of years of residence & 0.5 & 70.0 & 33.22 & 15.63 & 100 \\
Contact with urban centre & 0 & 26 & 2.07 & 3.36 & 100 \\
\hline
\end{tabular}

\section{b. Some descriptive network statistics}

With the social network survey we gathered network data for 100 of the 123 household heads $(81.3 \%)$. As is characteristic for small-scale societies, almost everybody knows each other. This was also the case in the village of our study where in $93.5 \%$ of all possible directed ties the other was known. Another characteristic of such small communities is their pluriform character of interaction. Many are not only related through kinship relations, but are also connected because they support each other or they engage in economic transactions. Others may be connected because they go to the same church, or they meet each other at the village school when picking up their children, etc. Concomitantly, the influence of social networks on dictator game giving might be highly contingent on the type of network we look at. For instance we expect friendship networks to be more important than economic relations, as the latter are based on a market-logic where there is little room for generosity. 
To investigate the influence of different types of networks, we distinguished six dimensions. General relations are relations irrespective of their type and thus aggregate all types of relations. With a support relation we refer to a relation where support is given in at least one of both directions. Relations through social public activities are relations through activities related to religion, political parties, the village school, sport, cooperative organization, development projects or the village committee. Economic relations are relations that result from an exchange of land or labour, a commercial activity, a service provision or a lending activity. Family relations are kinship relations with grandparents, parents, brothers/sisters, children or grandchildren. We extended these family relations by also including relations of godparenthood, which are important in Nicaraguan rural life. Table 4.2 presents each of these dimensions with its respective reciprocity, density, centrality and closure measures.

Table 4.2. Different types of social networks and its characteristics

\begin{tabular}{|c|c|c|c|c|c|}
\hline & & $\begin{array}{l}\text { Reciprocated } \\
\text { ties }^{\text {a }}\end{array}$ & Density $^{\mathrm{b}}$ & $\begin{array}{l}\text { Freeman's } \\
\text { graph } \\
\text { centralization } \\
\text { measure }^{b}\end{array}$ & $\begin{array}{l}\text { Overall } \\
\text { graph } \\
\text { clustering } \\
\text { coefficient }\end{array}$ \\
\hline 1 & General relation & $30.24 \%$ & $35.35 \%$ & $44.06 \%$ & 0.554 \\
\hline 2 & Friendship relation & $11.49 \%$ & $18.59 \%$ & $1.01 \%$ & 0.384 \\
\hline 3 & Support relation & $2.11 \%$ & $3.21 \%$ & $21.73 \%$ & 0.181 \\
\hline 4 & Neighbour relation & $14.52 \%$ & $7.29 \%$ & $0.99 \%$ & 0.372 \\
\hline 5 & Social public activities & $17.14 \%$ & $4.62 \%$ & $27.79 \%$ & 0.259 \\
\hline 6 & Economic relation & $8.79 \%$ & $4.53 \%$ & $48.72 \%$ & 0.374 \\
\hline 7 & Extended family relation & $42.34 \%$ & $3.28 \%$ & $8.33 \%$ & 0.377 \\
\hline
\end{tabular}

${ }^{\mathrm{a}}$ (\# $(\mathrm{x} \rightarrow \mathrm{y}$ AND $\mathrm{x} \leftarrow \mathrm{y}) / \#(\mathrm{x} \rightarrow \mathrm{y}$ OR $\mathrm{x} \leftarrow \mathrm{y})$; including all ties except intrahousehold relations.

${ }^{\mathrm{b}}$ OR-networks; intrahousehold relations are considered as valid links

Leider et al. (2007) when recording friendship networks had a reciprocation degree of $36.7 \%$, which is very similar to the $30.24 \%$ reciprocation degree of general relations in our case. The percentage of reciprocated ties becomes lower when we disaggregate between the different types of relations. Undoubtedly, there exists a methodological trade-off between the possibility of capturing multiple networks and reciprocated ties. People likely put different emphasis on different types of networks, which might lower the percentage of reciprocated 
ties when trying to record multiple networks. An important exception is extended family relations, which are considered important by most people. Reciprocation is very low with support relations. As this type of relation may be very asymmetric, it is not evident that both support giver and receiver put the same emphasis on this type of social relation ${ }^{31}$.

To process the information on social relations we proceeded in the following way. First, we only took account of the household heads, as only in a very limited number of cases did people identify links with other household members. Second, we consider intrahousehold links as valid links irrespective of the type of relation we are looking at. Ultimately, household members are not only family, they also tend to be friends, support each other, have an economic link, etc.). Third, we symmetrised the resulting adjacency matrix ${ }^{32}$. For each dyad, we took the maximum value of each of both directions and missing values were eliminated by the non-missing value in the other direction. In this way we obtained the OR-networks (a relation is assumed to exist if at least one node mentions the relation).

There are two arguments in favour of using OR-networks instead of ANDnetworks (where a relation is only assumed to exist if both nodes mention the relation). Both arguments are based on the danger that actually existing links tend to be omitted when the AND-networks are used. First, those who have relations with many people are more likely to forget to mention a link, in comparison with those who have only few relations. This mostly occurs when open lists are used to capture social links, and is therefore limited in our case as we covered the entire village population with the small identity cards (and thus all potential dyads). A second argument which is more relevant for our case is the fact that people when being asked for multiple relations tend to put different emphasis on different types of relations. This may make people forget to mention certain types of links.

In the following we discuss the density, centrality and clustering of the different OR-networks. Regarding the density of the networks, measured as the sum of the ties divided by the number of possible ties, it comes as no surprise that networks of general relations, which aggregate all types of relations, have the highest density. Friendship networks are also relatively dense, whereas other

\footnotetext{
${ }^{31}$ This is supported by the following evidence. Considering all support relations where at least one of both nodes identified this relation, nodes who posses cattle mentioned significantly less of their support relations themselves in comparison with nodes without cattle $(50.5 \%$ versus $66.2 \%$; twosided $\mathrm{P}=.005$ based on a chi-square test). The same holds when comparing between nodes with land and nodes without land (45.1\% versus $65.8 \%$; two-sided $\mathrm{P}=.000$ based on a chi-square test).

${ }^{32}$ Many network indices can only be calculated with symmetric network data.
} 
networks have lower densities. This is the result of friendship relations being a broader category in comparison with other types of relations. As we will show below (Table 4.3), in many cases having a specific type of relation implies also a friendship relation.

Network centrality is important when one wants to study the importance of brokerage in networks (Burt, 1992; 2005). To measure centrality we use a graph centralization measure, which approaches $100 \%$ the more it resembles a starshaped network. Table 4.2 shows that centrality is highest in case of general networks and economic networks, followed by support networks and networks through social public activities (For a graphical representation of support networks and economic networks see Figure 4.1.). The high centrality in economic relations and support relations is likely to be related to the very unequal economic structure in the village. As indicated before, 53\% of the households do not have cattle and $65 \%$ does not have land, whereas there is a small number of economically strong households who have up to 50 cows and 84 hectares of land. The centrality in support relations and social public activities is also related to the brokerage pattern that we often observe in support networks. In many cases, some agents assume a broker role by providing support to large part of the village or taking the lead in many social public activities.

Figure 4.1. Support networks and economic networks in the village

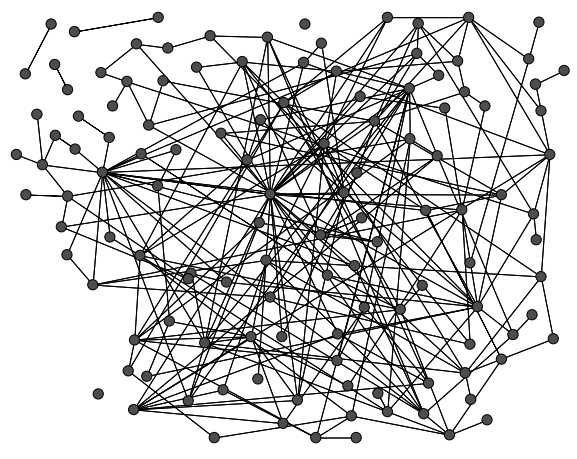

a- Support relations

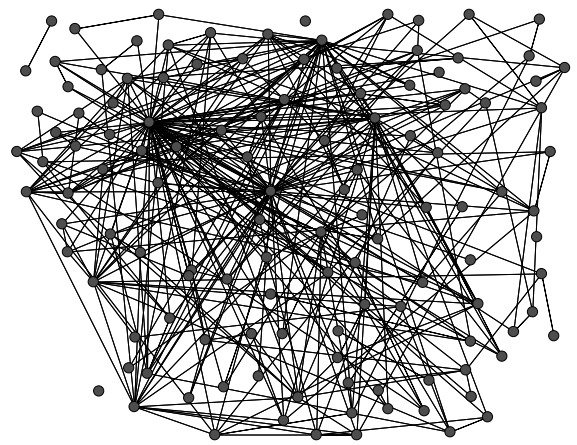

b- Economic relations

Another characteristic of social networks is its clustering degree. This measure is important if one is interested in Coleman's ideas (1990) on the importance of clustering in social networks to sustain cooperation or social norms. For this we 
use a clustering coefficient, which is equal to the average of the densities of the ego-networks of all actors ${ }^{33}$. Table 4.2 shows that clustering is highest with general type networks, with an average density of the ego-networks higher than 0.5. Clustering is lowest with support networks and networks through social public activities, which is consistent with the brokerage idea behind support giving and the organization of social public activities as discussed above. We also observe that the village network of economic relations while having the highest centrality has also a considerable clustering level. Economic egonetworks tend to be dense, whereas at the village level economic relations are centralized around some economically strong nodes.

Since we look at multiple networks, a final network characteristic that is of interest is the level of overlap between different types of networks. It might be that the fact that two agents are linked with each other on one particular dimension (e.g. they are friends) increases the likelihood that they have a link on another dimension as well. Table 4.3 shows the percentage of overlap between different types of relations at the dyad level. To interpret this table we need to start with the horizontal dimension. For instance, cell $1-2$ indicates that $6.38 \%$ of the friendship dyads are also support dyads, whereas $42.93 \%$ of the support dyads are also friendship dyads as indicated by cell 2-1.

Table 4.3. Overlap between different types of social relations

\begin{tabular}{l|ccccc|c}
\hline & Friendship & Support & Neighbour & Soc. act. & Economic & Ext. family \\
\hline Friendship & $100.00 \%$ & $6.38 \%$ & $12.67 \%$ & $9.44 \%$ & $8.93 \%$ & $2.74 \%$ \\
Support & $42.93 \%$ & $100.00 \%$ & $25.54 \%$ & $10.33 \%$ & $15.76 \%$ & $5.43 \%$ \\
Neighbour & $40.15 \%$ & $12.02 \%$ & $100.00 \%$ & $5.12 \%$ & $5.37 \%$ & $1.79 \%$ \\
Soc. act. & $40.34 \%$ & $6.55 \%$ & $6.90 \%$ & $100.00 \%$ & $5.17 \%$ & $1.38 \%$ \\
Economic & $36.75 \%$ & $10.25 \%$ & $7.42 \%$ & $5.30 \%$ & $100.00 \%$ & $2.83 \%$ \\
\hline Ext. family & $17.99 \%$ & $5.29 \%$ & $3.70 \%$ & $2.12 \%$ & $4.23 \%$ & $100.00 \%$ \\
\hline
\end{tabular}

Note. (dyad level - OR-links; ignoring intra-household links)

We observe that for most network types a high percentage of the dyads overlaps with friendship dyads, as demonstrated by the high percentages in the first column. Furthermore, there is a relatively large overlap between support and

\footnotetext{
${ }^{33}$ Ego-networks or neighborhoods are defined as the set of agents 'ego' has a direct link with.
} 
neighbour relations, as more than a quarter of support relations is between neighbours. Finally, a special category is extended family relations who show a low overlap with other types of relations. This is likely related to the very specific nature of extended family relations. In contrast with most other relations, extended family relations are not the result of an explicit decision-making process. More importantly, having an extended family relation often implies other types of relations (such as support, friendship, neighbour, etc.), which are not mentioned but naturally existing.

Taking account of the overlap but also the considerable differences between the different networks, we expect a differentiated influence of different layers of social networks on dictator giving. For this reason, our analysis of the influence of individual characteristics and social networks on dictator giving will be done separately for the different types of social networks.

\subsection{Experimental results}

In total 57 dictators participated in the experiment ${ }^{34}$. The left-hand histogram in Figure 4.2 shows the pooled dictator distributions with village recipients. We observe that the mode is the equal split. The rest of the decisions are more or less equally distributed around the mode (with a small exception with leaving nothing), implying a symmetric distribution. Note that this is very different from dictator game experiments conducted in common laboratory settings.

Figure 4.2. Distribution of dictator decisions
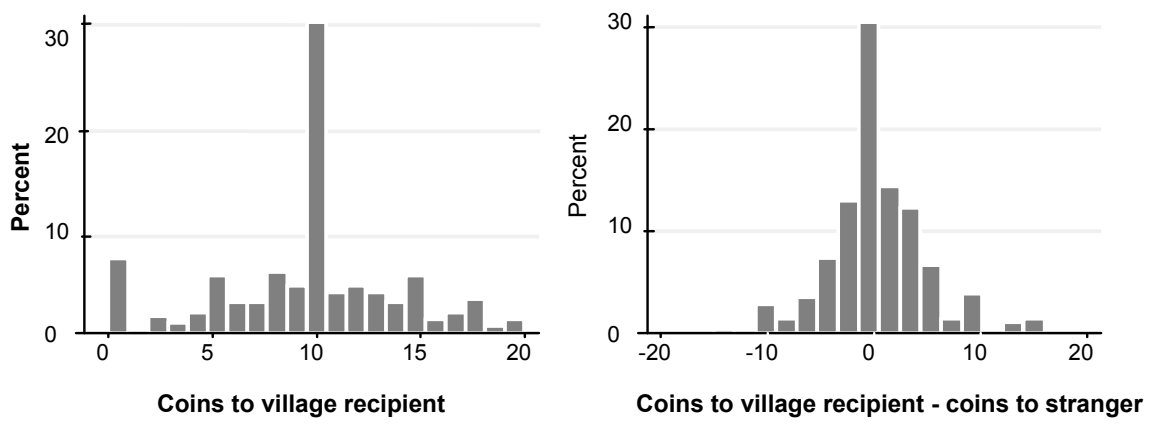

\footnotetext{
${ }^{34}$ Because of non-presence of some of the households and the fact that we opted for organizing the experiment in one day we did not manage to visit all 66 households for the experiment.
} 
Table 4.4.

\begin{tabular}{lcccccc}
\hline Variable & Obs. & Mean & Std. Dev. & Min & Max & Median \\
\hline Coins to village recipient & 285 & 9.6 & 4.58 & 0 & 20 & 10 \\
Coins to village recipient - coins to stranger & 285 & 0.4 & 4.63 & -15 & 16 & 0 \\
Coins to stranger & 57 & 9.2 & 5.43 & 0 & 20 & 10 \\
\hline
\end{tabular}

Participants in our dictator game show higher generosity than university students in experimental laboratories who rarely give more than $50 \%$ of the resources. This is even the case if we compare with single-blind procedures where dictators' generosity is somewhat higher as result of the lower social distance between the dictator and the experimenter (Hoffman et al., 1996). With singleblind procedures used in lab settings still a limited 21 percent of the dictators left the equal split and more than 20 percent left nothing to the recipient (Forsythe $e t$ al., 1994). It is unlikely that the higher generosity in our experiment in comparison with single-blind procedures can be attributed to differences of social distance between the dictator and the experimenter, as our procedures guaranteed that this social distance was actually lower in our experiment ${ }^{35}$.

The higher generosity in our experiment is likely to be related with the lower social distance between dictator and recipient. As shown by Bohnet $\&$ Frey (1999) letting the recipients present themselves before the experiment dramatically increases dictators' generosity. In our experiment the social distance between dictator and recipient was lowered in a similar way, in particular by revealing the name of the recipient to the dictator ${ }^{36}$. Leider et al. (2007) similarly found that dictators were less generous towards someone anonymous than towards someone whose name was revealed.

\footnotetext{
${ }^{35}$ Although the social distance between the dictator and the experimenter might be lowered by the face-to-face interview that precedes the experiment, it is actually the distance with a third supervisor that matters, as it is this person who records the dictator's decisions. As discussed before, this person does not have any social contact with the dictators.

${ }^{36}$ Social distance might also have been reduced by the fact that dictators knew that they distributed the resources with someone from their village or someone from a village in the region. This might be important in communities where reciprocity is part of daily life, even when directed reciprocity is not possible in the experiment. Ensminger (2004) who conducted a dictator game experiment in East Africa where dictators knew that the recipient was someone from their village, found similarly high frequencies of the equal split. An important difference with our experiment, however, lies in the very low frequency of distributions they observed where more than $50 \%$ is left to the recipient. A plausible explanation for this is that in contrast with our experiment they did not reveal the recipients' name.
} 
Leider et al. (2007) then considered the generosity towards the anonymous recipient as baseline generosity. We followed a similar procedure. We used the share dictators leave to the stranger as a proxy for 'general generosity', whereas we considered the share they leave to known village members as 'directed generosity ${ }^{37}$. We observe that general generosity is an important personality trait that explains part of people's generosity towards particular village recipients, as confirmed by a high and significant Spearman correlation (0.562; twosided $\mathrm{P}=.000 ; \mathrm{N}=285$ ).

We are aware that part of this correlation could also be attributed to an 'anchoring' effect (Tversky \& Kahneman, 1974), i.e. people who face a multiple decision task tend to stick to previously made decisions. The large variation of the difference between the share left to the village recipient and the share left to the stranger, shown in the right-hand histogram of Figure 4.2, indicates that this effect is limited. Also the variation of decisions made by the same dictator is considerable. Only 6 dictators $(10.5 \%)$ gave the same amount to all village members ( 5 of them chose the equal split and one left 8 coins to each recipient; 4 of them gave also the same amount to the stranger $)^{38}$.

Finally, the large variation of the difference between the share left to the village recipient and the share left to the stranger indicates that large part of the variation of directed generosity is not explained by general generosity. In the rest of this section we will look for further explanations behind this variation.

Table 4.5 shows the descriptive statistics of the influence of the social distance (measured by the number of links in the shortest path between dictator and recipient) on dictator giving, in dependence of the different types of networks. We observe that the effect of social distance is quite different between the network types, but there are also some similarities. Generally, in comparison with the stranger, dictators show higher generosity towards persons they have a direct link with (a distance of 1). Moreover, this generosity tends to be higher towards direct relations in comparison with indirect relations (distance 2). This

\footnotetext{
${ }^{37}$ In contrast with Leider et al. (2007) we also revealed the name of the stranger. This lowers the difference between the share left to the stranger and what is left to the village recipients, and probably explains why in contrast with their results this difference is not significantly different from zero. As shown by the right-hand histogram in figure 1, it is even symmetrically distributed around zero. In many occasions dictators give less to a village recipient than what they left to the stranger.

${ }^{38}$ When looking for other variables that explain the variation of generosity towards village recipients besides general generosity, such as individual characteristics and social network structures, an anchoring effect would not be problematic, as it reduces the variation of the explained variables, and thus only but leads to an underestimation of the correlation with these other explanatory variables.
} 
effect is relatively large with extended family relations, and to a lower extent with friendship relations, support relations and general relations. For most of the networks we do not observe a consistent social distance effect beyond step 2 . Regarding economic networks we do not observe any social distance effect at all.

Table 4.5. Social distance effect along different network types

\begin{tabular}{|c|c|c|c|c|c|c|c|}
\hline & & \multicolumn{6}{|c|}{ Coins to $\ldots$} \\
\hline & & Stranger & $\begin{array}{c}\text { Distance } \\
1\end{array}$ & $\begin{array}{c}\text { Distance } \\
2\end{array}$ & $\begin{array}{c}\text { Distance } \\
3\end{array}$ & $\begin{array}{c}\text { Distance } \\
4\end{array}$ & $\begin{array}{c}\geq \text { distance } \\
5\end{array}$ \\
\hline \multirow{3}{*}{ General type } & mean & 9.18 & 10.07 & 9.29 & 9.00 & - & - \\
\hline & st.dev. & 5.43 & 4.40 & 4.70 & . & & \\
\hline & $\mathrm{N}$ & 57 & 114 & 170 & 1 & - & - \\
\hline \multirow{3}{*}{$\begin{array}{l}\text { Friendship } \\
\text { relation }\end{array}$} & mean & 9.18 & 10.80 & 9.26 & 9.83 & - & - \\
\hline & st.dev. & 5.43 & 4.80 & 4.52 & 4.30 & & \\
\hline & $\mathrm{N}$ & 57 & 54 & 207 & 24 & - & - \\
\hline \multirow{3}{*}{$\begin{array}{l}\text { Support } \\
\text { relation }\end{array}$} & mean & 9.18 & 11.00 & 9.90 & 9.78 & 9.66 & 8.66 \\
\hline & st.dev. & 5.43 & 5.72 & 5.25 & 4.84 & 4.24 & 3.59 \\
\hline & $\mathrm{N}$ & 57 & 12 & 48 & 95 & 74 & 56 \\
\hline \multirow{3}{*}{$\begin{array}{l}\text { Extended } \\
\text { family }\end{array}$} & mean & 9.18 & 11.14 & 9.07 & 9.00 & 9.75 & 9.80 \\
\hline & st.dev. & 5.43 & 3.93 & 5.38 & 3.85 & 4.71 & 4.65 \\
\hline & $\mathrm{N}$ & 57 & 7 & 29 & 52 & 65 & 132 \\
\hline \multirow{3}{*}{$\begin{array}{l}\text { Social } \\
\text { public } \\
\text { activities }\end{array}$} & mean & 9.18 & 10.35 & 10.19 & 8.96 & 9.94 & 9.31 \\
\hline & st.dev. & 5.43 & 4.69 & 4.43 & 4.89 & 4.34 & 4.05 \\
\hline & $\mathrm{N}$ & 57 & 17 & 91 & 109 & 36 & 32 \\
\hline \multirow{3}{*}{$\begin{array}{l}\text { Economic } \\
\text { relation }\end{array}$} & mean & 9.18 & 9.67 & 9.99 & 9.11 & 9.52 & 9.48 \\
\hline & st.dev. & 5.43 & 5.33 & 4.69 & 4.70 & 3.40 & 4.31 \\
\hline & $\mathrm{N}$ & 57 & 15 & 128 & 94 & 27 & 21 \\
\hline
\end{tabular}

As indicated by the standard deviations, variation around the average levels for each of the social distances is considerable, which might obscure social distance effects on dictator giving when testing them statistically. It is therefore warranted to control for additional variables that might explain part of the variation in dictator giving. In particular, we will build a model that controls for individ- 
ual characteristics of dictator and recipient, the social distance between them, their ego-network characteristics and their level of general generosity.

For the estimation we use the following regression $\operatorname{model}^{39}$ :

$$
Y_{i j}=\alpha+\beta X_{i j}+e_{i j},
$$

with $\mathrm{i}$ and $\mathrm{j}$ being the dictator and the recipient. However, independence of observations is not guaranteed. The same dictator is asked to make five distribution decisions with community members, so that $E\left[e_{i j}, e_{i k}\right] \neq 0$ for all $\mathrm{k}$, and different dictators may have been asked to make a distribution decision with the same recipient, so that $E\left[e_{i j}, e_{k j}\right] \neq 0$ for all k. To correct standard errors for these dependencies and thus to obtain correct inference we apply clustering on both dimensions separately (for a more elaborate and technical discussion see e.g. Cameron et al., 2007).

Our research strategy in estimating the determinants of dictator giving is the following. In a first model we control for individual characteristics of the dictator and the recipient, which are likely to influence dictator-giving. In particular, we look at the influence of sex, age and wealth, which previous studies found to be correlated with dictator giving (Eckel \& Grossman, 1996; 1998; Harbaug et al., 2003; Brañas-Garza, 2006). As a proxy for wealth we use a dummy variable that indicates whether or not the respective household owns cattle $^{40}$, which is an important asset in the region. Besides these variables we control for education (measured by the years of schooling), the years of residence in the village, and the frequency of contact with the nearest urban centre (measured by the number of visits in last month). We expect these variables to be particularly important for social link formation (see section 4.3), but we also wanted to control for them in dictator decisions.

In a second model, we additionally control for the amount the dictator has left to the 'stranger'. This enables us to isolate 'directed' generosity. In a third model, we add the social distance between dictator and recipients - measured by the number of steps needed to link them - as explanatory variable.

In a fourth model, we add more sophisticated network variables which we expect to influence directed generosity. For both dictator and recipient we add the following variables. First, we control for their embeddedness in the village

\footnotetext{
${ }^{39}$ We also estimated a tobit regression model with random-effects at the level of the dictator (results not shown). Due to the very limited censoring (see left-hand histogram of Figure 4.2) results were very similar.

${ }^{40}$ As more than half of the village population does not have any cattle at all, we expect this dummy variable to have more explanatory power than controlling for the exact amount of cattle.
} 
by adding a variable 'size of ego-network', i.e. the number of nodes they have a direct link with. Second, we look at the nodes in their ego network and the links these nodes have. According to Coleman (1990), the more connections there are between the nodes the more beneficial a network tends to be for sustaining collective action and social norms. As this possibly influences dictator giving, we control for this by adding a variable 'number of ties in ego-network'. Third, according to Burt $(1992 ; 2005)$ an agent has more power if he/she is connected to many nodes that have few links and thus are very dependent on him/her. As this power possibly influences the dictator's generosity, we control for this by adding a variable 'two step reach', which measures the percentage of the population that is reached within two steps.

Following this stepwise procedure and looking at general-type relations, we observe in the first model of Table 4.6 (see appendix 1) that the sex dummies are important explanatory variables. Male recipients receive on average 2.7 coins more from male dictators than what they receive from female dictators. At the same time, on average male dictators give to female recipients 2.2 coins more than what female dictators give to male recipients. This contrasts with previous lab dictator game experiments (Eckel \& Grossman, 1996; 1998) that demonstrated that female dictators are more generous than male dictators. Young female students in Northern universities, however, can hardly be compared with poor women who struggle with fulfilling every day life responsibilities such as child health and education. In particular, a plausible explanation for this difference can be found in studies on gender differences regarding income spending in poor countries. As demonstrated by Thomas (1990) in urban Brazil the influence of unearned income (e.g. social benefits) in mother's hands on the children's health is substantially higher than the influence of this income controlled by fathers. Hoddinott \& Haddad (1995) showed in Cote d'Ivoire that the share of income controlled by women is positively correlated with food shares. Taking account of this evidence we think female dictators keep a larger part of the coins not because they are less generous, but because they are eager to spend it in health or food related household consumption, whereas they are reluctant to give it to male recipients who are expected to spend it more on non-household related consumption (alcohol, cigarettes, etc.).

Education, age and the number of years of residence in the village do not exert any influence on dictator giving. The contact with the nearest urban centre of the dictator, however, does exert an influence on dictator giving. Dictators give more when they have more contact with urban centres and ceteris paribus the less they differ with the recipient on this variable. 
Looking at economic variables the regression results indicate that dictators with cattle give on average 2 coins more than a dictator without cattle. Whether the recipient has cattle or not does not influence the distribution decision of the dictator. Thus, dictators do not compare with the economic status of the recipient, but only look at their own economic situation. This effect becomes much less important once we control for the number of coins left to the stranger (model 2). This indicates that dictators without cattle give less in general, irrespective of the recipient being a stranger or not. Moreover, as expected, the coins left to the stranger as proxy for general generosity results a very important and significant explanatory variable.

In a third model we control for the social distance between dictator and recipient. It is sufficient to include only one dummy variable since all but one dictators are connected with recipients at a maximum distance of two. We observe that on average, dictators give almost one coin less to indirect relations than to direct relations. The effect of social distance is only significant at $10 \%$ $(\text { two-sided })^{41}$. In a fourth model, we add the network characteristics of the dictator and the recipient as explanatory variables. They do not exert any significant influence on the dictator decisions, probably because of the low variance in these network characteristics (most people are connected at a maximum distance of 2).

In the following we present the estimations of models 3 and 4 for the separate network types. The same network measures will be used as with general-type networks. In the models in Table 4.7 (see appendix 1) we focus on friendship networks. We observe that the sex dummy variables have a similar effect as in the models with general-type relations. Also similarly, the social distance effect in model 3 is significant at the $10 \%$ (two-sided) ${ }^{42}$. Results regarding the influence of more specific network characteristics (model 4), however, are different. We observe that a higher percentage of the population reached within two steps along a dictator's friendship ties reduces generosity. A higher percentage of the population reached within two steps keeping the size of the ego-network constant reduces the centrality of the dictator. According to Burt's theory $(1992 ; 2005)$ this reduces the power of the dictator. It is however not directly clear how to interpret this positive correlation between power and

\footnotetext{
${ }^{41}$ As we expect social distance to be highly correlated with the sex dummy variables (for further analysis on this see next section), we exclude the latter (model not shown) and the effect of social distance becomes significant at $5 \%$ (two-sided).

${ }^{42}$ Here again, when excluding the sex dummy variables, social distance becomes significant at $5 \%$. Moreover, by doing so the effect becomes stronger as the coefficient decreases to -1.424.
} 
generosity. A plausible explanation is that power in such small-scale societies tends to be based on clientelism and can only be maintained if sufficient resources are transferred to the dependent clients (Wolf, 1977). Although direct reciprocity is limited in our experiment, it is plausible that participants bring this common patron-clientelistic logic to the experiment. Dictators connected with lowly connected nodes may therefore feel the obligation or responsibility to share with others, irrespective of the latter belonging to their ego-network.

In Table 4.8 we study the influence of support networks. Also in these models individual characteristics exert little influence on dictator giving, except for the sex dummy variables. Social distance does not exert a significant influence on dictator giving, even if we remove the sex dummy variables which are correlated with social distance (model not shown). An important difference with general type and friendship networks is the influence of the density of the dictator's ego-network. The higher this density (increasing the number of ties the nodes in the ego-network have among each other for a given size of the egonetwork, or reducing the size of the ego-network for a given number of ties among the nodes in the ego-network), the more a dictator tends to give to the recipient. This higher generosity is consistent with Coleman's evidence (1990) on the positive correlation between network clustering and the respect for social norms. When more people in the ego-network of a dictator interchange support, the more the dictator finds it to be a rightful behaviour to let part of the resources to the receiver, irrespective of his/her personal relation with the recipient.

In the models in Table 4.9 we focus on social links through social public activities. Interesting in these models is the influence of the ego-network of the recipients. Dictators give less to recipients with large ego-networks. These recipients are central and therefore have a leader position in social public activities. It is plausible that because of their favourable access to local and external opportunities they are deemed less entitled to additional resources. We also observe that recipients with cattle receive on average 1.5 coins less from dictators without cattle than from dictators with cattle. This effect which has been present only at a statistically insignificant level in most previous models becomes here significant as these economic variables are not correlated with network variables along social public activities (see next section for evidence on this).

In the models in Table 4.10 that look at economic relations, we do not find any statistically significant influence of network variables on dictator giving. This does not surprise us as economic relations in contrast with other types of relations (such as support relations, friendship relations or family relations) are 
based on a market-logic where there is little room for generosity. Market transactions are based on a quid pro quo basis, where the conditions are clearly defined. Unconditional generosity as observed through dictator giving is therefore not more likely between nodes that have an economic relation.

In Table 4.11 we look at extended family networks. Here too, the influence of the social distance between dictator and recipient is important. Interestingly, the size of the coefficient is high (more than 2), although only significant at the $10 \%$. On average, dictators give 2 coins less to a recipient they have not a direct family relation with. To control for the other network characteristics in model 4 , we decided not to control for the number of ties within the ego-network, since given our definition of extended family relations the density of extended family ego-networks is almost always complete. Instead, we added an interaction effect between social distance and the size of the ego-network. The main results are the following. The social distance coefficient drastically decreases and becomes significant at the $1 \%$ level. Moreover, the larger the size of a dictator's family network, the lower becomes his/her generosity. As indicated by the significant and positive interaction effect, this effect is lower for people that do not belong to the ego-network. This can be interpreted as follows. Dictators embedded in a larger family network have probably weaker ties with each family member, reducing their generosity towards a given recipient within their network. The same applies for the recipient's family networks. The larger the size of the recipient's family networks, the weaker the recipient's family ties and the lower the dictator's generosity if the dictator belongs to the recipient's family networks.

The results in this section have confirmed that to explain generosity it clearly matters what networks we look at. Lower social distance between dictator and recipient on general networks (i.e. irrespective of its type), friendship networks and extended family networks favour generosity. The network position and the structure of these networks also result important. In particular, generosity increases the more the dictator's friends have relatively few other friends, or with denser support networks of the dictator. Generosity also increases the smaller the family networks of the dictator or the recipient (if both have a direct family relation), or the smaller the recipient's network through social public activities. Finally, economic relations do not exert any influence on generosity. 


\subsection{Social link formation}

In previous section we have seen how individual characteristics of dictators and recipients influence distributive decision-making. We have observed that once we control for network variables, most coefficients of individual-specific characteristics (except sex dummy variables) become insignificant, whereas some network variables become powerful explanatory variables. This effect is likely due to the close relation between individual characteristics and social relations. To study the indirect effect of individual characteristics on distributive decision-making through its relation with social links, we conduct a separate analysis on link formation.

For each type of social relation ${ }^{43}$, we examine a model that explains the probability of an undirected link. For this we consider all potential links between the 123 household heads, excluding intra-household links ${ }^{44}$. For the estimation of the models we use the following logistic regression model:

$$
\operatorname{Logit}\left(p_{i j}\right)=\ln \left(\frac{p_{i j}}{1-p_{i j}}\right)=\alpha+\beta_{1}\left|z_{i}-z_{j}\right|+\beta_{2}\left(z_{i}+z_{j}\right)+\gamma \cdot w_{i j}+e_{i j}
$$

With $p_{i j}$ being the probability of a link between nodes $i$ and $j, z_{i}$ and $z_{j}$ being characteristics of nodes $\mathrm{i}$ and $\mathrm{j}$, and $\mathrm{w}_{\mathrm{ij}}$ characteristics of the link between $\mathrm{i}$ and $\mathrm{j}$, such as the fact that they are also neighbours and/or family. For each attribute of the nodes, we add the sum and the absolute value of the difference of the attributes. The former measures the effect of the combined level whereas the latter measures the effect of differences in attributes. Controlling for the differences in attributes allows us to test the homophily hypothesis. As illustrated extensively people have a tendency to associate with similar others (McPherson et al., 2001).

Dyadic observations involving the same node, however, are not independent. Thus, $E\left[e_{i j}, e_{i k}\right] \neq 0$ for all $\mathrm{k}$, and $E\left[e_{i j}, e_{k j}\right] \neq 0$ for all $\mathrm{k}$. To correct standard errors for these dependencies, and thus to obtain correct inference we apply clustering on both dimensions separately (Cameron et al., 2007; Fafchamps \& Gubert, 2007).

\footnotetext{
${ }^{43}$ We did not estimate such model for family relations or neighbor relations as they are only to a limited extent the result of a deliberate decision.

${ }^{44}$ It is assumed that household members are not only family, they also tend to be friends, support each other, have an economic link, etc. However, we did not capture information on the type of intra-household relations. Moreover, even with this information it would not be a good idea to pool intra-household and extra-household relations, because of their different character.
} 
Individual-specific variables we included in the model are the same as used in the regression models on generosity, namely sex, age, education, the number of years of residence in the village and the frequency of contact with the urban centre $^{45}$. Moreover, we control for the number of geodesic paths of length two between both nodes. This allows us to test the hypothesis of preferential linking (Jackson \& Rogers, 2007). In particular, we expect the likelihood of a link between two nodes to increase with the number of common direct links both nodes have with each other. We also control for the possibility that both nodes have a direct family or neighbour relation, as this might increase the likelihood of having a relation on other dimensions as well. To study the formation of 'general' relations (i.e. irrespective of its type) we do not control for family or neighbour relations, as these are included in the general relation.

Table 4.12 (see appendix 1) shows the results. Our results indicate that the probability of a support link is significantly lower between female and male persons in comparison with a situation where both persons are males. This applies to all types of links. We also observe that the formation of friendship links and general links is also less likely between women.

Larger age differences reduce the likelihood of a support relation or a relation through public social activities. Education levels exert a positive influence on the formation of friendship links. In particular, a higher combined level of both nodes increases the likelihood that a friendship relation or a relation through social public activities is formed. The number of years of residence in the village is relevant for the formation of general links. The likelihood of a general relation increases with a larger combined level or with a smaller absolute difference between both nodes. Regarding the contact with the nearest urban centre measured by the number of visits during last month, we observe that a larger difference between both nodes reduces the likelihood of a friendship link, a link through social public activities or an economic relation. The likelihood of a general relation or an economic relation also lowers with a smaller sum of both nodes.

Economic variables are especially important for the formation of economic relations. In comparison with a situation where both nodes have cattle, if only one node has cattle the likelihood of a link decreases, and it does even more if both nodes do not have any cattle. A similar pattern is observed for the formation of friendship links. This effect is not observed for general relations. This is likely due to multicollinearity between land, cattle and education. The influence

45 Other studies have analyzed the influence of individual characteristics on social capital formation. See for instance Glaeser et al. (2002). 
of cattle becomes significant, only when we exclude land and education (model not shown).

In all models the number of paths of length 2 results a very significant explanatory variable. The more relations both nodes have in common the higher the likelihood that they have a direct relation ${ }^{46}$. Finally, we observe that geographical distance between both nodes as measured by the distance along neighbour links lowers the probability of a support link or a friendship link. Having a kinship relation does not influence the likelihood of having another type of relation.

\section{Conclusion}

This chapter explores how social networks and individual characteristics influence distributive decisions within small rural societies. It reports the results of a series of dictator game experiments in a poor village in rural Nicaragua. Our results indicate that the only individual characteristics that directly influence dictator giving are the gender of the dictator and recipient. Women give significantly less to recipients, and even less when recipients are male.

Looking at networks, our results indicate that dictator giving correlates with network characteristics and social distance; though the kind of correlation is highly contingent upon the type of network we look at. Lower social distance between dictator and recipient on general networks (i.e. irrespective of its type), friendship networks and extended family networks favour generosity. The characteristics of friendship networks, support networks, family networks and networks through social/public activities are also important for dictator giving. Generosity increases the more the dictator's friends have relatively few other friends, the denser the support networks of the dictator, the smaller the family networks of the dictator and/or the recipient (if both have a direct family relation), and the larger the recipient's network through social/public activities.

Taking account of the demonstrated importance of social distance for dictator giving and the determinants behind link formation, we conclude that the poor, the less mobile, women and the young are most vulnerable to exclusion because they tend to be socially more distant from others in their village (when looking at friendship relations), and thus from the persons who distribute economic resources. The same applies for people that are very distant

\footnotetext{
${ }^{46}$ Being aware of possible inverse causality, we also estimated a model without this variable. Results were not very different, with most significant variables remaining significant.
} 
neighbours of those who distribute economic resources. As we do not observe any evidence of dictators taking account of the individual characteristics of the disadvantaged which might weaken these social network effects, these people might face a real poverty trap. 


\section{Appendix 1: regression results}

Table 4.6. Dictator giving and general-type networks (a)

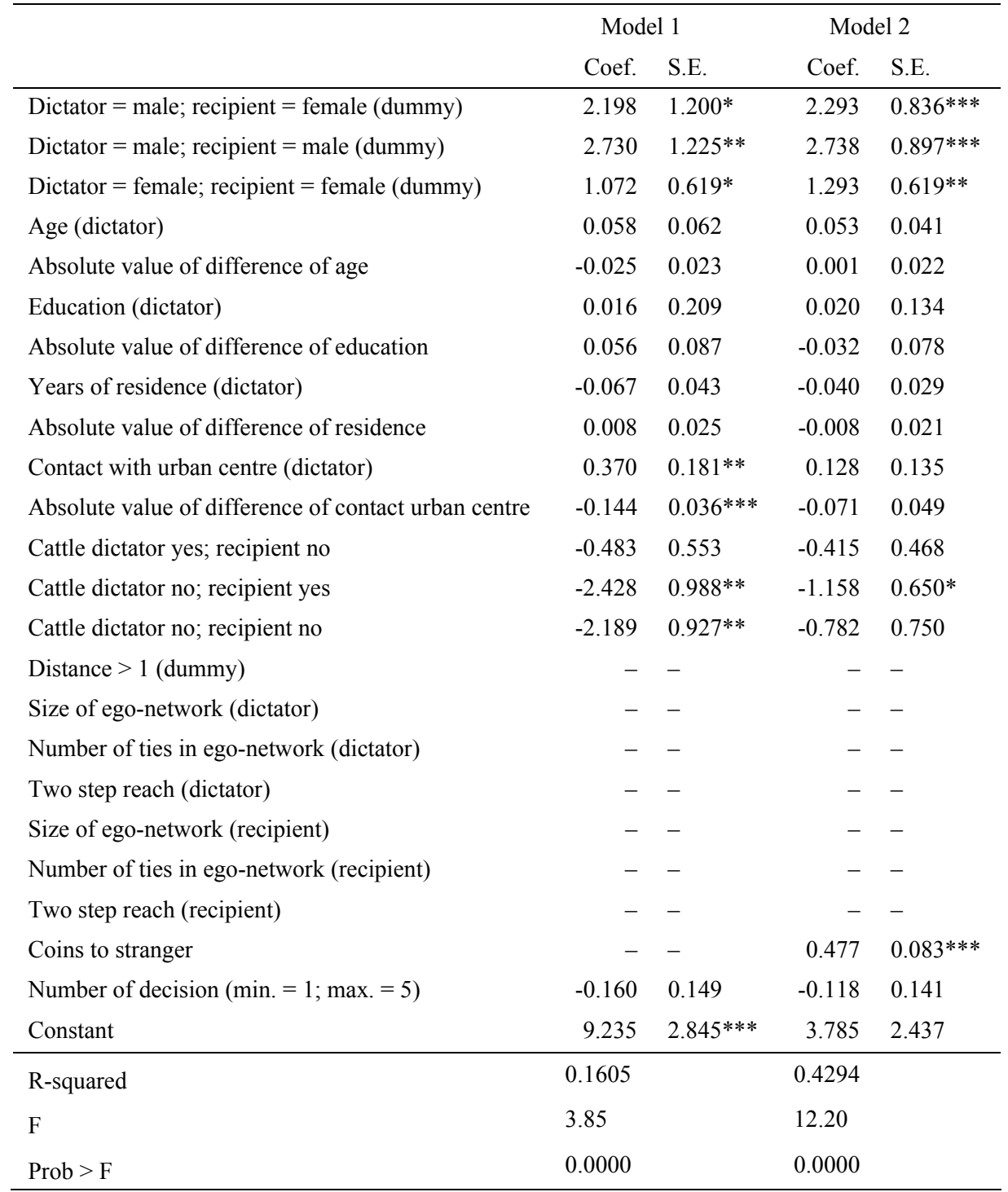

Note. Robust standard errors were obtained by means of two-way clustering (dictator and recipient level); significance levels (two-sided): $*=10 \%, * *=5 \% ; * * *=1 \% ; \mathrm{N}=273$. 
Table 4.6. Dictator giving and general-type networks (b)

\begin{tabular}{|c|c|c|c|c|}
\hline & \multicolumn{2}{|c|}{ Model 3} & \multicolumn{2}{|c|}{ Model 4} \\
\hline & Coef. & S.E. & Coef. & S.E. \\
\hline Dictator $=$ male; recipient $=$ female $($ dummy $)$ & 2.320 & $0.845^{* * *}$ & 2.579 & $2.430 * *$ \\
\hline Dictator $=$ male; recipient $=$ male $($ dummy $)$ & 2.518 & $0.920 * * *$ & 2.692 & $2.640 * * *$ \\
\hline Dictator $=$ female; recipient $=$ female $($ dummy $)$ & 1.255 & $0.632 * *$ & 1.431 & $1.920^{*}$ \\
\hline Age (dictator) & 0.052 & 0.041 & 0.049 & 1.220 \\
\hline Absolute value of difference of age & 0.002 & 0.021 & 0.005 & 0.300 \\
\hline Education (dictator) & 0.015 & 0.132 & 0.010 & 0.080 \\
\hline Absolute value of difference of education & -0.036 & 0.078 & -0.045 & -0.570 \\
\hline Years of residence (dictator) & -0.043 & 0.029 & -0.037 & -1.340 \\
\hline Absolute value of difference of residence & -0.003 & 0.022 & -0.005 & -0.210 \\
\hline Contact with urban centre (dictator) & 0.124 & 0.132 & 0.138 & 1.020 \\
\hline Absolute value of difference of contact urban centre & -0.074 & 0.050 & -0.077 & -1.480 \\
\hline Cattle dictator yes; recipient no & -0.326 & 0.453 & -0.275 & -0.600 \\
\hline Cattle dictator no; recipient yes & -1.131 & $0.659 *$ & -1.240 & $-1.730^{*}$ \\
\hline Cattle dictator no; recipient no & -0.817 & 0.754 & -0.992 & -1.250 \\
\hline Distance $>1$ (dummy) & -0.834 & $0.435^{*}$ & -0.903 & $-1.730^{*}$ \\
\hline Size of ego-network (dictator) & - & - & -0.006 & -0.040 \\
\hline Number of ties in ego-network (dictator) & - & - & 0.000 & 0.070 \\
\hline Two step reach (dictator) & - & - & -0.684 & -1.210 \\
\hline Size of ego-network (recipient) & - & - & -0.019 & -0.320 \\
\hline Number of ties in ego-network (recipient) & - & - & 0.000 & 0.250 \\
\hline Two step reach (recipient) & - & - & 0.342 & 1.050 \\
\hline Coins to stranger & 0.478 & $0.084 * * *$ & 0.462 & $5.420 * * *$ \\
\hline Number of decision $(\min .=1 ; \max .=5)$ & -0.110 & 0.139 & -0.106 & -0.740 \\
\hline Constant & 4.358 & $2.271 *$ & 38.903 & 0.640 \\
\hline R-squared & 0.4365 & & 0.4483 & \\
\hline $\mathrm{F}$ & 11.76 & & 8.77 & \\
\hline Prob $>F$ & 0.0000 & & 0.0000 & \\
\hline
\end{tabular}

Note. Robust standard errors were obtained by means of two-way clustering (dictator and recipient level); significance levels (two-sided): $*=10 \%, * *=5 \% ; * * *=1 \% ; \mathrm{N}=273$. 
Table 4.7. Dictator giving and friendship networks

\begin{tabular}{|c|c|c|c|c|}
\hline & \multicolumn{2}{|c|}{ Model 3} & \multicolumn{2}{|c|}{ Model 4} \\
\hline & Coef. & S.E. & Coef. & S.E. \\
\hline Dictator $=$ male; recipient $=$ female $($ dummy $)$ & 2.284 & $0.838 * * *$ & 2.080 & $1.067 *$ \\
\hline Dictator $=$ male; recipient $=$ male $($ dummy $)$ & 2.490 & $0.888 * * *$ & 2.780 & $0.974 * *$ \\
\hline Dictator $=$ female; recipient $=$ female $($ dummy $)$ & 1.280 & $0.608 * *$ & 0.732 & 0.853 \\
\hline Age (dictator) & 0.050 & 0.041 & 0.058 & 0.038 \\
\hline Absolute value of difference of age & 0.004 & 0.021 & 0.009 & 0.020 \\
\hline Education (dictator) & 0.011 & 0.128 & 0.026 & 0.116 \\
\hline Absolute value of difference of education & -0.043 & 0.078 & -0.036 & 0.083 \\
\hline Years of residence (dictator) & -0.042 & 0.029 & -0.038 & 0.027 \\
\hline Absolute value of difference of residence & -0.007 & 0.021 & -0.017 & 0.022 \\
\hline Contact with urban centre (dictator) & 0.107 & 0.129 & 0.124 & 0.114 \\
\hline Absolute value of difference of contact urban centre & -0.067 & 0.052 & -0.069 & 0.043 \\
\hline Cattle dictator yes; recipient no & -0.310 & 0.480 & -0.435 & 0.498 \\
\hline Cattle dictator no; recipient yes & -1.074 & 0.667 & -1.061 & 0.691 \\
\hline Cattle dictator no; recipient no & -0.652 & 0.741 & -0.876 & 0.704 \\
\hline Distance $>1$ (dummy) & -1.071 & 0.652 & -1.361 & $0.708^{*}$ \\
\hline Size of ego-network (dictator) & - & - & 0.091 & 0.125 \\
\hline Number of ties in ego-network (dictator) & - & - & -0.004 & 0.007 \\
\hline Two step reach (dictator) & - & - & -0.074 & $0.024 * * *$ \\
\hline Size of ego-network (recipient) & - & - & 0.001 & 0.072 \\
\hline Number of ties in ego-network (recipient) & - & - & -0.002 & 0.004 \\
\hline Two step reach (recipient) & - & - & -0.009 & 0.028 \\
\hline Coins to stranger & 0.481 & $0.083 * * *$ & 0.482 & $0.080 * * *$ \\
\hline Number of decision $(\min .=1 ; \max .=5)$ & -0.102 & 0.140 & -0.111 & 0.150 \\
\hline Constant & 4.793 & $2.420 * *$ & 11.421 & $3.008 * * *$ \\
\hline R-squared & 0.4370 & & 0.4671 & \\
\hline $\mathrm{F}$ & 12.02 & & 10.49 & \\
\hline Prob $>$ F & 0.0000 & & 0.0000 & \\
\hline
\end{tabular}

Note. Robust standard errors were obtained by means of two-way clustering (dictator and recipient level); significance levels (two-sided): $*=10 \%, * *=5 \% ; * * *=1 \% ; \mathrm{N}=273$. 
Table 4.8. Dictator giving and support networks

\begin{tabular}{|c|c|c|c|c|}
\hline & \multicolumn{2}{|c|}{ Model 3} & \multicolumn{2}{|c|}{ Model 4} \\
\hline & Coef. & S.E. & Coef. & S.E. \\
\hline Dictator $=$ male $;$ recipient $=$ female $($ dummy $)$ & 2.311 & $0.834 * * *$ & 2.497 & $0.812 * * *$ \\
\hline Dictator $=$ male; recipient $=$ male $($ dummy $)$ & 2.714 & $0.910 * * *$ & 3.007 & $0.931 * * *$ \\
\hline Dictator $=$ female; recipient $=$ female $($ dummy $)$ & 1.330 & $0.613 * *$ & 1.221 & $0.612 * *$ \\
\hline Age (dictator) & 0.055 & 0.042 & 0.057 & 0.043 \\
\hline Absolute value of difference of age & 0.001 & 0.021 & 0.001 & 0.022 \\
\hline Education (dictator) & 0.025 & 0.136 & 0.037 & 0.150 \\
\hline Absolute value of difference of education & -0.031 & 0.077 & -0.028 & 0.081 \\
\hline Years of residence (dictator) & -0.039 & 0.030 & -0.038 & 0.028 \\
\hline Absolute value of difference of residence & -0.006 & 0.022 & -0.013 & 0.022 \\
\hline Contact with urban centre (dictator) & 0.128 & 0.133 & 0.149 & 0.133 \\
\hline Absolute value of difference of contact urban centre & -0.064 & 0.048 & -0.076 & 0.047 \\
\hline Cattle dictator yes; recipient no & -0.423 & 0.488 & -0.512 & 0.486 \\
\hline Cattle dictator no; recipient yes & -1.117 & $0.649^{*}$ & -1.021 & 0.621 \\
\hline Cattle dictator no; recipient no & -0.718 & 0.757 & -0.740 & 0.715 \\
\hline Distance $>1$ (dummy) & -1.054 & 0.801 & -1.099 & 0.960 \\
\hline Size of ego-network (dictator) & - & - & -0.329 & $0.181^{*}$ \\
\hline Number of ties in ego-network (dictator) & - & - & 0.198 & $0.094 * *$ \\
\hline Two step reach (dictator) & - & - & 0.008 & 0.035 \\
\hline Size of ego-network (recipient) & - & - & -0.049 & 0.142 \\
\hline Number of ties in ego-network (recipient) & - & - & 0.038 & 0.054 \\
\hline Two step reach (recipient) & - & - & -0.009 & 0.030 \\
\hline Coins to stranger & 0.477 & $0.083^{* * *}$ & 0.447 & $0.081 * * *$ \\
\hline Number of decision $(\min .=1 ; \max .=5)$ & -0.125 & 0.142 & -0.113 & 0.141 \\
\hline Constant & 4.569 & $2.185^{* *}$ & 5.504 & $2.633 * *$ \\
\hline R-squared & 0.4314 & & 0.4576 & \\
\hline $\mathrm{F}$ & 11.59 & & 12.95 & \\
\hline Prob $>$ F & 0.0000 & & 0.0000 & \\
\hline
\end{tabular}

Note. Robust standard errors were obtained by means of two-way clustering (dictator and recipient level); significance levels (two-sided): $*=10 \%, * *=5 \% ; * * *=1 \% ; \mathrm{N}=273$. 
Table 4.9. Dictator giving and networks through social public activities

\begin{tabular}{|c|c|c|c|c|}
\hline & \multicolumn{2}{|c|}{ Model 3} & \multicolumn{2}{|c|}{ Model 4} \\
\hline & Coef. & S.E. & Coef. & S.E. \\
\hline Dictator $=$ male; recipient $=$ female $($ dummy $)$ & 2.307 & $0.831 * * *$ & 2.836 & $0.909 * * *$ \\
\hline Dictator $=$ male; recipient $=$ male $($ dummy $)$ & 2.766 & $0.883 * * *$ & 3.165 & $0.904 * * *$ \\
\hline Dictator $=$ female; recipient $=$ female $($ dummy $)$ & 1.295 & $0.616^{* *}$ & 1.414 & $0.600^{* *}$ \\
\hline Age (dictator) & 0.054 & 0.041 & 0.063 & 0.045 \\
\hline Absolute value of difference of age & 0.000 & 0.022 & -0.006 & 0.022 \\
\hline Education (dictator) & 0.019 & 0.132 & 0.048 & 0.152 \\
\hline Absolute value of difference of education & -0.028 & 0.077 & 0.000 & 0.086 \\
\hline Years of residence (dictator) & -0.040 & 0.029 & -0.033 & 0.029 \\
\hline Absolute value of difference of residence & -0.008 & 0.021 & 0.001 & 0.019 \\
\hline Contact with urban centre (dictator) & 0.131 & 0.136 & 0.129 & 0.159 \\
\hline Absolute value of difference of contact urban centre & -0.074 & 0.050 & -0.048 & 0.042 \\
\hline Cattle dictator yes; recipient no & -0.408 & 0.482 & -0.231 & 0.515 \\
\hline Cattle dictator no; recipient yes & -1.156 & $0.649^{*}$ & -1.590 & $0.751 * *$ \\
\hline Cattle dictator no; recipient no & -0.798 & 0.752 & -1.039 & 0.840 \\
\hline Distance $>1$ (dummy) & 0.421 & 1.171 & 0.494 & 1.093 \\
\hline Size of ego-network (dictator) & - & - & 0.302 & 0.189 \\
\hline Number of ties in ego-network (dictator) & - & - & -0.026 & 0.022 \\
\hline Two step reach (dictator) & - & - & -0.056 & $0.032 *$ \\
\hline Size of ego-network (recipient) & - & - & -0.106 & $0.046^{* *}$ \\
\hline Number of ties in ego-network (recipient) & - & - & 0.014 & $0.008^{*}$ \\
\hline Two step reach (recipient) & - & - & 0.021 & $0.013^{*}$ \\
\hline Coins to stranger & 0.477 & $0.083 * * *$ & 0.502 & $0.080 * * *$ \\
\hline Number of decision $(\min .=1 ; \max .=5)$ & -0.116 & 0.139 & -0.124 & 0.135 \\
\hline Constant & 3.350 & 2.774 & 2.190 & 3.007 \\
\hline R-squared & 0.4298 & & 0.4640 & \\
\hline $\mathrm{F}$ & 11.50 & & 9.93 & \\
\hline Prob $>$ F & 0.0000 & & 0.0000 & \\
\hline
\end{tabular}

Note. Robust standard errors were obtained by means of two-way clustering (dictator and recipient level); significance levels (two-sided): $*=10 \%, * *=5 \% ; * * *=1 \% ; \mathrm{N}=273$. 
Table 4.10. Dictator giving and economic networks

\begin{tabular}{|c|c|c|c|c|}
\hline & \multicolumn{2}{|c|}{ Model 3} & \multicolumn{2}{|c|}{ Model 4} \\
\hline & Coef. & S.E. & Coef. & S.E. \\
\hline Dictator $=$ male $;$ recipient $=$ female $($ dummy $)$ & 2.293 & $0.838 * * *$ & 1.912 & $0.949 * *$ \\
\hline Dictator $=$ male; recipient $=$ male $($ dummy $)$ & 2.742 & $0.896 * * *$ & 2.511 & $0.902 * * *$ \\
\hline Dictator $=$ female; recipient $=$ female $($ dummy $)$ & 1.295 & $0.622 * *$ & 1.189 & $0.651^{*}$ \\
\hline Age (dictator) & 0.053 & 0.041 & 0.049 & 0.044 \\
\hline Absolute value of difference of age & 0.001 & 0.022 & 0.002 & 0.019 \\
\hline Education (dictator) & 0.020 & 0.134 & -0.029 & 0.142 \\
\hline Absolute value of difference of education & -0.032 & 0.078 & 0.006 & 0.087 \\
\hline Years of residence (dictator) & -0.040 & 0.029 & -0.040 & 0.030 \\
\hline Absolute value of difference of residence & -0.008 & 0.021 & -0.001 & 0.023 \\
\hline Contact with urban centre (dictator) & 0.128 & 0.135 & 0.106 & 0.137 \\
\hline Absolute value of difference of contact urban centre & -0.071 & 0.049 & -0.069 & 0.053 \\
\hline Cattle dictator yes; recipient no & -0.417 & 0.471 & -0.344 & 0.522 \\
\hline Cattle dictator no; recipient yes & -1.153 & $0.644 *$ & -0.901 & 0.695 \\
\hline Cattle dictator no; recipient no & -0.791 & 0.751 & -0.527 & 0.744 \\
\hline Distance $>1$ (dummy) & 0.128 & 0.497 & 0.720 & 0.770 \\
\hline Size of ego-network (dictator) & - & - & 0.277 & 0.344 \\
\hline Number of ties in ego-network (dictator) & - & - & -0.060 & 0.095 \\
\hline Two step reach (dictator) & - & - & -0.009 & 0.015 \\
\hline Size of ego-network (recipient) & - & - & -0.038 & 0.202 \\
\hline Number of ties in ego-network (recipient) & - & - & 0.017 & 0.052 \\
\hline Two step reach (recipient) & - & - & 0.000 & 0.009 \\
\hline Coins to stranger & 0.477 & $0.083 * * *$ & 0.468 & $0.086^{* * *}$ \\
\hline Number of decision $(\min .=1 ; \max .=5)$ & -0.119 & 0.141 & -0.102 & 0.160 \\
\hline Constant & 3.663 & 2.337 & 2.764 & 2.892 \\
\hline R-squared & 0.4294 & & 0.4453 & \\
\hline $\mathrm{F}$ & 11.46 & & 9.56 & \\
\hline Prob $>$ F & 0.0000 & & 0.0000 & \\
\hline
\end{tabular}

Note. Robust standard errors were obtained by means of two-way clustering (dictator and recipient level); significance levels (two-sided): $*=10 \%, * *=5 \% ; * * *=1 \% ; \mathrm{N}=273$. 
Table 4.11. Dictator giving and extended family networks

\begin{tabular}{|c|c|c|c|c|}
\hline & \multicolumn{2}{|c|}{ Model 3} & \multicolumn{2}{|c|}{ Model 4} \\
\hline & Coef. & S.E. & Coef. & S.E. \\
\hline Dictator $=$ male; recipient $=$ female $($ dummy $)$ & 2.322 & $0.823 * * *$ & 2.336 & $0.737 * * *$ \\
\hline Dictator $=$ male; recipient $=$ male $($ dummy $)$ & 2.760 & $0.880 * * *$ & 2.747 & $0.846^{* * *}$ \\
\hline Dictator $=$ female; recipient $=$ female $($ dummy $)$ & 1.363 & $0.613 * *$ & 1.423 & $0.664 * *$ \\
\hline Age (dictator) & 0.048 & 0.039 & 0.042 & 0.038 \\
\hline Absolute value of difference of age & 0.002 & 0.022 & 0.007 & 0.021 \\
\hline Education (dictator) & 0.008 & 0.132 & -0.058 & 0.132 \\
\hline Absolute value of difference of education & -0.034 & 0.080 & -0.031 & 0.080 \\
\hline Years of residence (dictator) & -0.040 & 0.029 & -0.019 & 0.026 \\
\hline Absolute value of difference of residence & -0.005 & 0.022 & -0.009 & 0.020 \\
\hline Contact with urban centre (dictator) & 0.114 & 0.138 & 0.166 & 0.134 \\
\hline Absolute value of difference of contact urban centre & -0.066 & 0.048 & -0.031 & 0.048 \\
\hline Cattle dictator yes; recipient no & -0.253 & 0.459 & -0.257 & 0.495 \\
\hline Cattle dictator no; recipient yes & -1.026 & 0.641 & -1.043 & 0.694 \\
\hline Cattle dictator no; recipient no & -0.684 & 0.741 & -0.651 & 0.710 \\
\hline Distance $>1$ (dummy) & -2.299 & $1.242 *$ & -14.053 & $2.497 * * *$ \\
\hline Size of ego-network (dictator) & - & - & -1.009 & $0.279 * * *$ \\
\hline Distance $>1$ (dummy) $*$ Size of ego-network (dictator) & - & - & 0.449 & $0.173 * *$ \\
\hline Two step reach (dictator) & - & - & 0.092 & 0.107 \\
\hline Size of ego-network (recipient) & - & - & -1.336 & $0.361 * * *$ \\
\hline $\begin{array}{l}\text { Distance }>1 \text { (dummy) } * \text { Size of ego-network } \\
\text { (recipient) }\end{array}$ & - & - & 1.237 & $0.288 * * *$ \\
\hline Two step reach (recipient) & - & - & 0.018 & 0.059 \\
\hline Coins to stranger & 0.483 & $0.083 * * *$ & 0.500 & $0.085 * * *$ \\
\hline Number of decision $(\min .=1 ; \max .=5)$ & -0.121 & 0.141 & -0.095 & 0.156 \\
\hline Constant & 6.080 & $2.441 * *$ & 18.427 & $2.652 * * *$ \\
\hline R-squared & 0.4352 & & 0.4748 & \\
\hline $\mathrm{F}$ & 11.72 & & 12.59 & \\
\hline Prob $>$ F & 0.0000 & & 0.0000 & \\
\hline
\end{tabular}

Note. Robust standard errors were obtained by means of two-way clustering (dictator and recipient level); significance levels (two-sided): $*=10 \%, * *=5 \% ; * * *=1 \% ; \mathrm{N}=273$. 


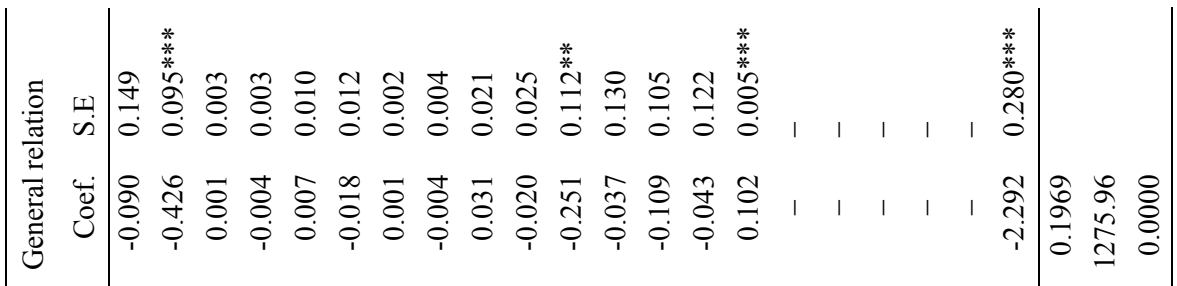

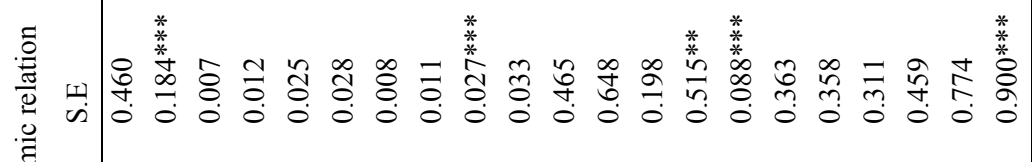

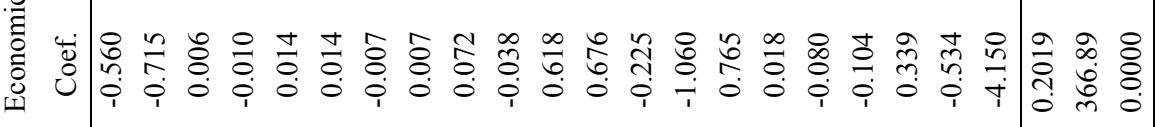

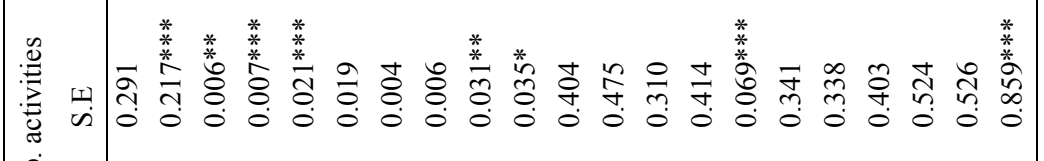

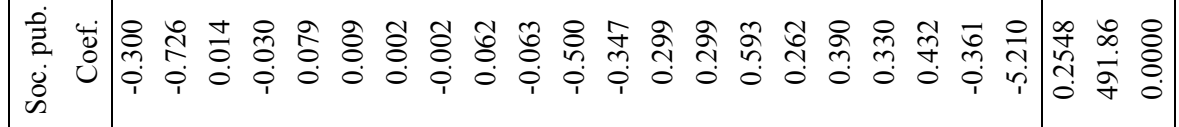

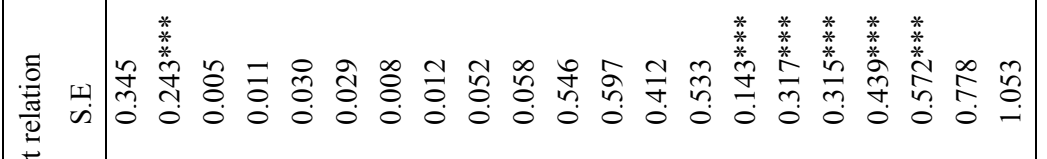

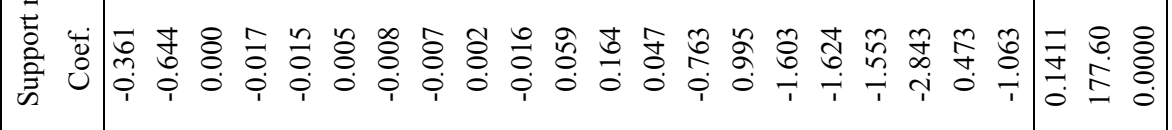

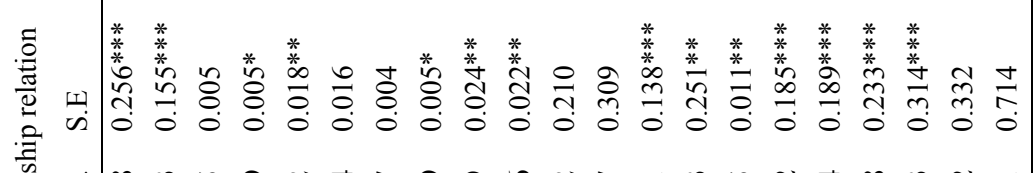

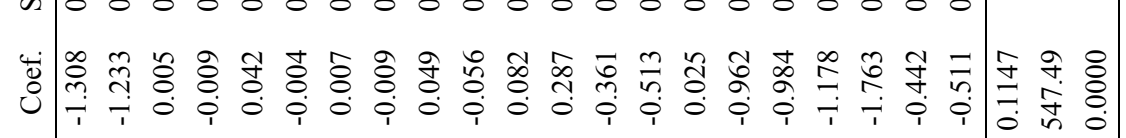

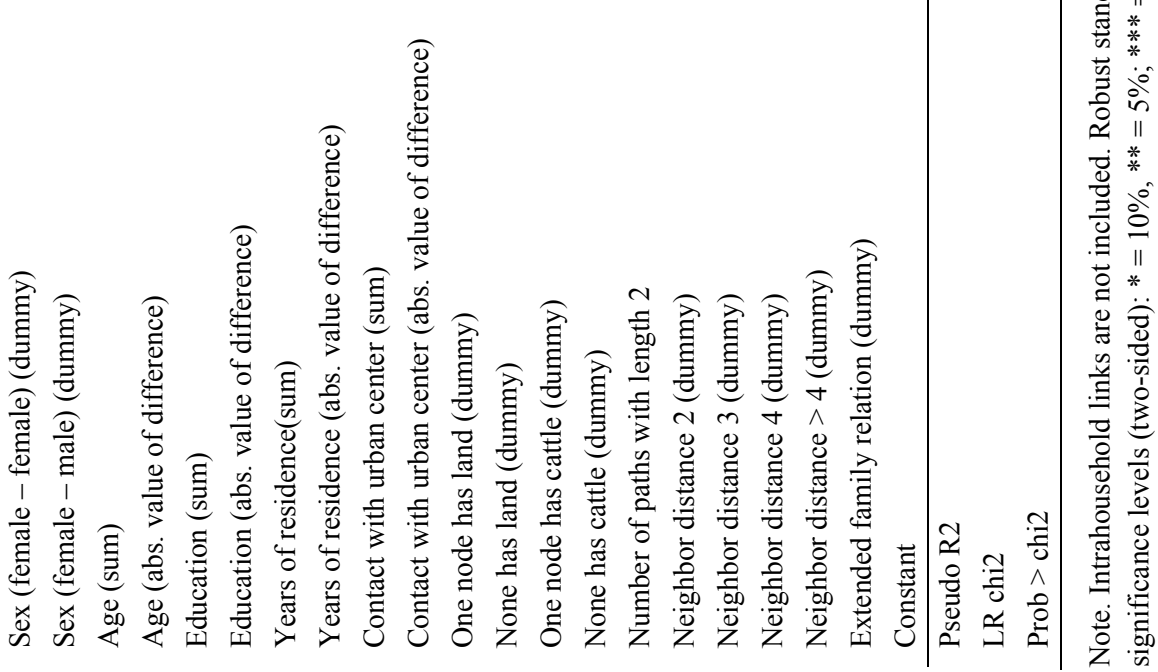




\section{Appendix 2: Experimental instructions}

We now ask you to participate in an experiment in which you can earn money. The amount of money you earn is yours, whatever the amount.

Shortly, I will give you 20 coins of 1 Córdoba and you will be free to divide this amount between yourself and another person. For this, we use this small black box [show the box]. In this box, you will find 20 coins of 1 Córdoba [open the box and show the 20 coins]. You are allowed to take as many coins as you wish. The coins you leave in the box will be given to another person. In particular, we ask you to do the following:

Take the number of you coins you want and leave the coins you want to give to the other person. Fill the box with these small rings and put the lid on the box. In this way, I will not be able to see how many coins you will have left in the box, or to have an idea about it through the weight of the box. The weight of the box will always be the same whatever the amount of coins you leave in the box.

Thereafter, we put a sticker on the box with the name of the person who will get the coins and we put some tape on it to seal the box. I will give the box to my supervisor, who is at the vehicle and who will bring the coins to the other person. Note that you will know the identity of the other person, whereas that other person will NOT know you identity.

I will now give you some arbitrary examples to clarify more the experiment. [Take the coins of one of the boxes and use them during the explication of the examples].

1) You have here 20 coins of 1 Córdoba. Imagine that you decide to take 2 coins out of the box. How many coins will the other person receive? (20 minus 2 equals 18)

2) I will give you another example. Imagine that you decide to take 10 coins out of the box. How many coins will the other person receive? (20 minus 10 equals 10)

3) I will give you a final example. Imagine that you decide to take 20 coins out of the box. How many coins will the other person receive? (20 minus 20 equals 0 ). 
We will repeat this experiment 6 times. Each time, you will be able to take coins and leave coins for the other person, who will each time be a different one. Thus, I will give you 6 boxes of 20 coins to divide between yourself and another person. Each time, this person will be a different one. The first time you will divide the 20 coins with someone from another village in this region. You will not know this person. The other 5 times you will divide 20 coins with someone from your community. Once again, note that these other person will NOT know your identity.

To select the 5 persons of your community, I will ask you to take small cards from this bag. Each card has a different number, and each number corresponds to a different person in the community. After having taken a number, I will look up this number on a list and I will give you the name of that person. Thereafter, I will give you a box with coins, so that you can decide on the number of coins you keep and how many you give to the other person. When taking this decision, I will give you complete privacy. You can go inside your house, (if not possible: I will turn my back so that I will be unable to know your decision; give me a signal when you are ready). Please do not tell me the decision you make.

After having made this decision and having closed the box, you are not allowed anymore to change your decision. At that moment, we will seal the box. Thereafter, we will draw another number from the bag and I will ask you to take the next decision. Do you have any questions at the moment?

I now write the first name on the first box [Ask whether the participant knows this person. If this is the case, select another person. Make sure you are not able to look at the participant when he/she handles the coins. Give him/her privacy. After the participant has made his/her decision seal the box and put the number on the sticker; thereafter the participant will not be allowed to change his/her decision.] 


\section{Appendix 3: Procedures of household survey, network survey and experi- ment}

The following criteria were taken into account to select the experimenterassistants. We selected assistants with research experience in rural areas. They all worked as employee of the research and development institute Nitlapán of the Central American University, we have a close cooperation with. This enabled us to screen the researchers on their dedication, their capacity to work in a systematic way, their trustworthiness and their capacity to radiate trust towards other people (such as the participants in our experiment).

The training of the assistants was crucial as none of them had any prior experience with conducting experiments. To make them familiar with experimental methods we let them play an ultimatum game. Thereafter, we explained them the instructions of our dictator game experiment and let them play a roleplaying game where each assistant acted out the role of dictator and experimenter. The other assistants observed each role-playing session and were allowed to comment afterwards. The aim of this was to come to a common understanding of the experimental procedures. Thereafter, we conducted two different pilots. After each pilot the assistants informed the other assistants about their experience, who could then give their comments or suggestions. One session by one assistant was recorded by video. After these pilots, the video material was shown to the team and allowed us to clear away any remaining vagueness.

To build trust with local people in the village, we started with the household and social network survey. We made ample use of the support of the local wellrespected community leader who before the start of our study presented our team to each household and asked people to cooperate. He also explained the village members that our study was not related with politics, religion or aid projects in any way, and that we would treat the obtained information in a confidential way.

For the household survey we interviewed as many households as possible. If a household head was not present, we interviewed the other household head. For the social network survey we interviewed both household heads (in case of a two-headed household) of as many households as possible. In case one household head was absent we figured out whether he/she would be available within the time span of our field planning and returned to interview this person. This procedure enabled us to obtain satisfactory coverage rates. The good timing of our study was also important in this respect. At the moment of our study most 
temporal migrants had already returned to the village and economic activity was still low as villagers were awaiting the start of the economically more active rain season.

For the social network survey, we used small cards, each representing a household in the village. On each card we put the names of the household heads. In case of two-headed households the names of both husband and wife were put on the card. We asked for each of these cards whether the interviewed person knew the household and whether he/she had a social relation of any kind with one of its members. If a social relation was identified we asked for details on the type of social relation. Before the start of this exercise we had explained the different types of relations (see codes in appendix 6), so that each participant would consider the same types of social relations.

After finishing the household survey and the network survey (which took four days), we immediately organized the experiment. By conducting the experiment in only one day we minimized contagion. To explain the instructions, fixed scripts were used, which were memorized by the assistants (we decided not to read them aloud from paper as this could make participants loosing interest). After explaining the instructions to the participant, some preplay questions were asked to test whether the participant had understood the instructions. We prohibited our assistants to invent other examples than the ones included in the instructions, to make references to the daily life of the participants when explaining the instructions, to make jokes (e.g. about the money the dictator could keep to him/herself) or to remove the tap of one of the small boxes once they were sealed.

We tried to conduct the experiment with as many households as possible, but with only one person per household, as letting two household heads sequentially participate in the experiment puts the door open to contagion. If the selected household head was not present (and would not be present on the same day of our experiment) we selected the other household head in case of a twoheaded household. The assistants also asked some post-experimental questions (see appendix 4) and made a subjective evaluation about the participant's dedication, trust and understanding of the experiment. For this, the following questions were used: experiment?

1. Well dedicated

2. Neutral

3. Aversive; distrust towards the aim of the experiment 


\begin{tabular}{|l|l|}
\hline $\begin{array}{l}\text { 2. Did the participant understand the instruc- } \\
\text { tions? }\end{array}$ & $\begin{array}{l}\text { 1. No problems } \\
\text { 2. Some questions for clarification } \\
\text { 3. I have serious doubts about } \\
\text { whether he/she completely under- } \\
\text { stood them }\end{array}$ \\
\hline $\begin{array}{l}\text { 3. Was he/she reluctant to take a decision? } \\
\text { 4. On average, how much time did he/she take to }\end{array}$ & $\begin{array}{l}\text { 1. Instantly } \\
\text { 2. More than a minute }-[\text { ] } 0 . \text { No } \\
\text { make a decision? }\end{array}$ \\
\hline
\end{tabular}

Other personal observations 


\section{Appendix 4: Post-experimental questionnaire}

1. Please describe how you made your distribution decision. What were the elements you used to take into account when making this decision?

2. What did the experiment remind you of in real life?

3. Did someone of the village who participated before in the experiment, talk to you about the experiment?

[] 1. yes ... [ ] 0. no

If yes, what did you talk about?

\section{A. Economic ranking}

Imagine the richest and the poorest household of the village. We put both households on a straight line with the poorest on the most left-hand side and the richest on the most right-hand side (see figure on next page; show this figure to the peasant). All other households of the village find themselves somewhere on this line. Where would you put yourself? Where would you put . . . (do this for all 5 persons of the experiment he/she was linked with)

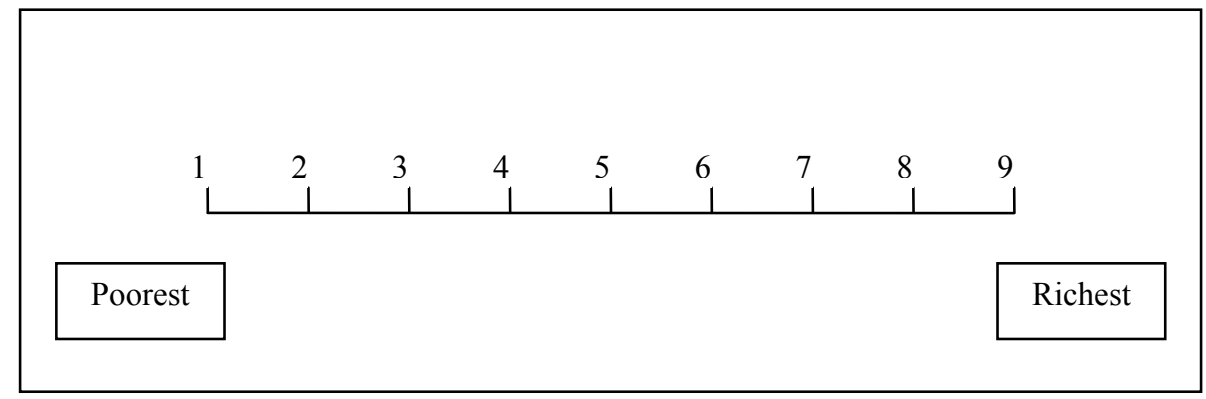




\section{B. Cause of economic welfare}

First go through the first row before starting with the second row, . . !!!

\begin{tabular}{|c|c|c|c|c|c|}
\hline & \multicolumn{5}{|c|}{ Recipients of the experiment } \\
\hline & 1 & 2 & 3 & 4 & 5 \\
\hline $\begin{array}{l}\text { a. According to your opinion, did this person in } \\
\text { recent years have a lot of bad luck affecting him/her } \\
\text { economically? } \\
\text { 1. Quite a lot } \\
\text { 2. Not more than normal } \\
\text { 3. Very little }\end{array}$ & & & & & \\
\hline $\begin{array}{l}\text { b. According to your opinion, has this person spent } \\
\text { time and effort to improve his/her economic } \\
\text { situation? } \\
\text { 1. A lot of effort } \\
\text { 2. Not more than normal } \\
\text { 3. Very little }\end{array}$ & & & & & \\
\hline $\begin{array}{l}\text { c. You talk to this person about any kind of problem } \\
\text { in this village... } \\
\text { 1. Regularly } \\
\text { 2. Sometimes } \\
\text { 3. Very rarely or never }\end{array}$ & & & & & \\
\hline
\end{tabular}

\section{Accountability}

A. Imagine there are two farmers in this village, who have the same age, similar experience and have the same economic activities. Each of them has 1 hectare of land. This year the first one has had a bad harvest so that his production was only $100 \mathrm{~kg}$ of maize, whereas the other farmer obtained a normal production of $200 \mathrm{~kg}$. As a result the first farmer can give his family only one meal per day to eat, whereas the second one does not face any food difficulties. At a certain moment in time, a development program arrives at the village. 
The program gives each farmer 100 US\$. Do you agree with the program's decision?

Agree - 1-2-3-4-5-Disagree

The program gives the poorer farmer 150 US\$ and the other farmer 50 US\$. Do you agree with the program's decision?

Agree $-1-2-3-4-5-$ Disagree

B. Imagine now that the bad harvest of the first farmer is due to a plague of insects.

The program gives each farmer 100 US\$. Do you agree with the program's decision?

Agree - 1-2-3-4-5-Disagree

The program gives the poorer farmer 150 US\$ and the other farmer 50 US\$. Do you agree with the program's decision?

Agree $-1-2-3-4-5-$ Disagree

C. Imagine now that the bad harvest of the first farmer is due to a lack of effort. In comparison with the second farmer he has dedicated little time to his plot.

The program gives each farmer 100 US\$. Do you agree with the program's decision?

Agree - 1-2-3-4-5-Disagree

The program gives the poorer farmer 150 US\$ and the other farmer 50 US\$. Do you agree with the program's decision?

Agree $-1-2-3-4-5-$ Disagree

\section{Trust towards strangers}

Imagine that someone you have never seen before visits your village, for instance someone who proposes you to buy cattle or your harvest. This person 
proposes you to take your cattle or harvest to the market in the urban centre, and after selling it pays you according to the price in the market.

1. Would you accept such proposal? [ ] 1. yes.... [ ] 0. no

2. If you only accept this proposal with a cash advance, what is the minimum percentage that this person needs to give you to accept this proposal? . . . . \% 


\title{
Appendix 5: Household Survey
}

\author{
Number:
}

\section{Name of interviewer:}

Name of the household head:

Replacement:

\section{A. General data}

1. Name of the interviewed person:

2. Sex of the interviewed person:

3. How many years do you live in this village? years

4. Last month, how many times have you been in the urban centre?

\section{B. Household data}

1. How many persons live in your house (during most of the year) and share the same dish?

2. How many of these persons are older than 8 years?

(Only include members older than 8 years!) 


\begin{tabular}{|c|c|c|c|c|c|}
\hline 3. & a. Name & $\begin{array}{l}\text { b. Relation } \\
\text { (family relation with the } \\
\text { interviewed person) } \\
1 \text { = partner } \\
2=\text { father } \\
3=\text { mother } \\
4=\text { son/daughter } \\
5=\text { son/daughter-in-law } \\
6=\text { grandchild } \\
7=\text { grandfather/mother } \\
8=\text { other (specify) }\end{array}$ & c. Sex & d. Age & $\begin{array}{l}\text { e. What is } \\
\text { the last } \\
\text { approved } \\
\text { year of } \\
\text { education? } \\
\left(2^{\text {do }} \text { year }=8\right) \\
\text { Adult } \\
\text { education }= \\
98\end{array}$ \\
\hline 1 & & & $M-F$ & & \\
\hline 2 & & & $M-F$ & & \\
\hline 3 & & & $M-F$ & & \\
\hline 4 & & & $M-F$ & & \\
\hline 5 & & & $M-F$ & & \\
\hline 6 & & & $M-F$ & & \\
\hline 7 & & & $M-F$ & & \\
\hline 8 & & & $M-F$ & & \\
\hline 9 & & & $M-F$ & & \\
\hline 10 & & & $M-F$ & & \\
\hline 11 & & & $M-F$ & & \\
\hline 12 & & & $\mathrm{M}-\mathrm{F}$ & & \\
\hline
\end{tabular}

\section{Economic activities}

\begin{tabular}{|l|l|l|}
\hline $\begin{array}{l}\text { 1. During the entire last year what economic } \\
\text { activities did realize your family? }\end{array}$ & $\begin{array}{l}\text { a.Who realizes this } \\
\text { activity? } \\
\text { Indicate the number on } \\
\text { the list of question 2; } \\
\text { In case of several } \\
\text { members, only indicate } \\
\text { those who take decisions }\end{array}$ & $\begin{array}{l}\text { (in c\$) per year, } \\
\text { after deducting costs }\end{array}$ \\
\hline & & \\
\hline & & \\
\hline
\end{tabular}




\section{Land}

1. Has your family own plots of land? [ ] 1. yes ... [ ] 0. no (go to question 3)

\begin{tabular}{|l|l|}
\hline a. Plot (area) & b. Family member - owner \\
Use numbers on the list of question B3
\end{tabular}

\section{E. Subjective well-being}

1. How do you consider the economic situation of your family?

[] 1. very good

[] 2. good

(read the options)

[ ] 3. regular

[] 4. difficult

[ ] 5. very difficult

2. In comparison with five years ago, your family lives in ...

[ ] 1. a lot better conditions?

[] 2. better

[] 3. similar

(read the options)

[] ]. worse

[] 5. a lot worse

\section{F. Livestock}

1. Do you have cattle? [ ] 1. yes ... [ ] 0. no

2 . How many ... do you have?

\begin{tabular}{|l|l|l|l|l|l|}
\hline a. Cows & b. Heifer & c. Bull calf & d. Young calf & e. Bullock & f. Bull \\
\hline & & & & & \\
\hline
\end{tabular}

3 . How many ... do you have?

\begin{tabular}{|l|l|l|l|l|}
\hline a. Pigs & b. Chicken & c. Turkey & d. Duck & e. Other: \\
\hline & & & & \\
\hline
\end{tabular}




\section{Appendix 6: Network Survey}

We now ask you about the social relations you have with the other households in the village. We have here a pile of cards. Each card represents a household of the village. All households are included in this pile of cards. For each household we will ask you whether you have a social relation with one of its members. If you have a social relation, we will ask you to specify the type of relation. For this, we first explain you all possible types of social relations.

\begin{tabular}{|l|l|l|}
\hline Household & $\begin{array}{l}\text { Do you } \\
\text { know? } \\
\text { 1.yes } \\
\text { 0. no }\end{array}$ & $\begin{array}{l}\text { Relation? } \\
\text { 1.yes } \\
\text { 0. no }\end{array}$ \\
\hline 1 & & \\
\hline 2 & & \\
\hline 3 & & \\
\hline 4 & & \\
\hline 6 & & \\
\hline 8 & & \\
\hline 9 & & \\
\hline 10 & & \\
\hline 11 & & \\
\hline 13 & & \\
\hline 14 & & \\
\hline 15 & & \\
\hline 16 & & \\
\hline 17 & & \\
\hline 18 & & \\
\hline 19 & & \\
\hline 20 & & \\
\hline 21 & & \\
\hline 22 & & \\
\hline
\end{tabular}

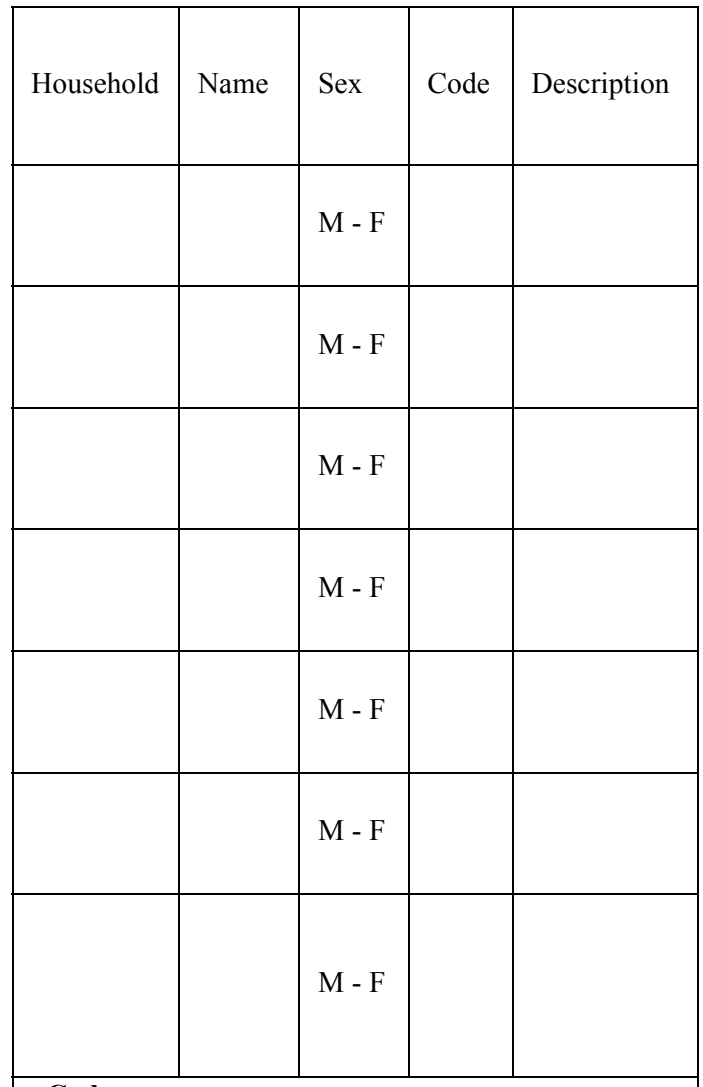

\section{Codes:}

1. Land rental 2. Labour transaction 3. Religion 4. Politics 5. School 6. Sports 7. Cooperatives 8.

Projects 9. Neighbours 10. Family 11. Health 12.

Friendship 13. Support 14. Commercial relation 15. Other, specify 


\section{Social Capital Formation and Economic Inequality: A Laboratory Study}

\section{Introduction ${ }^{47}$}

The results in the previous chapter confirmed that social ties are very important in distributive decision making and exclusionary processes. We also observed that the economically-poorer agents have a lower likelihood of having a social tie with other members in their community, which puts them at a disadvantage when economic resources or opportunities are distributed. To identify the correlations between social ties and economic variables, we implicitly assumed that social ties are dichotomous, and we looked at them in a static way. In reality, however, social ties are not dichotomous and static. They vary in intensity and may be under a continuous process of adaptation. Considering one's friendship ties, for instance, in most cases they are not all equally intense. Some friendship ties may be very intense, whereas others may be less intense. Moreover, some friendship ties dissolve with time while new ones are formed.

In this chapter, we will re-examine the relation between economic inequality and social ties, following these more realistic assumptions. In particular, we study the influence of economic inequality on the formation of social ties and allow for variable tie intensity. For this, we look at the individual decision making behind the formation of social ties. The underlying assumption is that social ties have a functional value from which people obtain benefits, and that

\footnotetext{
${ }^{47}$ I thank Hermann Brandstaetter for the support on the measurement and analysis of the personality characteristics of the participants in the experiment. I benefited from comments of colleagues at MU on the experimental design. I also thank Jeroen Weesie and Vincent Buskens of the Utrecht School of Economics and participants at a BEE meeting at MU for comments on earlier versions of this chapter.
} 
people form social ties because they conceive of them as investments from which they expect a return (Lin, 2001).

An important type of social tie, consistent with this conceptualization and which we will focus on in this chapter, is that formed through the exchange of favours. A favour can be understood as support that is given to a person who has requested this support, and the future repayment of which is indefinite. Support-giving in this form is a common transaction in small-scale societies. Examples extend from personal recommendations or information sharing on the job floor in companies in well-developed economies, to lending small amounts of money, labour and/or food in rural villages confronted with extreme poverty.

To study the formation of networks of social ties through exchanges of favours and the influence of economic inequality, we conduct an experimental repeated 'favour game' with groups of six players. In each round, one player is randomly selected to have the opportunity to request support from one or more of the other five players. Each player who is asked for support decides on the amount of support to give, which is then multiplied with an efficiency factor. We also ask the participants for the support they expect to receive. This enables us to obtain better insights into reciprocity and trust, two closely-related behavioural motives behind support-giving. Economic inequality is introduced in the experiment by allocating different endowments to the participants at the beginning of each round.

Our experimental favour game bears some resemblance to the intensivelystudied trust game. Also, recent extensions to this trust game; that allow for repeated play, endogenous partner selection and economic inequality, have identified mechanisms that are at work in our favour game. An important distinguishing feature of our experiment, however, relates to the variable time interval between the different transfers. According to our experimental results, this has an important behavioural influence, suggesting that people follow certain 'equality matching' over time.

Other results of our experiment confirm that both the decisions to request support and to give support are influenced by direct reciprocity motives and by the individual expectations about future returns, which corroborate our conceptualization of social ties as investments from which people expect a return. Furthermore, we observe that both expected returns and direct reciprocity are somewhat biased by economic inequality. In particular, low-endowment players expect high-endowment players to return more support than other lowendowment players. This explains why they give more support to highendowment players. We also observe that they are more likely to request support from high-endowment players than from other low-endowment players. 
At the same time, high-endowment players give more support to lowendowment players than they receive from them. This difference becomes greater the larger the most recent support they received from low-endowment players. This bias in reciprocity and expected returns lies at the basis of certain centralization in the formed networks. It also explains why in the inequality treatment we observe low and high-support paths. Whereas most groups evolve towards very low support levels, equal or lower than the lowest levels in the equality treatment, groups with high support given early in the game evolve towards very high support levels, exceeding the highest support levels in the equality treatment.

\section{Related literature}

Since the seminal work of Putnam et al. (1993), the concept of social capital has been intensively debated in the social sciences ${ }^{48}$. A large part of this debate has evolved around the conceptualization of social capital, and different, often competing, theories have been formed. Despite the very different views on social capital, according to Lin (2001) there is a premise which is consistent with most social capital theories, and which amounts to "investment in social relations with expected returns in the marketplace". Whatever the type of marketplace (e.g. economic, political, community, etc.), people form social ties because they expect a return from doing so.

Investing in a social tie requires making oneself vulnerable to exploitation by others, so that a minimum level of 'trust' is needed for the investment to be made. We, therefore, expect trust and social ties to be closely-related. Consequently, investments in social ties show some resemblance to the intensivelystudied trust game (Berg et al., 1995; for a recent overview of trust game experiments, see Ostrom \& Walker, 2003) and the similar gift-exchange game (Fehr et al., 1998; Brandts \& Charness, 2004) ${ }^{49}$. Therefore, in the rest of this section we will briefly review the experimental trust game literature and its findings on trust formation. We will pay attention to some recent extensions that have allowed for repeated play, endogenous partner selection and economic

\footnotetext{
${ }^{48}$ For empirical evidence on the role of social capital in development and poverty reduction, see Grootaert \& van Bastelaer (2002).

${ }^{49}$ The formation of social ties has also been experimentally studied in the context of public good games. Sonnemans et al. (2006) and Van Dijk et al. (2002) found that participants, after having played a public good game, were found to have more intense social ties with participants who had contributed more to the public good.
} 
inequality, and that have identified mechanisms that are also at work with social tie formation through favour-giving. Thereafter, we review some elements that distinguish favour-giving from trust games.

In the trust game, one player (the trustor) receives a fixed amount of resources, part or all of which he/she can transfer to a second player (the trustee). The transferred amount is increased and the second player, then, has to decide how much to return to the first player. Standard economic theory predicts that the second player would not return anything, and the first player, anticipating this, would not transfer anything in the first place. This assumes an absence of reciprocity and trust. Evidence in experimental labs, however, has shown that people have a non-negligible initial trust in other people, as considerable proportions ( $50 \%$ in the one-shot trust game) are transferred by the trusters. On average $95 \%$ of the initially invested amount is returned (Camerer, 2003). Recently, extensions have been made to this basic trust game, which allow for repeated play, endogenous partner selection and economic inequality. Through these extensions, mechanisms have been identified that are also at work with social tie formation through favour-giving. We will briefly review them in the rest of this section.

Recently, repeated trust game experiments have been conducted. Comparing it with the one-shot trust game allows the identification of those mechanisms responsible for the reinforcement or break-down of trust. Cochard et al. (2004) used a repeated trust game with fixed pairs of players and compared it with a one-shot trust game. They showed that more is sent $(75 \%$ vs. $50 \%)$ and returned (56\% vs. $38 \%$ ) in comparison with the one-shot trust game (for a similar result on gift-exchange, see Falk et al., 1999). Moreover, at the end of the game, returning behaviour is again similar to the one-shot experiment. They argue that this confirms that, besides reciprocity, strategic anticipation remains important in repeated trust games. Moreover, Engle-Warnick \& Slonim (2006) showed that trust reinforcement needs time, and that it increases with the length of repeated trust games. Players who play longer trust games learn that trusting and reciprocating pays and will, in this sense, adapt their strategies.

In her field experiments in Zimbabwe, Barr (1999) also identified the importance of successful reciprocation on trust levels. She played the trust game in both resettled and non-resettled villages, and observed significantly lesstrusting behaviour in resettled villages. She attributed this result to 'a lack of familiarity and to the consequentially greater uncertainty faced by resettled villagers when trying to predict each other's behaviour in strategic situations'.

Whereas in the one-shot trust game the trustor is driven by trust and the trustee by reciprocity, in a repeated setting both trust and reciprocity may be 
important for all players. In a repeated setting, the support the trustee receives not only influences the support he/she will return through some reciprocity motive. The trustee may also consider the support he/she receives as returned support, which may influence his/her trust as a belief about the support the trustor will reciprocate. Consequently, it becomes difficult to distinguish between reciprocity and trust. Actually, both motives are intrinsically related. In a repeated setting, trust is updated by what people have received in previous interaction. As Alesina \& La Ferrara (2002: 209) put it: “... trust may be based on past experience. One trusts others if he is used to be treated fairly by his fellow men. This is a sort of a reciprocity argument for trust."

In contrast with most trust games where the trustor is randomly paired with one trustee, in reality people themselves select the persons they request support from. Recent experimental trust game studies on the influence of endogenous partner selection are interesting in this respect. Bornhorst et al. (2004) played a repeated trust game with multiple players. In each round players can freely choose one and only one of the other players with whom to interact. In their experiment, the amounts sent are higher than in the one-shot game (also confirmed by Eckel \& Wilson, 2000), and people tend to interchange more; the more rounds they manage to continue reciprocating with each other.

A final extension to the basic trust game, which might be of interest for our study, relates to the influence of economic inequality between trustor and trustee. When behaving reciprocally or trusting others, people may also take account of their economic position relative to others, possibly causing a bias in reciprocity and trust. Only recently, however, has trust game literature started to pay attention to inequality and other-regarding preferences. This interest came with the doubts thrown on the explanatory power of trust and trustworthiness in trust games. More particularly, trust-like behaviour in trust games might also be explained by social preferences instead of real trust (i.e. as an expectation of reciprocity by the trustee). The investments made by trustors in trust games might be the result of both trusting other people (that they would reciprocate) and (outcome-based) other-regarding preferences. Also, the return by the trustees might be the result of both reciprocity and other-regarding preferences.

Gneezy et al. (2000) confirmed the importance of trust and reciprocity in the trust game. By varying the upper bound on repayments for the trustees, they observed more trusting behaviour in treatments with higher possible repayments. At the same time, they did not completely refute the distributional preferences hypothesis. Cox (2004) elaborated a triadic design to disentangle both effects for single-game trust experiments. He observed significant explanatory power of trust, reciprocity and social preferences. 
In trust game experiments with economic (endowment) inequality, social preferences might come more into prominence, which might also influence trust and reciprocity. Interesting questions become then, whether an economically worse-off player should always reciprocate a favour, and if not, whether the better-off would then be inclined to offer support to the worse-off, in the first place. A similar question would be whether economically better-off players reciprocate more than worse-off players, and if this is the case whether worseoff players would therefore invest more in the better-off.

An important trust game experiment that allows for inequality is Brülhart \& Usunier (2004). They conducted a one-shot trust game experiment with different show-up fees. They let trustors play simultaneously with a poor and a rich trustee. They did not find a significant negative relationship between the amount transferred by the trustor and the trustee's wealth. Anderson et al. (2005) also conducted a trust game experiment with economic inequality created by different show-up fees. Letting participants play a repeated trust game, with constant roles but with each player randomly re-paired each round, they did not find a statistically significant effect on the behaviour of the trustor, but they found that trustees with lower show-up fees return somewhat less.

An important feature which distinguishes 'favour-giving' from trust games and constitutes an important innovation in our research is related to the sequence of the different transfers. In contrast with trust games, every favour is not automatically followed by an opportunity for the opponent to reciprocate. With favour-giving the decision moment of the opponent is not determined a priori. Fate determines who is able to request support, and the person who is able to request support is not obliged to request support from the person he/she received support from. Thus, requesting support is an important condition for favourgiving, which it is not for trust games.

This implies that the time interval between support-giving and supportreceiving is variable, and it is not guaranteed that every act of support is followed by an opportunity to reciprocate. For instance, before providing an opportunity to reciprocate, fate can attribute a second need for support to the same person. We expect that those who are able to request support in two consecutive occasions may receive lower levels of support the second time, if support was not yet reciprocated. As explained by Fiske (1992: 705), people tend to follow an 'equality matching' principle: "People think about how much they have to give to reciprocate or compensate others to come out even with them. Equality matching always entails some kind of additive tally of who owes what and who is entitled to what". 
After this short literature review, we present in a next section the design of our experiment. Thereafter we present the empirical results. A final section summarizes our main results and concludes.

\section{Experimental design}

To experimentally study the formation of networks of social ties through favourgiving and investigate how it is influenced by endowment inequality we set-up an experimental repeated favour game. We group participants in groups of six. Group composition remains unchanged. In each round, all players receive a constant and individual endowment, which is public knowledge. In each round, the computer randomly chooses one group member to be the investment player ${ }^{50}$, who is allowed to ask (at a positive but low cost) one or more of the other five players for support (called 'support players'). Each support player that is asked for support can transfer part or all of his/her endowment to the 'investment person'. Transferred resources are multiplied by $1.4^{51}$.

Each round consists of the following six steps:

$1{ }^{\circ}$ step: The computer randomly selects the 'investment player' in the current round.

$2^{\circ}$ step: The investment player decides from whom of the other persons ('support players') to request support. Each request for support costs five 'francs'. Before taking this decision the investment player may review all past interactions he/she had with all other players.

30 step: The investment player is asked how much he/she expects to receive from each of the players he/she asks for support.

4 step: Each support player who is asked for support decides how much of his/her endowment to transfer to the 'investment player'. Before taking this

\footnotetext{
${ }^{50}$ In the experiment we told the participants that this person faces an investment opportunity for which he/she needs the support of the other group members.

${ }^{51}$ Note that this differs from the trust game where only the transfer from the trustor to the trustee entails an efficiency gain whereas the return from the trustee to the trustor does not. In our favor game, in contrast, every transfer is multiplied with an efficiency parameter. This is consistent with the fact that in each round we have a new investment opportunity, for which support from other group members is required.
} 
decision each support player may review all past interactions he/she had with the other players.

$5^{\circ}$ step: After taking the support decision, each 'support player' is asked how much he/she expects the investment player to transfer to him/her when the roles would be reversed in one of the future rounds, i.e. when the support player faces an investment opportunity and asks the current investment player for support.

$6^{\circ}$ step: Each 'investment player' receives information on the transfers he/she received from the 'support players' he/she asked for support. The investment player's 'earnings' are then equal to the total received support (after multiplication by 1.4) plus their endowment minus the costs of requesting support.

The experiment lasts 30 rounds, which is public knowledge before the start of the experiment. To study the influence of economic inequality we organized two treatments $^{52}$, one with economic equality and another with economic inequality. Economic inequality is introduced in the experiment by allocating different endowments to the participants at the beginning of each round. More particularly:

1- Equal endowments: six participants receive 100 'francs' each at the beginning of each round

2- Unequal endowments: five participants receive 80 'francs' each and one participant receives 200 'francs' at the beginning of each round ${ }^{53}$.

The endowment a player receives at the beginning of each round is fixed throughout all 30 rounds and is determined before the start of the first round in a

\footnotetext{
${ }^{52}$ We guaranteed that the sequences of the randomly chosen investment players were pair wise the same between both treatments. In particular, for each group in the equality treatment we have a group in the inequality treatment with the same sequence of randomly selected investment players. That these sequences were prepared before the start of the experiment does not imply any form of deception, because this does not change that investment players were indeed selected randomly, as was explained to the participants in the instructions (see appendix 1 for instructions and procedures).

${ }^{53}$ As we want to isolate the effect of inequality the total endowment in each group (600 'francs') is the same in both treatments.
} 
completely arbitrary way ${ }^{54}$. Information on these endowments is public. To reduce spill-over effects from support decisions (e.g. through imitation), information on the support transfers is private. This information is only accessible for the players directly involved. In other words, the investment player obtains information on the support received from individual support players and the support players have information on the support they have given but not on the support the other players have given.

As we expect personality characteristics of the participants to influence their decision-making in this experiment, we included a list of personality questions in the post-experimental questionnaire, which was created and tested by Brandstätter (1988; see also Brandstätter \& Königstein, 2001). Students are asked to self-report on their personality on 16 primary personality adjective scales, which are converted into 5 global personality dimensions (see appendix 2 for a description of the global personality dimensions) ${ }^{55}$. Before the experiment, subjects also participated in a circle test (Offerman et al., 1996) to measure their social value orientation towards a 'generalized other'.

The experiment was conducted in the behavioural computer lab of Maastricht University in spring 2006. It was computerized using Z-tree software (Fischbacher, 2007). In total 132 students participated in 22 groups, most of them students in economics and business administration, all at Maastricht University. Average age was 22.5 with a minimum of 18 and maximum of 34 . $53 \%$ of the participants were male. Students had not participated in a similar experiment before. Each session took between 90 and 120 minutes and average earnings were 17.91 Euros, with the highest earnings 36.80 Euros and lowest earnings 11.40 Euros. More detailed experimental procedures and the instructions can be found in Appendix 1.

\section{Empirical findings}

This empirical section is structured in the following way. We start with some descriptive statistics. We then proceed with an analysis of the density of the formed networks of social ties and its evolution over time. Thereafter, we look

\footnotetext{
${ }^{54}$ Thus, inequality is difficult to justify morally. In reality, however, it is common that economic inequality is justified by certain actors. This might reduce the influence of inequality. Therefore, we decide to include this somewhat more extreme case (where economic inequality is determined ad random) and to compare it with a situation with complete equality.

${ }^{55}$ This list can be filled in within a short period of time ( 5 minutes) and is therefore very useful as part of a post-experimental questionnaire.
} 
at the determinants of individual decision-making behind social tie formation. Recall that the formation of a directed tie between two agents is made by two consecutive decisions. First, the investment player has to ask a support player for support, and second, conditional on being asked for support the support player decides on the amount of support to give. Both decisions will be examined in two consecutive subsections. We then return to the density of the formed networks and use our findings on individual decision-making to explain the large diversity across groups we observed. Finally, we look at the implications of individual decision-making for the network structures and the final economic distribution between the group members.

Pooling all support decisions over all rounds and players, Table 5.1 presents the mean and the standard deviations of the given support and the expected return, grouped by the different combinations of the endowments of support player and investment player ${ }^{56}$. The following observations are important. First, the average support 80 -endowment players give to 200 -endowment players, $\mathrm{S}(80-200)^{57}$, is clearly higher than the average support they give to other 80 endowment players, $\mathrm{S}(80-80)$. Second, the support 80-endowment players expect to receive from 200-endowment players is substantially higher in comparison with the other endowment combinations. Third, in all endowment combinations except for 200-80 the expected returns are higher than the given support. 200-endowment players expect to receive less from 80-endowment players than what they give to them. Putting all observations together, this suggests that inequality exerts an important influence on the support that is given and the support that is expected to receive in return.

Table 5.1. Descriptive statistics

\begin{tabular}{lc|ccc}
\hline \multirow{2}{*}{ Treatment } & Equality & \multicolumn{3}{|c}{ Inequality } \\
\hline & $100-100$ & $80-80$ & $80-200$ & $200-80$ \\
\hline \multirow{2}{*}{ Mean support (st.dev.) } & 31.61 & 22.49 & 31.96 & 37.10 \\
& $(30.41)$ & $(23.16)$ & $(27.51)$ & $(28.86)$ \\
Mean expected return (st.dev.) & 36.40 & 29.35 & 50.78 & 33.07 \\
& $(31.46)$ & $(25.85)$ & $(44.24)$ & $(25.02)$ \\
\hline
\end{tabular}

${ }^{56}$ For all empirical analyses in this chapter, support is measured before multiplication by the efficiency factor, unless otherwise stated.

${ }^{57} \mathrm{~S}(\mathrm{x}-\mathrm{y})$ refers to the support players with endowment $\mathrm{x}$ give to players with endowment $\mathrm{y}$. 


\subsection{The evolution of network density}

In this section, we look at the density of the formed networks of social ties and compare it between both treatments. To study the social ties in our favour game, we need to take account of two aspects that are important for each (directed) tie: 1) whether player $\mathrm{j}$ requests support from player $\mathrm{i}$ in a certain round t, i.e. $r_{j i}^{t}=1$, otherwise $r_{j i}^{t}=0$

2) the amount of support $s_{i j}^{t}$ player i gives to player $\mathrm{j}$ in round $\mathrm{t}$.

While the first variable is dichotomous, the second is 'continuous' and allows us to study the strength of a directed tie. To study a directed tie $d_{i j}^{t}$ from $\mathrm{i}$ to $\mathrm{j}$ over time, we apply the following updating formula:

$$
\begin{aligned}
& d_{i j}^{t}=d_{i j}^{t-1} \text { if } r_{j i}^{t}=0 \\
& d_{i j}^{t}=s_{i j}^{t} \text { if } r_{j i}^{t}=1
\end{aligned}
$$

with $r_{j i}^{t}=1$ if player $\mathrm{j}$ has an investment opportunity and asks player $\mathrm{i}$ for support, otherwise $r_{j i}^{t}=0$. Thus, if $\mathrm{j}$ faces an investment opportunity but does not request support from $i$, we assume that the tie strength remains unchanged. The reason for this is that the trust relation is not put to the test and therefore the tie strength is expected to remain constant ${ }^{58}$.

As a measure of the density of the formed networks of social ties, we use the group aggregated tie strength, i.e. the sum of the intensities of all directed ties in a group. We normalized this variable by the maximum attainable group aggregated tie strength, taking into account that only players that have had an investment opportunity are able to receive support. Figure 5.1 plots this variable for each group over time and by treatment.

The following observations are important. First, in the last 5 rounds, group aggregated tie strength sharply declines. This indicates that favours are only important as long as the game is repeated. Once the end of the game comes close support players may anticipate that they will not receive anything in return anymore. This is consistent with the premise that social capital is formed by investments in social relations. Social relations have a functional value as long

\footnotetext{
${ }^{58}$ One could argue that the tie strength between an investment player and a particular support player decreases if the investment player when having a new investment opportunity does not request support again from the support player. However, as we will see in next section, the average probability that an investment player does not request support again from a particular support player when he/she has already done so in a previous investment opportunity is very low (around $20 \%$ ) and decreases the more support he/she has received before from the support player.
} 
as they are profitable (Lin, 2001). That is why support levels drop once their expected return decreases, which is the case at the end of the game.

Second, we observe large variation across the groups. In both treatments, there are groups that reach a considerably high level, with levels of up to about $50 \%$ of the maximum attainable level, whereas other groups remain at very low levels.

Figure 5.1. The evolution of group aggregated tie strength
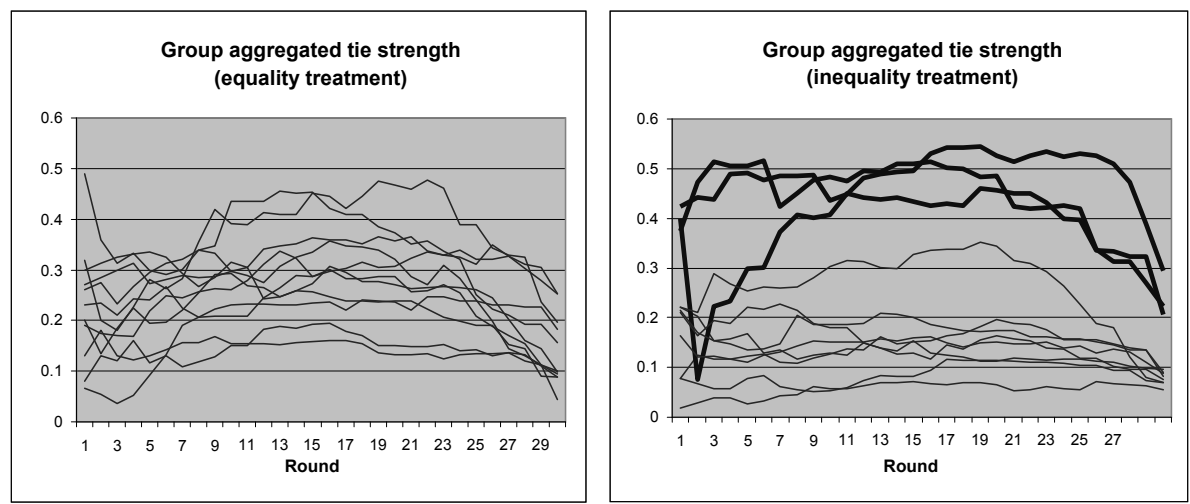

Third, we observe that in the inequality treatment most groups have support levels that are equal or lower than the lowest support levels in the equality treatment. Average levels, however, are not significantly different between both treatments. Calculating for each group the average group aggregated tie strength between rounds 15 and $25^{59}$, this variable is not significantly different between both treatments (Mann-Whitney $\mathrm{U}=46.0$; two-sided $\mathrm{P}=.365$ ). This is the result of a few groups in the inequality treatment which attain support levels that are even higher than the highest support levels in the equality treatment (the thick line in Figure 5.1).

In other words, in the inequality treatment one can identify low and high trajectories. Consequently, when studying the influence of inequality on the formation of social ties, it becomes crucial to know what conditions drive an economically unequal group to a higher or a lower support path. We will come back to this question at the end of this empirical section, after having studied individual decision-making behind support-giving and support-requesting.

\footnotetext{
${ }^{59}$ We select these rounds, as we expect social ties to be most stable then. After round 25 directed tie intensities tend to drop drastically, whereas before round 15 support decisions may be relatively more volatile as some players have not had any investment opportunity yet.
} 


\subsection{Requesting support}

As explained before, the formation of a directed tie $d_{i j}^{t}$ from player $\mathrm{i}$ to player $\mathrm{j}$ depends on two consecutive decisions. First, player $\mathrm{j}$ when facing an investment opportunity has to decide whether to ask player i for support. Second, only then can player i decide on the amount of support to give to $\mathrm{j}$. In our analysis, we deal separately with both decisions. In this section, we address what drives people to ask a particular other group member for support, whereas in the next section we look at the determinants behind support-giving conditional on being asked for support.

Table 5.2. Number of requests for support when facing an investment opportunity

\begin{tabular}{lll}
\hline & $\#$ & Percent \\
\hline 0 & 9 & $1.36 \%$ \\
1 & 17 & $2.58 \%$ \\
2 & 67 & $10.15 \%$ \\
3 & 116 & $17.58 \%$ \\
4 & 144 & $21.82 \%$ \\
5 & 307 & $46.52 \%$ \\
\hline Total & 660 & $100.00 \%$ \\
\hline
\end{tabular}

Note. Pooling all investment opportunities over all groups, rounds and both treatments

Table 5.2 indicates that in about half of the cases investment players request support from all five other players in their group. This may not be too surprising, given the low cost of asking another person for support (only 5 'francs' for each support request) and the potentially high benefits. In the other half of the cases the investment player does not request support from all other group members. At the dyad level, in $20.91 \%$ of the potential requests for support $(660 \times 5=3300)$ the investment player does not ask the support player for support. As requesting support is a necessary condition for ties to be formed at all, it is of interest to study what drives an investment person to request support from a particular other group member.

For this, we examine a probit regression model with the following explanatory variables. First, we control for the support received the previous time the investment person had requested support from that group member. Given the nature of social capital as investments in social ties, we expect that the lower the support received from a support person, the less inclined an investment player will be to ask this person for support again. Second, investment players may 
follow a certain reciprocity logic when requesting support from support players. In particular, an investment player may be more reluctant to request support from a particular group member if the latter has never asked him/her for support before while having the opportunity to do so. Furthermore, we add dummies for the endowments of both the investment person and the group member that may be asked for support. We also add time dummies and we control for the personality characteristics ${ }^{60}$ of the investment person.

Before presenting the results, we provide some details about the model estimation. The error terms of all decisions of a specific support-giver tend to be correlated due to omitted variables. Due to the random sequence of the investment player selection and the fact that investment players do not necessarily request the support from all other group members our data are too unbalanced to estimate a panel data model. For that reason we correct for the dependencies of the errors in another way. To guarantee correct standard errors, we use robust (Huber-White) standard errors ${ }^{61}$. As decisions of different players may also be correlated within the same group, we decide to use robust standard errors at the group level instead of the individual level. The same procedure will be applied to all other regression models in this chapter.

Table 5.3 shows the results of a probit regression, which estimates the probability that an investment person requests support from a particular group member. We estimate two separate models: one model with only the dyads where the investment person has not yet requested support from the other group member, and a second model with only the dyads where the investment player has already requested support at least once before from the other group member. We do this, because we can only control for the 'most recent support received' (an important variable we expect to influence the investment player's decision), if the investment player has already requested support from the other group member before.

In the first model, we observe that the probability that 'ego' requests support from 'alter' is $25.8 \%$ lower if 'alter' has not requested support from

\footnotetext{
${ }^{60}$ In another model (not shown) we also controlled for the age and the sex of the investment player. Coefficients were not significant and close to zero, whereas the model was robust to adding these variables. We therefore do not include them in this model.

${ }^{61}$ We could make specific assumptions about the type of autocorrelation between the decisions of the same investment player. However, as the selection of investment player is completely at random, autocorrelation can have a very complex structure. We therefore prefer not to make any assumptions about autocorrelation in the model and we use robust standard errors, which deals in a conservative way with these dependencies.
} 
'ego' before but had the opportunity to do so, i.e. he/she had an investment opportunity. The same effect is present in the second model.

Previously received support is an important determinant of requesting support again (model 2). The larger the previously received support the higher the probability of requesting support again. This is consistent with the conceptualization of social capital as investment in social ties. People seem to select deliberately people with whom they can make profits.

Table 5.3. Requesting support in directed ties

\begin{tabular}{|c|c|c|c|c|}
\hline \multirow{3}{*}{ Had already requested support before? } & \multirow{2}{*}{\multicolumn{2}{|c|}{$\begin{array}{l}\text { Model } 1 . \\
\text { No }\end{array}$}} & \multirow{2}{*}{\multicolumn{2}{|c|}{$\begin{array}{c}\text { Model } 2 . \\
\text { Yes }\end{array}$}} \\
\hline & & & & \\
\hline & $\begin{array}{l}\text { Marg. } \\
\text { Prob. }\end{array}$ & S.E. & $\begin{array}{l}\text { Marg. } \\
\text { Prob. }\end{array}$ & S.E. \\
\hline Alter did not ask for support but had the opportunity & -0.258 & $0.126^{* *}$ & -0.320 & $0.073 * * *$ \\
\hline Most recent received support & - & - & 0.006 & $0.001 * * *$ \\
\hline $100-100$ (dummy) & -0.117 & 0.119 & -0.027 & 0.070 \\
\hline $80-80$ (dummy) & -0.259 & $0.063 * * *$ & -0.058 & 0.087 \\
\hline $200-80$ (dummy) & -0.135 & 0.093 & -0.071 & 0.053 \\
\hline Personality (self-control) & 0.010 & 0.038 & 0.009 & 0.016 \\
\hline Personality (anxiety) & -0.030 & 0.016 & -0.006 & 0.009 \\
\hline Personality (independence) & 0.031 & $0.015^{* *}$ & -0.002 & 0.012 \\
\hline Personality (tough-mindedness) & -0.010 & 0.039 & -0.040 & $0.013 * * *$ \\
\hline Personality (extraversion) & 0.015 & 0.024 & -0.006 & 0.011 \\
\hline Round 6-10 (dummy) & -0.052 & 0.080 & 0.114 & $0.022 * * *$ \\
\hline Round 11-15 (dummy) & -0.246 & 0.084 & 0.091 & $0.037 * *$ \\
\hline Round 16-20 (dummy) & -0.337 & $0.137 * * *$ & 0.085 & $0.035^{* *}$ \\
\hline Round 21-25 (dummy) & -0.477 & $0.229 * * *$ & 0.044 & 0.035 \\
\hline Round 26-30 (dummy) & -0.736 & $0.049 * *$ & -0.069 & 0.049 \\
\hline $\mathrm{N}$ & 704 & & 1996 & \\
\hline Pseudo R-squared & 0.1986 & & 0.1768 & \\
\hline Prob $>$ chi2 & 0.0000 & & 0.0000 & \\
\hline Wald chi2 & 507.90 & & 634.38 & \\
\hline Observed probability & .7386 & & .7921 & \\
\hline
\end{tabular}

Note. Probit regression with robust standard errors to correct for intra-group correlations. Significance levels (two-sided): $*=10 \%, * *=5 \% ; * * *=1 \%$.

We also observe that, when support is requested for the first time (model 1), 80endowment players have a $25.9 \%$ lower probability to request support from 
another 80 -endowment player than from a 200 -endowment player. This suggests that they expect to receive more support from 200-endowment players. As we only have data on the expected support for those who decided to request support, we cannot do any test on this. However, as will be demonstrated later, similar differences in expectations are observed when they have to decide on the support to give before having had a possibility to request support.

This endowment effect disappears once support has already been requested before (model 2). We can assume that the investment player when having requested support before, did so because he/she expected to receive sufficient support from the support player, so that possible differences in expectations between high and low-endowment player are not determinant anymore when deciding to request support (again).

Other interesting results are related to the influence of the individual characteristics of the investment player. According to the regression results, people with higher values on 'independence' are more inclined to request support from a particular group member if they have not done so before. As suggested by the description of this personality characteristic in appendix 2 , this may be due to their lower inhibition by social considerateness or fear of conflicts. In the second model we observe that keeping all other variables constant investment players with higher values on 'tough-mindedness' are somewhat less likely to request support from a particular support player if they have already done so before. They are thus more likely to switch their decision. Support players may interpret such behaviour as a signal that their behaviour was not approved of by the investment player. As suggested by the description of this personality characteristic in appendix 2, 'tough-minded' people have lower empathy and may therefore care less about such possible interpretation by the other group member.

Furthermore, we observe that the probability of requesting support changes over time. In the first model, time has a negative effect on the probability of requesting support. The more rounds have passed while the investment player has not yet requested support from a particular group member, the less likely it becomes that the investment person will still request support. Moreover, the probability of requesting support sharply declines in the last five rounds, where it becomes $70 \%$ less likely that support is requested in comparison with the first five rounds. This suggests that investment players anticipate an end-game effect. It is very unlikely that investment players suddenly request support in the last rounds if they have not done before and if they anticipate support levels to decline in the last rounds (see more on this in next section). 
In the second model, we observe that in comparison with the first five rounds, the probability that the investment player requests support becomes $10 \%$ higher after round 5 up to round 20. If an investment player within the first five rounds has to decide whether to ask a particular group member for support while he/she has already requested support from this person before, the same investment person faces two investment opportunities in a relatively short term. The results suggest that on average investment persons are relatively less inclined to ask the same group member two times for support in such a relatively short time period. This confirms that certain 'equality matching' over time is taken into account by the investment player. Furthermore, in the last ten rounds this difference with the first five rounds disappears. The probability of requesting support again from a particular support player declines due to an anticipated end-game effect and is therefore not significantly different anymore from the first five rounds.

\subsection{Giving support}

In this section, we examine determinants of support-giving ${ }^{62}$. A first important element people may consider when deciding on the amount of support to give is their expectations about future returns. Moreover, based on the large experimental literature which confirms the importance of reciprocity in human interaction, we also expect reciprocity to be an important determinant behind supportgiving. The influence of these determinants might be contingent on the number of investment opportunities one has had before, because expectations about future returns can only be updated when a player faces an investment opportunity and asks other players for support.

For these reasons, when looking at these and other determinants of supportgiving we structure this section in the following way. In a first subsection we study whether there is a general upwards or downwards tendency of supportgiving by the number of investment opportunities one has had before. We then build explanatory models on support-giving (both in absolute and relative terms) and its difference with expected returns. Here we differentiate between the situation before and after having had the first investment opportunity, as only after having received support for the first time, may reciprocity start to influence

\footnotetext{
${ }^{62}$ The analyses in this section look at support-giving and thus only consider those cases where a support player is asked for support by the investment player.
} 
individual decision-making. These situations will be separately studied in a second and third subsection.

\section{a. Support-giving and the number of preceding investment opportunities}

In this section, we test whether there is a general influence of the number of preceding investment opportunities on individual support decisions. For this, we compare the average support levels by the number of preceding investment opportunities of the support player ${ }^{63}$. As individual support decisions are not independent within a group, we look at group averages. In addition, we disaggregate this variable for the different endowment combinations of support player and investment player.

Figure 5.2. Support and preceding investment opportunities

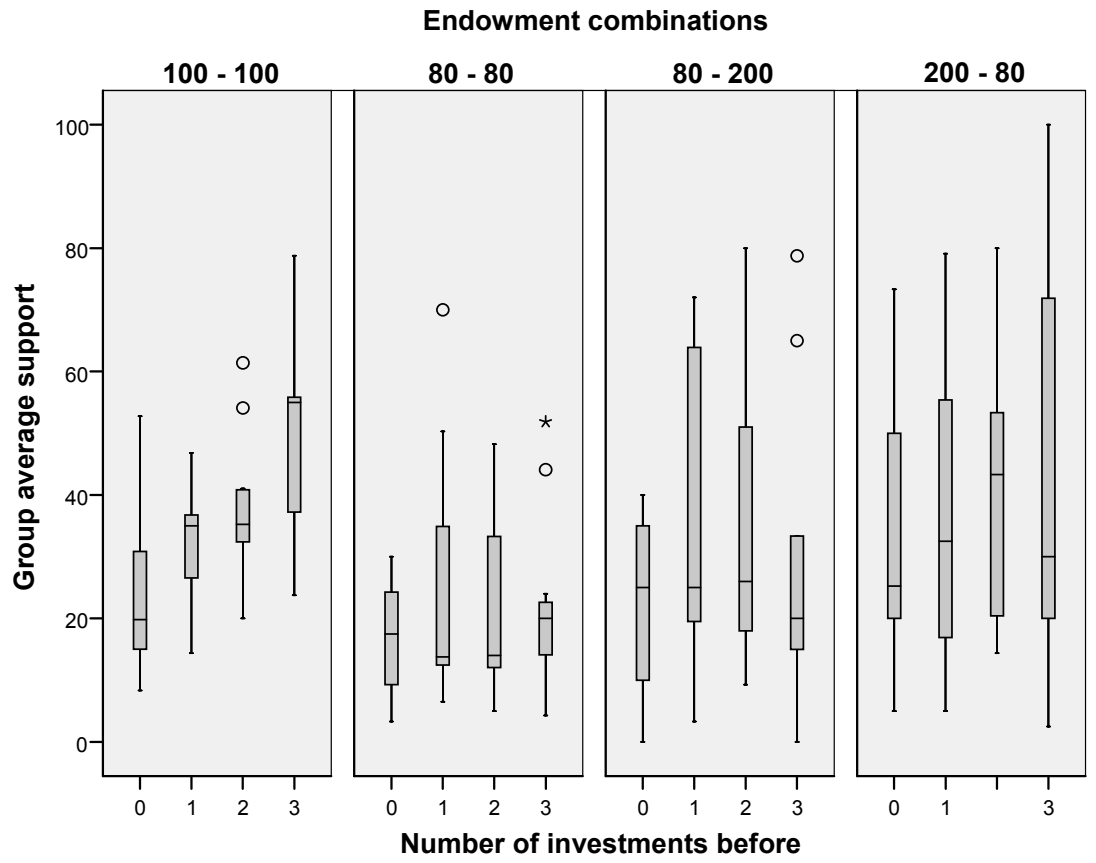

\footnotetext{
${ }^{63} \mathrm{We}$ only include support decisions before round 25 to exclude any end-game effect. From this round onwards it becomes more likely that one ends with supporting other persons without receiving a return. Round 25 may be focal as from this round there are still 6 rounds to go, equal to the number of players in each group.
} 
Figure 5.2 shows a box-plot of the group averages of the given support by the number of preceding investment opportunities and by endowment combination. In the 100-100 endowment combination, we observe a positive and significant correlation between the support levels and the number of investment opportunities the support player had before (Spearman's rho $=0.596$; two-sided $\mathrm{P}=.000$ ). This upwards tendency of support-giving with each investment opportunity, may be the result of the fact that trust formation requires time. Part of these dynamics may also be due to the fact that - as previously confirmed - people who give little support are not asked for support again and therefore are excluded from the observations. In the inequality treatment, in contrast, this correlation is much lower and statistically insignificant for all endowment combinations (for 80-80 Spearman's rho $=0.106$, two-sided $\mathrm{P}=.495$; for 80 200 Spearman's rho $=0.047$, two-sided $\mathrm{P}=.766$; for 200-80 Spearman's rho $=$ 0.099 , two-sided $\mathrm{P}=.572$ ).

\section{b. Support-giving before first investment opportunity}

To study the individual decision-making behind support-giving before the first investment opportunity, we pool all support decisions before the support players' first investment opportunity over all rounds and both treatments. We estimate three different OLS models, all having the same explanatory variables but each with a different dependent variable. In the first two models, we examine the support provided by the support player in absolute terms and in terms relative to his/her endowment. In a third model we look at the difference between the given support and the expected support in return. This model gives us insight in the importance of expected returns when support players decide on the amount of support to give.

In each model we control for the endowment combination of support player and investment player. The benchmark endowment combination is the situation where support is given by 80 -endowment players to 200 -endowment players. We also control for sex, age and personality characteristics of the support player. Here we also control for the decisions made in the circle test. In particular, we use the angle of the distribution decision made in this social value orientation test, with a higher angle indicating a higher orientation towards a 'generalized other'.

Finally, we control for the number of times the support player has given support before to the current investment player ('Times support before'). Due to the randomness of the selection of the investment player it is possible that a 
specific support player is repeatedly asked for support by the same player while the support player has not yet had any investment opportunity. If support players follow certain 'equality matching' over time we expect that support players who have not had any investment opportunity will lower their support the more times the investment player has asked them for support before.

Table 5.4. Support given before first investment opportunity

\begin{tabular}{|c|c|c|c|c|c|c|}
\hline & \multicolumn{2}{|c|}{$\begin{array}{l}\text { Model } 1 . \\
\text { Support }\end{array}$} & \multicolumn{2}{|c|}{$\begin{array}{c}\text { Model } 2 . \\
\text { Support / own } \\
\text { endowment }\end{array}$} & \multicolumn{2}{|c|}{$\begin{array}{c}\text { Model } 3 . \\
\text { Support - expected } \\
\text { return }\end{array}$} \\
\hline & Coef. & S.E. & Coef. & S.E. & Coef. & S.E. \\
\hline 100 - 100 (dummy) & -5.305 & 3.303 & -0.123 & $0.034 * * *$ & 18.654 & $6.304 * * *$ \\
\hline $80-80$ (dummy) & -11.598 & $2.078 * * *$ & -0.143 & $0.024 * * *$ & 13.179 & $4.739 * *$ \\
\hline $200-80$ (dummy) & 6.116 & 8.042 & -0.146 & $0.064 * *$ & 30.765 & $9.149 * * *$ \\
\hline Angle circle test & 0.100 & 0.082 & 0.001 & $0.001^{*}$ & -0.046 & 0.077 \\
\hline Personality (self-control) & -3.643 & $1.343^{* *}$ & -0.027 & $0.012 * *$ & -0.427 & 1.615 \\
\hline Personality (anxiety) & -3.781 & $1.237 * * *$ & -0.032 & $0.012 * *$ & 0.096 & 0.864 \\
\hline Personality (independence) & 3.201 & $1.070 * * *$ & 0.036 & $0.013 * *$ & 0.330 & 1.416 \\
\hline Personality (tough-mindedness) & -3.136 & 1.978 & -0.028 & 0.020 & 5.712 & 3.313 \\
\hline Personality (extraversion) & 2.143 & 1.652 & 0.028 & 0.017 & -0.472 & 1.082 \\
\hline $\operatorname{Sex}(1=$ male; $0=$ female $)$ & 14.372 & $4.187 * * *$ & 0.156 & $0.043 * * *$ & -3.392 & 4.304 \\
\hline Age & -1.094 & $0.593 *$ & -0.010 & 0.006 & -1.008 & 1.273 \\
\hline Times support before & -4.041 & $1.232 * * *$ & -0.043 & $0.013 * * *$ & -11.112 & $4.355 * *$ \\
\hline Constant & 74.868 & $26.866^{* *}$ & 0.633 & $0.261 * *$ & -12.943 & 22.304 \\
\hline $\mathrm{N}$ & 382 & & 382 & & 382 & \\
\hline R-squared & 0.3249 & & 0.3298 & & 0.3183 & \\
\hline $\mathrm{F}$ & 27.68 & & 60.57 & & 10.12 & \\
\hline Prob $>$ F & 0.0000 & & 0.0000 & & 0.0000 & \\
\hline
\end{tabular}

Note. OLS regression with robust standard errors to correct for intra-group correlations. Significance levels (two-sided): $*=10 \%, * *=5 \% ; * * *=1 \%$.

Table 5.4 shows the regression results. Looking at the influence of the endowment variables in the three models, we observe that 80 -endowment players give on average 11 'francs' less to other 80 -endowment players than what they give to 200-endowment players. When looking at support relative to the endowment of the support giver (model 2) we observe that 80-endowment players do not only give larger proportions of their endowment to 200-endowment players in comparison with what they give to other 80 -endowment players. They also give 
larger proportions of their endowment to 200 -endowment players in comparison with $100-100$ and 200-80.

According to the mean predicted value of the difference between the given support and the expected return (model 3), which is equal to -9.3377 , support players expect on average to receive 9 'francs' more in return than what they give. Model 3 indicates that this difference is larger when 80 -endowment players give support to 200 -endowment players, as confirmed by the significant positive coefficients of the endowment dummy variables. This suggests that their relatively higher support to 200-endowment players is the result of the higher profits they expect to obtain from supporting 200-endowment players.

Other interesting results are the influence of the individual characteristics of the support player. The regression results indicate that support players with a high value on 'independence' give more support to the investment person, both in absolute and relative terms. As suggested in appendix 2, these support players have a dominant personality. They give much support, imposing their will to receive much in return, i.e. they disregard that by giving support they oblige other people to reciprocate. People with a high value on 'self-control' or on 'anxiety' tend to give less support, both in absolute and relative terms. Selfcontrol induces support players not to start with very high support levels, whereas anxiety by its affinity with risk aversion makes support players wary of the potential losses of giving support to the investment person.

The influence of the angle of the circle test is only significant in the second model. People with a higher social value orientation towards a 'generalized other' tend to give more support relative to what they are able to give. We also observe that sex is important. Male participants tend to give on average 14 'francs' more. This effect also remains when measuring support in relative terms. This is consistent with previous experimental studies that confirmed that male participants are less risk averse (Eckel \& Wilson, 2004; Gupta et al., 2005).

Finally, the results confirm that people also follow certain 'equality matching' over time. Keeping all other variables constant, the more times the support player has given support to the current investment person before, the less support he/she tends to give to this investment person, both in absolute and relative terms, and as confirmed by model 3 the more he/she expects to receive in return from this investment person in the future. 


\section{c. Support-giving after first investment opportunity}

After looking at what drives individual agents when making support decisions before having had their first opportunity to receive support, we look here at additional motives that enter individual decision-making after having had at least one investment opportunity before. One such behavioural motive that we expect to influence support-giving is 'reciprocity'. What people received before from a specific group member may influence support-giving to this person when he/she requests support.

To study reciprocity we estimated the support given to the current investment player as a function of the most recently received support ${ }^{64}$ from that investment player. To test whether reciprocity depends on the endowment of the players involved we add endowment dummies and interaction terms between the received support and these endowment dummies. We also add time dummies to control for any time trend.

The results reported in Table 5.5 confirm that the most recent support received from the current investment person is a very important determinant when support players have to decide on the support to give to this investment person, both in absolute and relative terms. The strength of the reciprocal relation is also partly influenced by the endowment of both support player and investment player, as indicated by the significant interaction effect between the most recently received support and the 200-80 dummy. The marginal effect of the most recent support is 0.118 higher for support decisions taken by 200 endowment players in comparison with decisions made by 80 -endowment players on the support to give to 200-endowment players. At the same time, the 200-80 dummy is also a significant determinant for the support given in absolute terms. Combining both results, we conclude that 200-endowment players give more to 80 -endowment players than what the latter give to 200 -endowment players, and that this difference becomes larger, the larger the most recent support 200-endowment players received from 80 -endowment players.

\footnotetext{
${ }^{64}$ We look at the most recent support because it is the most salient. We do not exclude the possibility that also other less recent support might still exert an influence on current supportgiving.
} 


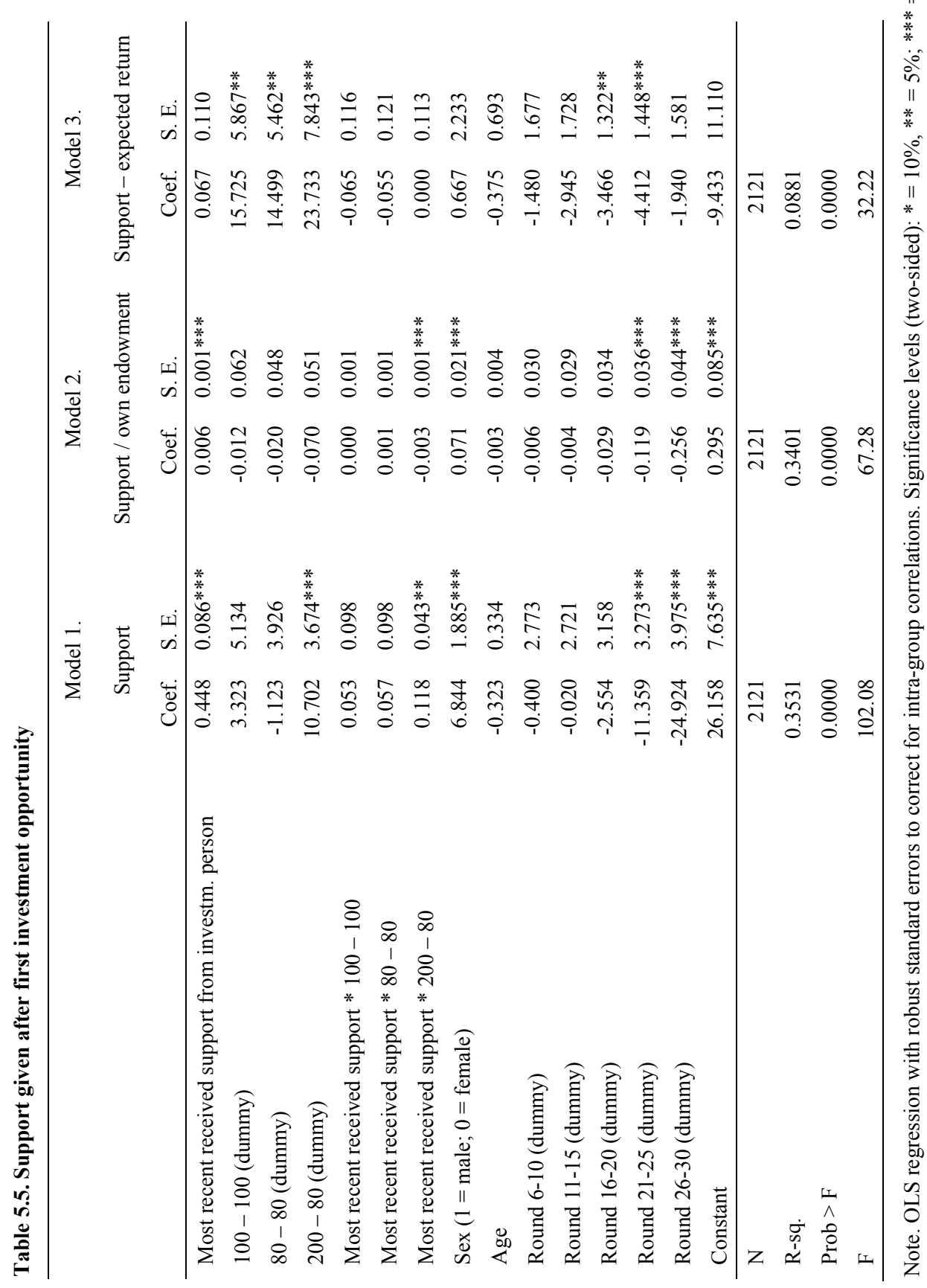


This bias in reciprocity is also reflected in the expectations about the returned support. In model 3, we observe that the difference between given support and expected return, which has a predicted mean value of -5.04 , is significantly more negative for 80 -endowment players who give support to 200endowment players in comparison with the inverse situation (and also compared with $80-80$ and 100-100). This combined with the bias in reciprocity indicates that both 80 -endowment and 200 -endowment players have realistic expectations about the support to receive from each other.

Furthermore, the results confirm that also after their first investment opportunity male support players continue to give more support than female support players, both in absolute and relative terms ${ }^{65}$.

Finally, as was already indicated in Figure 5.1, the regression results indicate a strong end-game effect behind the support decisions, both in absolute and relative terms. Looking at the difference between the given support and the expected return in model 3, we observe that this difference starts to change already before the observed end-game effect of the support levels, i.e. already from rounds 16-20. This suggests that support levels are earlier affected by an anticipated end-game effect than the expected returns. In the last five rounds, the difference between support levels and expected return become similar again to the first five rounds, which indicates that in these rounds the expected returns decrease at a faster rate than support levels.

As it might be that support decisions do not only depend on the support previously received from the current investment person (the direct reciprocity motivation we confirmed above) but also on the support previously received from other group members, we control for this in a next model. We estimate separate models for different endowment combinations of support person and investment person. We do this as the 'other group members' might be very different in dependence of the endowment combination of support person and investment person. For instance, when support is given between 80 -endowment players, the 'other players' consist of 80-endowment players and one 200endowment player, whereas in case support is given to the 200 -endowment player the 'other players' form a homogenous group of 80-endowment players.

\footnotetext{
${ }^{65}$ We also estimated models with controls for the support players' personality characteristics and their social value orientation towards a generalized other, captured by the circle test. Coefficients of these variables were low and statistically not significant, whereas the estimates of the coefficients of the other variables were robust to adding these variables. This indicates that the influence of these individual characteristics (which was confirmed by regression models in Table 5.4) is wiped out once reciprocity becomes a possible behavioural motive, i.e. after having had at least one investment opportunity.
} 


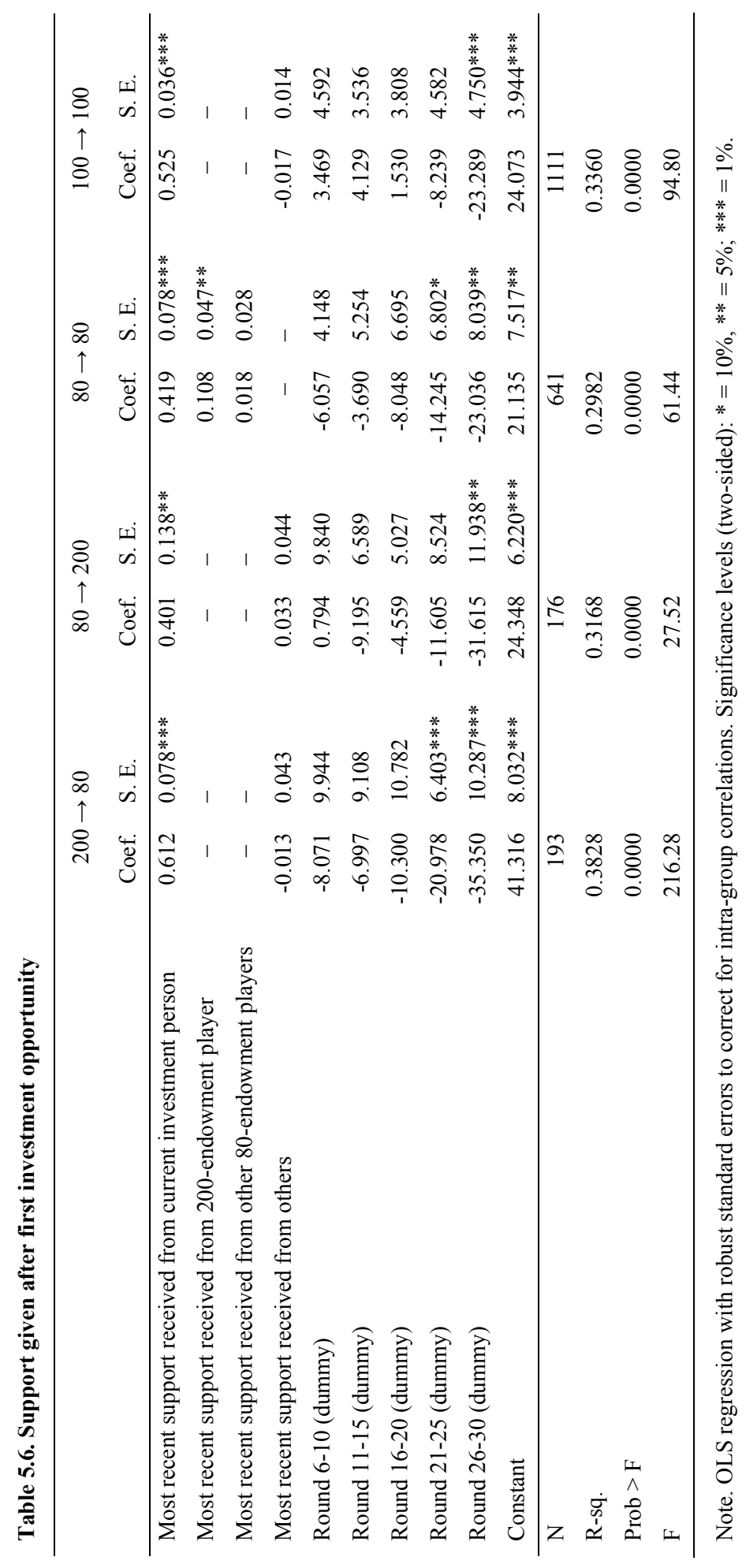


We distinguish two possible effects. First, the more a support player has received from the other players (except the current investment player), the more support he/she may be willing to give to the current investment player. This effect has been described by Kolm (2006: 390): “ . . . you tend to help others if you have been helped yourself, to be nice if others have been nice to you, and so on, even if the people you help or favour are not those who favoured or helped you in the first place."

Second, there may be an effect that goes in the opposite direction. The more a support player has received from the other players except the current investment player, the lower the previously received support from the current investment player is valued by the support player. The coefficient of the total received support of the other players is positive if the first effect outweighs the second effect, whereas it is negative if the second effect outweighs the first effect. Looking at the results reported in Table 5.6, only in the third model we detect a significant influence of the received support from the 200 -endowment player. The coefficient is positive, which indicates that support among 80-endowment players is stimulated with higher support received from the 200-endowment player.

\subsection{Explaining differences in group aggregated tie strength}

In this and next subsections we use our acquired knowledge on individual support-giving to understand better what social tie structures are more likely to be formed, and under what conditions. More specifically, we look at the role of economic inequality on the group aggregated tie strength and the centrality of the formed group networks of social ties.

As shown by Figure 5.1., there exists large variation between the different groups both in the equality and inequality treatment. A plausible explanation for this variation is the initial decisions made, which might determine which path is followed thereafter. To test this, we look at the correlations between the group average of all support decisions (divided by the own endowment) before the support players' first investment opportunity and the average over rounds 15-25 of the group aggregated tie strength. As in the inequality treatment there are three different endowment combinations of support player and investment player, we calculate the average of the support decisions before the support players' first investment opportunity separately for each endowment combination. Consequently, in total we have four different correlations with the average group aggregated tie strength. Figure 5.3 shows the scatter plots for the different 
endowment combinations and a simple linear fit. Each observation refers to one group, which is labelled by the number of support decisions.

For the equality treatment Spearman's rho is equal to 0.236 (two-sided $\mathrm{P}=$ .484). When we ignore the outlier in the under-right corner, Spearman's rho increases and becomes significant at the $10 \%(0.552$, two-sided $\mathrm{P}=.098)$. For support-giving among 80-endowment players Spearman's rho is equal to 0.745 (two-sided $\mathrm{P}=.008$ ). For support-giving from 80-endowment players to 200endowment players Spearman's rho is equal to 0.571 (two-sided $\mathrm{P}=.084$ ) whereas for support-giving in the other direction Spearman's rho is equal to 0.669 (two-sided $\mathrm{P}=.035$ ).

Figure 5.3. The importance of the support before the first investment opportunity

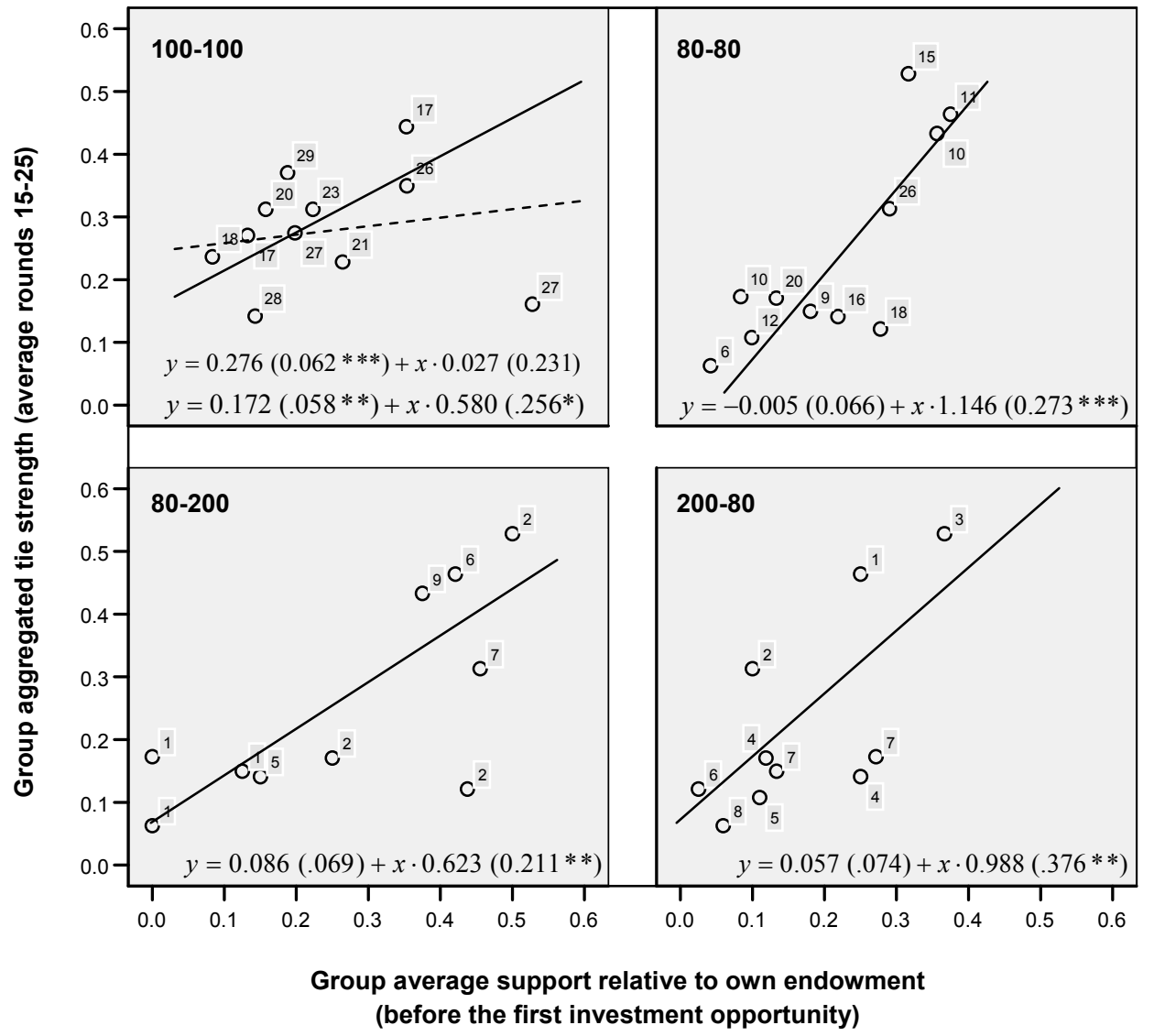

This evidence indicates that for all endowment combinations the support decisions before the first investment opportunity tend to influence which path is 
followed thereafter. There are however large differences as to the strength of this influence. The regression coefficients indicate that this influence is particularly strong for the 80-80 combination, whereas for the 100-100 combination it is substantially weaker. The latter is consistent with our previously observed positive correlation between the number of preceding investment opportunities and the group average support (see Figure 5.2). The variation in the group aggregated tie strength in the equality treatment is relatively less determined at the start of the game, but created while the game proceeds.

Remind that in the inequality treatment we observed high and low trajectories of group aggregated tie strength. The three groups with the highest average group aggregated tie strength in the inequality treatment are the same groups that were represented by thick lines in Figure 5.1 before. In these groups average group support before the first investment opportunity is not only high from 80endowment players to other 80-endowment players, but also from 80endowment players to 200 -endowment players.

\subsection{Structure of the formed networks of social ties}

Is the formation of social ties such that certain group network structures are more likely to be formed? When studying the formation of social ties we identified three mechanisms with possible implications for the structure of the evolving networks of social ties.

First, 80-endowment players tend to give more support to 200-endowment players than to other 80-endowment players, which may stimulate certain centralization in the network structures, i.e. around the 200 -endowment player. Before having had an investment opportunity, 80-endowment players tend to give on average 11 'francs' more to 200 -endowment players than they give to other 80-endowment players. At the same time, they expect 200-endowment players to return relatively more. Second, the expectations 80-endowment players have about the support-giving of 200-endowment players is confirmed, as after having had at least one investment opportunity, 200-endowment players return relatively more support to 80 -endowment players than other 80endowment players do. This stimulates the formation of intense social ties between 80 -endowment and 200-endowment players. Third, we observed that the support 80-endowment players give to each other increases with the support received from the 200 -endowment player. This mechanism may counteract the centralization of networks of social ties.

To study network centrality with variable tie strength, we make use of the centrality measure proposed by Kretschmer \& Kretschmer (2006) which, in 
contrast with standard degree centrality measures, takes account of the tie strength. According to their measure individual degree centrality of a node A is equal to the geometric mean of the total strength of the social ties of A (we refer to section 4.1. where we defined 'tie strength') and the 'number of ties' A has with the other nodes. The 'number of ties' of $\mathrm{A}, D C_{A}$, is weighted by the strength of each tie.

In particular, $\left.D C_{A}=2^{\left(-\sum_{i=1}^{z} h_{i=1} \cdot \log _{2}\left(l_{i}\right)\right.}\right)$, with $h_{i}=K_{i} / \sum_{i=1}^{z} K_{i}, K_{i}$ representing the tie strength with node i. As the social ties at the basis of the formed networks in our experiment are directed ties, we calculate separate measures for in-degree (based on support-receiving) and out-degree (based on support-giving).

We decide to take a snapshot of the network in each group at round 20, with each directed dyad representing the most recent transfer. We do this at round 20, as support levels are then expected to be at their highest level. Many rounds have passed since the start of the game, so that participants have had multiple opportunities to build trust and increase support levels. At the same time, the end of the game is still remote, so that participants do not yet reduce their support levels. For a graphical representation of the formed networks in each group we refer to appendix $4^{66}$. To test whether the 200 -endowment player has a significantly higher in-degree or out-degree centrality in comparison with the other players we applied a Wilcoxon signed ranks test. According to this test the out-degree centrality of the 200-endowment player is significantly larger than the average out-degree centrality of the other group members (two-sided $\mathrm{P}=$ .008). In-degree centralities are not significantly different between the 200endowment player and the average in-degree centrality of the other group members (two-sided $\mathrm{P}=.328$ ) $^{67}$. These results are in line with our previous observation that 200 -endowment players give more to 80 -endowment players than what the latter give to 200 -endowment players. This difference in supportgiving makes the difference of the degree centrality between the 200endowment players and the 80 -endowment players larger when measured as outdegree than when measured as in-degree.

\footnotetext{
${ }^{66}$ In the inequality treatment player 6 is the 200 -endowment player.

${ }^{67} \mathrm{We}$ have done the same analyses for the social ties at rounds 19 and 21, and obtained similar results. For out-degree centrality two-sided P-values are respectively .008 and .008 whereas for indegree centrality they are respectively .131 and .182 .
} 


\subsection{Final distributive results}

In a final analysis we look at the distributive implications of the formation of social ties. We have seen that 200-endowment players give more support than 80 -endowment players, but they also receive more support. To assess its distributive implications, we look at the individual final profit for the entire experiment. For this we use a profitability ratio, defined as the proportional difference between the total profit in the experiment (i.e. endowment, plus received support, minus given support and costs of requesting support) and the sum of the endowments received in the experiment. This ratio indicates how profitable it has been for a specific agent of being active in the favour game in comparison with only receiving the constant endowment each round. Note that the individual total profit also depends on the randomly determined number of investment opportunities.

$$
P_{i}=\left(\frac{\sum_{t} \pi_{i}}{\sum_{t} y_{i}}\right)-1
$$

Figure 5.5 shows the distribution of this profitability measure for the different types of players. We observe that 100-endowment and 80-endowment players have an average profitability ratio which is significantly larger than zero, whereas the profitability ratio for 200-endowment players is not significantly different from zero.

80-endowment players have the highest profitability - slightly higher than 100-endowment players - whereas 200-endowment players face the lowest profitability. Based on a regression with the profitability ratios of 80 -endowment and 200-endowment players and only adding a dummy which equals 1 for a 200-endowment player, 200-endowment players have a significantly lower profitability ratio than 80 -endowment players (coefficient of the dummy equals -0.065 , two-sided $\mathrm{P}=.025)$. This indicates some redistribution in favour of 80 endowment players, although not strong enough to level out inequalities.

The latter would only be possible in case 80-endowment and 200endowment players transfer almost their entire endowment to investment players. As shown in Table 5.6, in such a case, the profitability of 200endowment players would be -0.554 (leading to an equivalent endowment of less than 100), whereas the profitability of low-endowment players would be 
0.465 (leading to an equivalent endowment of almost 120$)^{68}$. As shown by Figure 5.5, however, 200-endowment players do not incur a negative profitability. In the end, 80 -endowment players have similar profitability ratios as $100-$ endowment players and are incapable of benefiting from their potentially better position, i.e. their maximum attainable profitability ratio (see Table 5.7) is almost 4 times as high in comparison with 100 -endowment players $(0.465$ versus 0.125$)$.

Figure 5.5. Distribution results: profitability ratio by endowment of player

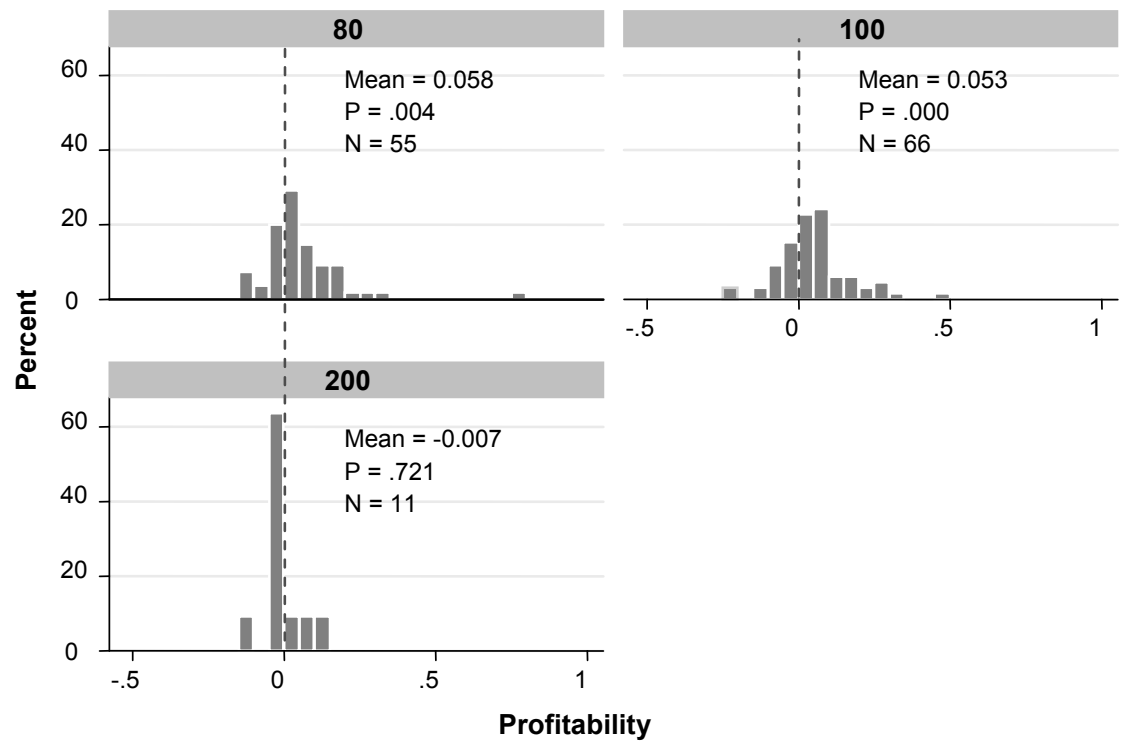

Note. Two-sided P-values were calculated by estimating an OLS regression with only a constant term and applying robust standard errors to correct for intra-group correlations

${ }^{68}$ The theoretical maximum profitability is attained when each investment player asks all support players for support and all support players transfer their entire endowment to the investment player. To calculate this theoretical maximum in the inequality treatment, we also assume that each player has 5 investment opportunities (the average number of investment opportunities with 6 players and 30 rounds). 
Table 5.7. Theoretical and observed profitability

\begin{tabular}{ccccc}
\hline & & \multicolumn{2}{c}{ Maximum support-giving ${ }^{\text {a }}$} & Mean observed \\
Endowment & Total endowment & Profit & Profitability & Profitability \\
\hline 100 & 3000 & 3375 & 0.125 & 0.053 \\
80 & 2400 & 3515 & 0.465 & 0.058 \\
200 & 6000 & 2675 & -0.554 & -0.007 \\
\hline
\end{tabular}

${ }^{\text {a }}$ Assuming each player has 5 investment opportunities, each investment player asks everyone for support and all support players transfer their entire endowment.

\section{Conclusion}

To study the formation of social capital, conceived as social networks of social ties, and how endowment inequality influences its density and centrality, we conducted an experimental repeated favour game with groups of six players. In each round, one player is randomly selected to have the opportunity to ask one or more of the other five players for support. A player who is asked for support decides on the amount of support to give, which is then multiplied with an efficiency factor.

Two closely-related behavioural motives that influence support requests and support-giving are direct reciprocity and the expectations about future support. First, consistent with the investment idea behind social capital formation, individual decision making is influenced by individual expectations about future returns. We observed that the higher the previously received support the higher the probability of requesting support again. We also observed how endowment inequality, through its influence on expectations about future returns, influences individual decision making. As 80-endowment players expect to receive more in return from 200 -endowment players than from 80 -endowment players, they have a $25.9 \%$ higher probability to request support from a 200 endowment player than from another 80-endowment player, and they give significantly more support to 200-endowment players than to other 80 endowment players.

Second, favour requests and support-giving are also driven by direct reciprocity motives. We observed that the probability that an investment player requests support from a specific support player is more than $25 \%$ lower if that support player has not requested support from the current investment player before but had the opportunity to do so. Furthermore, regarding support-giving, the influence of personality characteristics, which was important before having 
had any investment opportunity, is eliminated by the influence of the 'most recent support received', once people have received support.

Furthermore, we observed how endowment inequality biases expectations and reciprocity. 200-endowment players return more than 80-endowment players, which is consistent with the expectations 80 -endowment players have about returns from investing in social relations with 200 -endowment players. It is this bias in reciprocity and expectations which lies at the heart of certain centralization in the formed networks of social ties, and which explains why in the inequality treatment very high levels of support-giving are obtained if much support is given between 80 -endowment players and from 80 -endowment players to 200-endowment players early in the game.

\section{Appendix 1: Experimental procedures and instructions}

\section{Experimental procedures}

Several measures were taken to guarantee anonymity. To exclude the possibility that participants could make inferences about the group to which they belonged each session was organized with at least two groups. Moreover, participants were seated randomly in the computer lab with isolated cubicles. It was explained that computer numbers were used to recognize participants during the experiment and the data analysis afterwards, but could not be linked to the participants' names. In addition, during the experiment no communication was allowed, mobile phones were switched off and no participants could leave the lab. If participants had a question they were asked to raise their hand so that one of the experimenters could come and answer the question in private.

After reading the instructions, the participants had to go through some control questions. The experiment did not start before all participants had correctly answered these questions. At the end of the experiment, participants were asked to fill in a short questionnaire. After all had completed this questionnaire, they were paid out confidentially in cash. 


\section{Instructions}

In this experiment, you can earn money. The experiment consists of two unrelated parts. In both parts you can earn 'francs'. The 'francs' you earn will be converted to Euro according to 200 'francs' = $\mathbf{1}$ Euro and paid out to you privately and confidentially.

During the whole experiment you are not allowed to communicate with the other participants in any other way than described in these instructions.

\section{Instructions for part 1}

In part 1 of the experiment you have to make a single choice. The choice concerns the allocation of an amount of 'francs' to yourself and to a randomly chosen other participant. You will not get to know the identity of this other participant, nor will this other participant get to know your identity.

You have to choose one single point on a circle on a sheet of paper handed out to you. With the choice you make you can make yourself and the other earn more or less.

At the same time another participant will have to make a similar decision on an allocation between him/her and you. This other participant, however, will not be the one you are linked with.

\section{Instructions for part 2}

In the second part of the experiment you are in a group of 6 participants. Group compositions do not change during the whole experiment.

The composition of your group is anonymous.

Each group member receives randomly one of the letters A, B, C, D, E, F as 'ID'. Each letter corresponds to the same person during the entire experiment.

The second part of the experiment consists of 30 rounds. 
You and all other members in your group receive a fixed amount of 'francs' at the beginning of each round. This is called your 'endowment'. This endowment is the same for everybody. Each member of your group receives 100 'francs' at the beginning of each round ${ }^{69}$. The endowment does not change over rounds.

In each round, one of the six group members will be randomly selected to have an investment opportunity and is, therefore, called 'investment person'. In each round each group member has the same chance to be selected.

To make use of the investment opportunity the investment person needs support from the other group members. The other group members are called 'support persons' in that round.

The investment person can ask one or more of the support persons for support. Each request for support costs the investment person 5 'francs'.

If a support person is asked for support, he/she can transfer nothing, part or all of his/her endowment to the investment person. The amount of 'francs' a support person transfers to the investment person is multiplied by 1.4. A support person who is not asked for support can not do anything.

The earnings of an investment person in a round is equal to the endowment plus the total amount of 'francs' all the support persons transfer to the investment person (multiplied by 1.4) minus the costs of requesting support.

The earnings of a support person in a round will be equal to the endowment minus the amount of 'francs' he/she transferred to the investment person.

Before taking any decision in a specific round as an investment person or a support person you can review all interactions you had in all past rounds. You can only receive information about your own personal history.

\footnotetext{
${ }^{69}$ With the inequality treatment this phrase was replaced by: "This endowment is not the same for everybody but depends on the letter ID. One member of your group receives 200 'francs' at the beginning of each round and each of the other members receives 80 'francs' at the beginning of each round."
} 


\section{Appendix 2: Personality dimensions (Brandstätter, 1988)}

\section{Extraversion}

Extravert people search and find contact easily. They go public, are communicative and sociable. At the same time they are also interested in the feelings and needs of others. They take to it like a duck to the water if 'something is happening'. They enjoy being in the centre of attention.

Introvert people like to withdraw themselves in order to be alone. They are not easily accessible and appear being reserved. They do not feel themselves at ease in a loud and turbulent environment. They do not like to attract the attention of other people on themselves.

\section{Anxiety}

Anxious (emotionally unstable) people are easily detuned and vulnerable. They suffer from self doubts and mood changes. They often perceive challenges as a threat. They tend to underestimate their abilities.

Emotionally stable people do not easily let themselves getting disconcerted. They are calm, and satisfied with themselves. In their interaction with others they appear confident and easy-going. They get along well with stress. They are mentally resilient. Every now and then they tend to underestimate the difficulties of tasks.

\section{Self-control}

People with pronounced self-control do not let themselves go. They are conscious about rules and they are inclined to perfectionism. Social conventions are important to them. They take their obligations seriously. They are well-planned and systematic in their work.

People with low self-control follow their internal impulses, do not care a lot about rules by which they feel constrained. Preparing themselves thoroughly and 
making long-term plans is not their thing. They can surprise with unorthodox ideas and ways of acting.

\section{Independence}

Independent people cut their own path with their own ideas. They are willing and able to stand one's ground. Every now and then they appear dominant and often claim leadership. Social considerateness is not their strength.

Low values on this dimension mark people who avoid conflicts. They are ready to adapt themselves and leave leadership to others. They do not oppose strongly against attempts to be influenced.

\section{Tough-mindedness}

People with high values on tough-mindedness are rather insensitive, down-toearth and realistic. They are not easily irritated. One could say they are rather thick-skinned and not easily impressed. They somewhat lack the willingness and ability for empathy and flexibility.

People with low values on tough-mindedness are sensitive and tender-footed, they are open for ideas. They show value imaginativeness and a more artistic view of the world. They have less interest in strong and down-to-earth facts. They are somewhat 'dreamy'. 

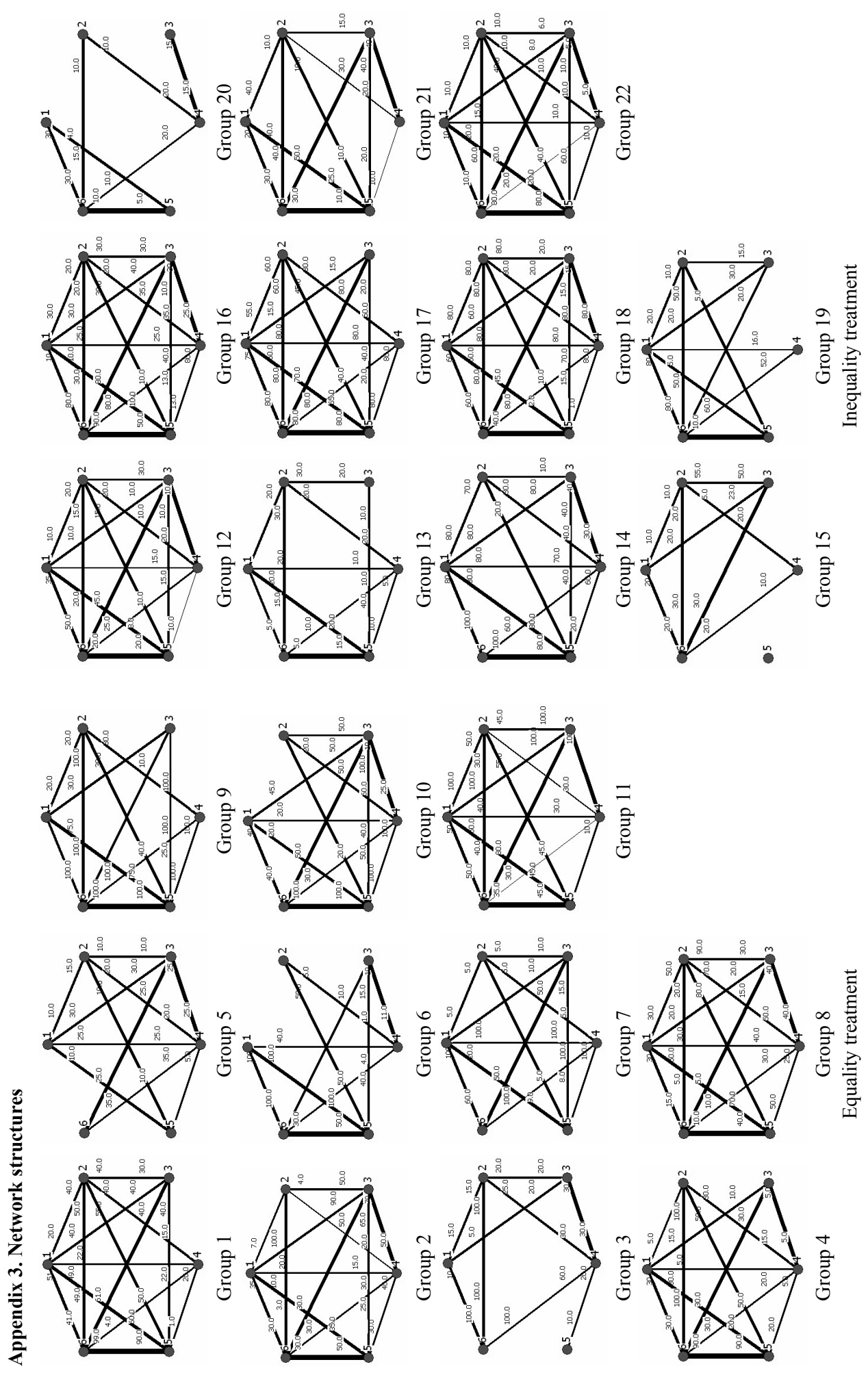


\section{Conclusion}

This work has examined how the embeddedness of economic agents in smallscale societies influences distributive decision making and exclusion processes of economic resources. Looking at small-scale societies characterized by considerable economic inequality, one of the main research questions has focused on the processes behind the reproduction of economic inequality. In particular, we have studied to what extent and under what conditions the poor face a relatively higher likelihood of being excluded from economic resources. Although important in many settings, we have focused on the relevance of these issues for local development and poverty reduction.

To study this research question, we have not only looked at the individual decision making of agents who distribute economic resources, but also at the decision making of potential recipients of these resources when they are given the means to react. In other words, we have also examined the political dimensions at work when economic resources are distributed within small-scale societies. Consolidating our analyses and conclusions, we have acquired the following insights regarding the processes behind the reproduction of economic inequality. These are related to the less-beneficial position of the poor in both social and political terms.

Looking at the social dimension, the results of chapter 4 indicate that social network positions correlate strongly with generosity, but that this correlation is highly contingent upon the type of network we look at. Social proximity in general networks, friendship networks and extended family networks, increases generosity. As poorer agents have a lower likelihood of having friendship links with other agents, they are more vulnerable to exclusion because they tend to be more socially isolated from others.

Chapter 5 enriches this analysis by looking at the determinants of the dynamic formation of social links through support giving and its relation with economic inequality. Based on experimental evidence, we conclude that reciprocity and expectations about future returns are very important behavioral motives, which are biased by economic inequality. The poor are more likely to request support from rich agents than from other poor agents. If asked for 
support they tend to give more support to rich agents than to other poor agents. They do so because they (correctly) expect higher returned support from rich agents. These results are consistent with the poor's lower likelihood of having friendship links, as observed in chapter 4.

The poor may not only have less beneficial network positions. They may also face disadvantages in the political field. To look at this, we examined in chapter 3 the decision making of a permanent group representative, being the richest of an economically heterogeneous group, who distributes resources among the group members. The latter are given the opportunity to punish the representative by means of simple majority voting.

We have observed that punishment, instead of enforcing representatives to reduce their share, actually induces them to increase the share they keep to themselves. Only when voting decisions are made public and distribution decisions remain private, are representatives able to limit punishment rates. They do so by successfully applying an exclusion strategy. They give two respondents more than their acceptance threshold so that they do not vote in favour of punishment. Because of the majority voting rule the approval of the third respondent is then not required to avoid punishment, and this respondent is completely excluded from the resources. When voting is public, the poor are relatively more vulnerable to this type of exclusion. As the poor are more inclined to vote in favour of punishment, they have a higher likelihood of being excluded by the representative when the latter receives information on the individual voting decisions.

Chapter 3 also demonstrated that if the poor in some way or another manage to take the representative's role, punishment rates drop and distributions become substantially more equal. Thus, political change in favour of the poorest is not only beneficial in distributional terms. It also reduces efficiency losses due to punishment.

The situation simulated in chapter 3 mainly applies to communities where a single representative remains firmly in power. In such conditions it is difficult to make the representative accountable to the community members. The distribution decisions made by the representative, however, might be different when alternative representatives are ready to take his/her place.

Chapter 2, which studied the distribution of development aid in rural villages, complements the analysis in this respect, as it abandons the assumption of a single permanent representative. Making use of a household survey it looked at aid flows and the extent to which mediation of these flows is monopolized by a limited number of representatives/brokers. The results demonstrated that higher brokerage concentration leads to a higher proportion of the village 
that is completely excluded from aid. Moreover, the analysis showed that, in contrast with the situation modelled in chapter 3 where all group members equally depend on the representative for access to outside resources, in reality the poor make relatively more use of brokerage to get access to aid. Besides the higher vulnerability of the poor to deliberate exclusion by the representative as observed in chapter 3 , this higher reliance of the poor on brokerage as such makes political change even more relevant for the poor, especially when brokerage is highly concentrated.

Political change in favour of the poor, however, is not evident. Chapter 2 showed that where political change is most needed (i.e. where brokerage is highly centralized) political alternatives are less identified in general, hampering any political change. Moreover, if representatives are replaced it is not likely that poorer agents benefit from such political change. Persons excluded from the resources of outside aid donors, know fewer political alternatives that could replace the ruling political representatives and thereby improve their representation, which is necessary to reduce their exclusion. Given the observed impediments to political change in favour of the poor, a more active or engaged role for outside aid donors may be appropriate. In particular, aid donors should look for new political actors that represent the most excluded even if they are not very intensively identified by community members. Because of the lower identification by community members, however, it increases search and operation costs, and requires more time and energy than aid donors usually invest in such activities.

A final observation relates to the ability of aid donors to support political change processes. Chapter 2 showed that relations with market-oriented donors are less mediated by brokers. Consequently, market-oriented aid donors may have less capacity to change brokerage structures. Relations with other aid donors are more likely established through the mediation of community brokers, so that these donors may have more potential to change local brokerage structures. This may be counteracted, however, if these donors require the support of community brokers to facilitate their local operations, making them vulnerable to local resistance from the ruling brokers to any political change. This may constitute a real dilemma, which hampers donors to make an effort to expand their outreach beyond the networks of the ruling brokers. Given the demonstrated benefits of a more decentralized brokerage, this is an important research question, which requires further research. 



\section{References}

Abbink, K. \& Ellman, M. (2005). 'The Donor Problem', mimeo.

Alderman, H. (2001). 'Do local officials know something we don't? Decentralization of targeted transfers in Albania', Journal of Public Economics 83(3), 375-404.

Alesina, A. \& La Ferrara, E. (2002). 'Who Trusts Others?', Journal of Public Economics 85(2), 207-34.

Anderson, L.R., Mellor, J.M. \& Milyo, J. (2005). 'An Experimental Study of the Effects of Inequality and Relative Deprivation on Trusting Behavior', College of William and Mary, Department of Economics, Working paper number 14 .

Armantier, O. (2006). 'Do wealth differences affect fairness considerations?', International Economic Review 47(2), 391-429.

Bardsley, N. (2005). 'Altruism or Artefact? A Note on Representative Game Giving', CEDEX - University of Nottingham, Discussion Paper 2005-10.

Bardhan, P.K. (2000). 'Understanding underdevelopment: challenges for institutional economics from the point of view of poor countries', Journal of Institutional and Theoretical Economics 156, 216-35.

Barr, A. (2004). 'Kinship, Familiarity, and Trust: An Experimental Investigation', in: Henrich, J., Boyd, R., Bowles, S., Camerer, C., Fehr, E. \& Gintis, H. (eds). Foundations of Human Sociality: Economic Experiments and Ethnographic Evidence from Fifteen Small-Scale Societies. Oxford University Press.

Bastiaensen, J., \& D’Exelle, B. (2002). 'To pay or not to pay? Local institutional differences and the viability of rural credit in Nicaragua', Journal of Microfinance 4(2), 31-56.

Berg, J., Dickhaut, J. \& McCabe, K. (1995). 'Trust, Reciprocity, and Social History', Games and Economic Behavior 10, 122-142

Bierschenk, T., Chauveau, J.-P., \& Olivier De Sardan, J.-P. (2000). Courtiers en développement; les villages africains en quête de projets. Paris: Karthala. 
Bohnet, I. \& Frey, B. (1999). 'Social distance and other-regarding behavior in dictator games: comment', American Economic Review 89, 335-340.

Bolton, G. \& Ockenfels, A. (2000). 'ERC - A Theory of Equity, Reciprocity and Competition', American Economic Review 90, 166-93.

Bornhorst, F., Ichino, A., Kirchkamp, O., Schlag, K. \& Winter, E. (2004). 'How do People Play a Repeated Trust Game? Experimental Evidence', mimeo.

Brandstätter, H. (1988). 'Sechzehn Persönlichkeits-Adjektivskalen (16PA) als Forschungsinstrument anstelle des 16PF [Sixteen Personality Adjective Scales (16PA) as a substitute for the 16PF in research settings]', Zeitschrift für experimentelle und angewandte Psychologie 35, 370-391.

Brandstätter, H. \& Königstein, M. (2001). 'Personality Influences on Ultimatum Bargaining Decisions', European Journal of Personality 15, S53-S70.

Brandts, J. \& Charness, G. (2004). 'Do Labour Market Conditions Affect Gift Exchange? Some Experimental Evidence', Economic Journal 114(497), 684-708.

Brañas-Garza, P. (2006). 'Poverty in Dictator Games: Awakening Solidarity', Journal of Economic Behavior \& Organization 60(3), 306-320.

Brañas-Garza, P., Cobo-Reyes, R., Paz Espinosa, M., Jiménez, N. \& Ponti, G. (2006). 'Altruism in the (Social) Network', DFAEII Working Paper no. 200604, University of the Basque Country - Department of Foundations of Economic Analysis II

Brülhart, M. \& Usunier, J.C. (2004). ,Verified Trust: Reciprocity, Altruism, and Noise in Trust Games', mimeo.

Burt, R.S. (1992). Structural Holes: The Social Structure of Competition. Harvard University Press, Cambridge, MA.

Burt, R.S. (2005). Brokerage and Closure: An Introduction to Social Capital. Oxford University Press, Oxford.

Camerer, C. \& Thaler, R. (1995). 'Anomalies: Ultimatums, Dictators and Manners', Journal of Economic Perspectives 9(2), 209-219.

Camerer, C. (2003). Behavioral Game Theory: Experiments in Strategic Interaction, Princeton: Princeton University Press.

Cameron, A.C.; Gelbach, J.B. \& Miller, D.L. (2007). 'Robust Inference with Multi-way Clustering', mimeo.

Cardenas, J.C., Stranlund, J. \& Willis, C. (2000). 'Local Environmental Control and Institutional Crowding-Out', World Development 28(10), 1719-1733

Charness, G. \& Gneezy, U. (forthcoming) 'What's in a Name? Reducing the Social Distance in Dictator and Ultimatum Games', Journal of Economic Behavior and Organization. 
Cleaver, F. (1999). 'Paradoxes of participation: questioning participatory approaches to development', Journal of International Development 11, 597-612.

Cochard, F., Nguyen Van, P. \& Willinger, M. (2004). 'Trusting behavior in a repeated investment game', Journal of Economic Behavior \& Organization $55,31-44$.

Coleman, J.S. (1990). Foundations of Social Theory. Harvard University Press, Cambridge, MA.

Conning, J., \& Kevane, M. (2002). 'Community-based targeting mechanisms for social safety nets: a critical review', World Development 30(3), 375-94.

Cox, J.C. (2004). 'How to identify trust and reciprocity', Games and Economic Behavior 46, 260-281

Dercon, S. \& de Weerdt, J. (2002). 'Risk-Sharing Networks and Insurance Against Illness', Technical report CSAE Working Paper Series No. 200216, Department of Economics, Oxford University Oxford.

Eckel, C.C. \& Grossman, P.J. (1996). 'Altruism in Anonymous Dictator Games', Games and economic behavior 16, 181-191.

Eckel, C.C. \& Grossman, P.J. (1998). 'Are Women Less Selfish Than Men?: Evidence from Dictator Experiments', The Economic Journal 108(448), 726-735.

Eckel, C. \&. Wilson, R. (2000). 'Whom to trust? Choice of partner in a trust game', Working paper

Eckel, C. \&. Wilson, R. (2004). 'Is trust a risky decision?', Journal of Economic Behavior and Organization 55, 447-465.

Engle-Warnick, J. \& Slonim, R. (2006). 'Learning to Trust in Indefinitely Repeated Games', Games and Economic Behavior 54(1), 95-114.

Ensminger, J. (2004). 'Market Integration and Fairness: Evidence from Ultimatum, Dictator and Public Goods Experiments in East Africa', in: Henrich, J., Boyd, R., Bowles, S., Camerer, C., Fehr, E. \& Gintis, H. (eds). Foundations of Human Sociality: Economic Experiments and Ethnographic Evidence from Fifteen Small-Scale Societies. Oxford University Press.

Fafchamps, M. \& Gubert, F. (2007). 'The formation of risk sharing networks', Journal of Development Economics 83(2), 326-350.

Falk, A. \& Fischbacher, U. (2006). 'A theory of reciprocity', Games and Economic Behavior 54(2), 293-315.

Falk, A., Gächter, S. \& Kovács, J. (1999). 'Intrinsic motivations and extrinsic incentives in a repeated game with incomplete contracts', Journal of Economic Psychology 20, 251-284. 
Fehr, E., Kirchsteiger, G. \& Riedl, A. (1998). 'Gift Exchange and Reciprocity in Competitive Experimental Markets', European Economic Review 42(1), 134.

Fehr, E. \& Schmidt, K.M. (1999). 'A Theory of Fairness, Competition and Cooperation', Quarterly Journal of Economics 114(3), 817-68.

Fischbacher U., Gächter, S. \& Fehr, E. (2001). 'Are People Conditionally Cooperative? Evidence from a Public Goods Experiment', Economic Letters 71, 397- 404.

Fischbacher, U. (2007). 'z-Tree: Zurich toolbox for ready-made economic experiments', Experimental Economics 10(2), 171-178.

Fiske, A. P. (1992). 'The Four Elementary Forms of Sociality: Framework for a Unified Theory of Social Relations', Psychological Review 99(4), 689-723.

Forsythe R., Horowitz, J.L., Savin, N.E. \& Sefton, M. (1994). 'Fairness in simple bargaining experiments'. Games and Economic Behavior 6(3), 347369.

Galasso, E. \& Ravallion, M. (2001). 'Decentralised targeting of an anti-poverty program', the World Bank Development Research Group.

Glaeser, E. L., Laibson, D. \& Sacerdote, B. (2002). 'An Economic Approach To Social Capital', Economic Journal 112(483), 437-58.

Gneezy, U., Güth, W. \& Verboven, F. (2000). 'Presents or investments? An experimental analysis', Journal of Economic Psychology 21, 481-493.

Goeree, J. K., McConnell, M., Mitchell, T., Tromp, T. \& Yariv, L. (2006). 'A Simple 1/d Law of Giving', Mimeo.

Goodin R. \& Le Grand, J. (1987). Not Only the Poor: the Middle Classes and the Welfare State, London: Allen and Unwin.

Granovetter, M. (1985). 'Economic action and social structure: The problem of embeddedness', American Journal of Sociology 91, 481-510.

Grootaert C. \& van Bastelaer, T. (eds.) (2002). The Role of Social Capital in Development: An Empirical Assessment. Cambridge: Cambridge University Press, 360p.

Gupta, N.D., Poulsen, A. \& Villeval, M-C. (2005). 'Male and Female Competitive Behavior: Experimental Evidence', IZA Discussion paper No. 1833.

Güth W., Schmittberger, R. \& Schwarze, B. (1982). 'An experimental analysis of ultimatum bargaining', Journal of Economic Behavior and Organization 3, 367-388.

Güth, W., Schmidt, C. \& Sutter, M. (2004). 'Bargaining Outside the Lab: A Newspaper Experiment of a Three Person Ultimatum Game', The Economic Journal 117(3), 449-469. 
Harbaug, W., Krause, K. \& Liday, S.G. (2003). 'Bargaining by Children', University of Oregon Economics Department Working Papers.

Henrich, J., Boyd, R., Bowles, S., Camerer, C., Fehr, E. \& Gintis, H. (2004). Foundations of Human Sociality: Economic Experiments and Ethnographic Evidence from Fifteen Small-Scale Societies. Oxford University Press.

Hoddinott, J. \& Haddad, L. (1995). 'Does Female Income Share Influence Household Expenditures? Evidence from Côte d'Ivoire', Oxford Bulletin of Economics and Statistics 57(1), 77-96.

Hoffman E., McCabe, K., Shachat, K. \& Smith, V. (1994). 'Preferences, Property Rights, and Anonymity in Bargaining Games', Games and Economic Behavior 7(3), 346-380.

Hoffman, E., McCabe, K. \& Smith, V. (1996). 'Social Distance and otherregarding behavior in dictator games', American Economic Review 86, 65360 .

Jackson, M.O. \& Rogers, B.W. (2007). 'Meeting Strangers and Friends of Friends: How Random Are Social Networks?', American Economic Review 97(3), 890-915.

Kolm, S.-Ch. (2006). 'Reciprocity: Its Scope, Rationales, and Consequences', in: Kolm, S.-Ch. \& Ythier, J.M. (eds.) Handbook of the Economics of Giving, Altruism and Reciprocity: Foundations Volume 1, North-Holland.

Knez, M.J. \& Camerer, C.F. (1995). 'Outside options and social comparison in three-player ultimatum game experiments', Games and Economic Behavior 10, 65-94.

Kothari, U. (2001). 'Power, knowledge and social control in participatory development', in: Cooke, B. \& Kothari, U. (eds.) Participation: the new tyranny?, London-New York: Sed Books Ltd.

Kretschmer, H. \& Kretschmer, T. (2006). 'A New Centrality Measure for Social Network Analysis Applicable to Bibliometric and Webometric Data', In Proceedings International Workshop on Webometrics, Informetrics and Scientometrics \& Seventh COLLNET Meeting, Nancy (France).

Krishnan, P. \& Sciubba, E. (2004). 'Endogenous Network Formation and Informal Institutions in Village Economies', Technical report Cambridge Working Paper in Economics No. 462 Cambridge.

Landé, C.H. (1977). 'Group Politics and Dyadic Politics: Notes for a Theory', in: Schmidt S.W., Scott, J.C., Landé, C.H. \& Guasti, L. (eds.) Friends, followers and factions: a reader in political clientelism, University of California Press.

Laurent, P.J. (1998). Une association de développement en pays mossi: le don comme ruse, Paris: Karthala. 
Leider, S., Mobius, M., Rosenblat, T. \& Do, Q-A. (2007). 'Directed Altruism and Enforced Reciprocity in Social Networks: How Much is A Friend Worth?', NBER Working Paper No. 13135.

Lin, N. (2001). Social Capital: a Theory of Social Structure and Action, Cambridge University Press, 278p.

Long, N. (2001). Development sociology: actor perspectives, London: Routledge.

Maldidier, C. \& Marchetti, P. (1996). El campesino finquero y el potencial económico del campesinado nicaragüense: Tipología y regionalización agrosocioeconómica de los sistemas de producción y los sectores sociales en el agro nicaragüense, Nitlapan-UCA. Nicaragua.

Mansuri, G. \& Rao, V. (2004). Community-based and -driven development: a critical review. The World Bank Research Observer 19(1), 1-39

McPherson, M., Smith-Lovin, L. \& Cook, J. (2001). 'Birds of a feather: Homophily in Social Networks', Annual Review of Sociology 27, 415-44.

Mosse, D. (1994). 'Authority, Gender and Knowledge: Theoretical Reflections on the Practice of Participatory Rural Appraisal', Development and Change $25,497-526$.

Mosse, D. (2001). 'People's knowledge, participation and patronage: operations and representations in rural development', in: Cooke, B. \& Kothari, U. (eds.) Participation: the new tyranny?, London-New York: Sed Books Ltd.

Offerman, T. (1997). Beliefs and Decision Rules in Public Good Games: Theory and Experiments, Kluwer, Dordrecht/Boston/London.

Ostrom, E. (1990). Governing the commons: The evolution of institutions for collective action, Cambridge: Cambridge University Press.

Ostrom, E. \& Walker, J. (eds.) (2003). Trust and Reciprocity: Interdisciplinary Lessons from Experimental Research, New York, N.Y.: Russell Sage Foundation.

Platteau, J.P. \& Abraham, A. (2002). 'Participatory development in the presence of endogenous community imperfections', Journal of Development Studies 39(2), 104-36.

Platteau, J.P. \& Gaspart, F. (2003). 'The risk of resource misappropriation in community-driven development', World Development 31(10), 1687-703.

Putnam, R.D., Leonardi, R. \& Nanetti, R.Y. (1993). Making Democracy Work, Princeton: Princeton University Press.

Ravallion, M. (2003). 'Targeted transfers in poor countries: revisiting the tradeoffs and policy options', World Bank Policy Research Working Paper 3048, Washington. 
Riedl, A. \& Vyrastekova, J. (2004). 'Responder Behavior in Three-Person Ultimatum Game Experiments', mimeo

Sen (1995). 'The Political Economy of Targeting', in: van de Walle, D. \& Nead, K. (1995). Public Spending and the Poor, The World Bank.

Slembeck, T. (1999). 'Reputations and Fairness in Bargaining Experimental Evidence from a Repeated Ultimatum Game With Fixed Opponents', Discussion Paper No. 9904, Department of Economics - University of St. Gallen.

Sonnemans, J., van Dijk, F. \& van Winden, F. (2006). 'On the dynamics of social ties structures in groups', Journal of Economic Psychology 27, 187204.

Thomas, D. (1990). 'Intra-household Resource Allocation: An Inferential Approach', Journal of Human Resources 25(4), 635-64.

Tversky, A. \& Kahneman D. (1974). 'Judgment under uncertainty: heuristics and biases', Science 185, 1124-31.

Van Dijk, F., Sonnemans, J. \& van Winden, F. (2002). 'Social ties in a public good experiment', Journal of Public Economics 85, 275-299.

Wolf, E.R. (1977). 'Kinship, friendship, and patron-client relations in complex societies', in: Schmidt S.W., Scott, J.C., Landé, C.H. \& Guasti, L. (eds.) Friends, followers and factions: a reader in political clientelism, University of California Press.

Woolcock, M. (1998). 'Social capital and economic development: Toward a theoretical synthesis and policy framework', Theory and Society 27(2), 151-208.

World Bank (1990). Poverty, World Development Report 1990, New York: Oxford University Press.

World Bank (2000). Entering the 21st century: the changing development landscape, World Development Report 1999/2000, New York: Oxford University Press.

World Bank (2003). Reaching the rural poor: a renewed strategy for rural development.

World Bank (2006). Equity and Development, World Development Report 2006, New York: Oxford University Press. 



\section{Nederlandse Samenvatting (Summary in Dutch)}

Dit werk onderzoekt individuele verdelingsbeslissingen en de daaruit volgende uitsluitingprocessen in economisch ongelijke micro-samenlevingen. Het bouwt daarbij op de groeiende erkenning binnen de economische wetenschap dat economische actoren ingebed zijn in sociale structuren, die een belangrijke invloed uitoefenen op hun beslissingen en de resulterende werking van markten en organisaties (Granovetter, 1985). Onder een micro-samenleving verstaan we een samenleving waar er een herhaald en frequent contact bestaat tussen haar leden. Voorbeelden gaan van de sociale relaties op de arbeidsvloer in bedrijven in sterk ontwikkelde economieën, tot sociale relaties in landelijke dorpen in landen die geteisterd worden door extreme armoede.

In het bijzonder bestuderen we op welke manier de sociale inbedding van economische actoren in micro-samenlevingen een invloed uitoefent op verdelingsbeslissingen en processen van uitsluiting. We zullen niet enkel het individuele beslissingsgedrag onder de loep nemen van de actoren die economische middelen verdelen, maar ook het beslissingsgedrag van mogelijke ontvangers van deze middelen wanneer hen de mogelijkheid gegeven wordt om te protesteren. We zullen, in andere woorden, ook de politieke dimensie bestuderen van de verdeling van economische middelen in micro-samenlevingen. Rekening houdend met het beslissingsgedrag van zowel de verdelers als de potentiële ontvangers van economische middelen, willen we uiteindelijk de processen identificeren en begrijpen die verantwoordelijk zijn voor de bestendiging van economische ongelijkheden.

Hoewel deze zaken van toepassing zijn op vele en zeer verschillende omgevingen, leggen we waar mogelijk de nadruk op hun relevantie voor locale economische ontwikkeling en armoedebestrijding. Recent nog heeft economische gelijkheid en rechtvaardigheid opnieuw aandacht gekregen binnen het internationale debat rond armoedebestrijding en economische ontwikkeling. De Wereldbank besluit in haar World Development Report van 2006 dat economische gelijkheid en rechtvaardigheid belangrijk zijn in het tot stand brengen van 
structurele ontwikkeling en armoedebestrijding. Beleidsmakers moeten daarom ook belang hechten aan de implicaties van het beleid dat ze uitstippelen in termen van economische gelijkheid en rechtvaardigheid.

Dit debat is zeer relevant in Latijns Amerika, waar een groot deel van het empirisch onderzoek van dit werk uitgevoerd werd en waar inkomensverdelingen de meest ongelijke van de ontwikkelingswereld zijn. Reeds in 1990 beweerde de Wereldbank dat "nergens anders in de ontwikkelingswereld de contrasten tussen armoede en nationaal inkomen groter zijn dan in Latijns Amerika en de Caraïben. Ondanks gemiddelde inkomens die vijf tot zes keer hoger zijn dan in Zuid-Azië en Sub-Sahara Afrika, leeft bijna één vijfde van de bevolking nog steeds in armoede" (World Bank, 1990: 141). Gebaseerd op recente gegevens, kunnen we stellen dat deze situatie nauwelijks veranderd is in de laatste decennia, aangezien de economische ongelijkheid in dit continent bij de hoogste in de ontwikkelingswereld blijft (WDR, 2006). Eén van de hoofdvragen is dus waarom economische ongelijkheid zo hardnekkig kan zijn.

Eén van de belangrijkste redenen heeft betrekking op het gebrek aan politieke haalbaarheid van beleidsmaatregelen die economische ongelijkheden trachten te verminderen (Sen, 1995). Het komt er natuurlijk op neer dat wanneer dergelijke beleidsmaatregelen ontworpen en geïmplementeerd worden, beleidsmakers aandacht moeten schenken aan de preferenties van de kiezers en dat de armste groepen politiek zwak vertegenwoordigd zijn. In dezelfde zin, wordt er vaak geargumenteerd dat programma's of beleidsmaatregelen die enkel de armen bevoordelen uiteindelijk van slechte kwaliteit zijn (Goodin \& Le Grand, 1987), omdat ze de steun missen van de minder arme en machtigere sectoren.

In dit werk nemen we twee elementen onder de loep die tot nog toe onvoldoende aandacht gekregen hebben in het beleidsdebat en die toch een zeer belangrijke invloed uitoefenen op de politieke haalbaarheid van maatregelen ter vermindering van economische ongelijkheden. Beide hebben te maken met de 'sociale afstand' tussen de betrokken actoren.

Ten eerste, wordt er vaak over het hoofd gezien dat de mensen die getroffen worden door (her)verdelingsmaatregelen ingebed zijn in sociale netwerken. Het belang van sociale netwerken en hun invloed op de haalbaarheid van (her)verdelingsmaatregelen wordt zeer goed geïllustreerd door de gewapende boerenopstand tegen de Nicaraguaanse overheid in de jaren '80. Het is heel opmerkelijk dat dezelfde arme boeren die eerder gevochten hadden voor de Sandinistische revolutie daarna de wapens opnamen tegen de revolutionaire Sandinistische overheid. Deze guerrillaopstand was onder andere het gevolg van een reactie tegen de negatieve gevolgen die een nationale landhervorming zou hebben op locale sociale netwerken (Horton, 1998). Vele arme boeren hadden 
informele hulprelaties gevormd met locale grootgrondbezitters, die hen een geprivilegieerde toegang verschaften tot economische middelen. De Sandinistische landhervorming confisqueerde grote landeigendommen en bedreigde daarmee ook de sociale relaties die vele arme boeren hadden met deze grootgrondbezitters. Daarom beschouwden vele arme boeren dit overheidsprogramma als een serieuze bedreiging, ook al beloofde de overheid hen land, werk en sociale diensten. Dit geeft aan dat sociale netwerken serieus genomen moeten worden wanneer herverdelingsmaatregelen uitgevoerd worden, omdat ze een belangrijke bron van middelen en mogelijkheden vormen.

Ten tweede, wordt er vaak verondersteld dat de actoren die verdelingsbeslissingen nemen zich op een sociaal grote afstand bevinden van potentieel bevoordeelden en benadeelden. Dit is het geval wanneer de centrale overheid de enige is die verdelingsbeslissingen neemt. Deze assumptie wordt echter zeer onrealistisch nu beleidsmakers alsmaar meer aandacht schenken aan decentralisatie en locale participatie (World Bank, 2000). In de mate dat verdelingsbeslissingen meer en meer genomen worden op het locale niveau verkleint natuurlijk de sociale afstand tussen degenen die economische middelen verdelen en potentieel bevoordeelden en benadeelden.

Het is het doel van deze studie om tot een beter begrip te komen van de complexe processen die verantwoordelijk zijn voor sociale uitsluiting en de instandhouding van economische ongelijkheden, en de invloed die sociale netwerken en economische ongelijkheid daarop uitoefenen. Daarvoor bestuderen we verdelingsbeslissingen in micro-samenlevingen met behulp van enquêtes, laboratoriumexperimenten en veldexperimenten.

Hoofdstuk 2 presenteert de resultaten van een veldstudie over de invloed die gemeenschapsvertegenwoordigers uitoefenen op uitsluiting van ontwikkelingsmiddelen. Gebruik makende van een huishoudenquête in 33 Nicaraguaanse landelijke dorpen, observeren we dat vele huishoudens hun toevlucht nemen tot een dorpsvertegenwoordiger om toegang te verkrijgen tot de economische middelen die externe hulpdonoren aanbieden. Bovendien blijkt dat de vertegenwoordigingsstructuren op dorpsniveau een bepalende invloed uitoefenen op de uitsluiting van externe hulp. Hoe meer deze vertegenwoordiging gemonopoliseerd wordt door een beperkt aantal vertegenwoordigers, hoe groter de groep die uitgesloten blijft van externe hulpmiddelen. Aangezien het voornamelijk de armsten zijn die relatief meer gebruik maken van gemeenschapsvertegenwoordigers om toegang te verkrijgen tot externe hulp, zijn zij ook het kwetsbaarst voor deze uitsluiting. Om deze redenen, hebben we gekeken naar de locale politieke dimensie die verantwoordelijk is voor de bestendiging of transformatie van deze vertegenwoordigingsstructuren. 
We hebben verschillende mechanismen geïdentificeerd die politieke verandering belemmeren. Ten eerste, in dorpen met zeer gecentraliseerde vertegenwoordigingsstructuren worden minder politieke alternatieven geïdentificeerd, wat de perspectieven voor een meer gedecentraliseerde structuur beperkt. Ten tweede, de meest uitgeslotenen kennen minder vertegenwoordigers en hebben dus minder capaciteit om politieke alternatieven voor te stellen. Bijgevolg, als politieke verandering tot stand komt met locale steun is het vrij onwaarschijnlijk dat het de vertegenwoordiging van de meest uitgeslotenen verbetert. Dit pleit voor een actievere rol voor externe hulpdonoren.

In de andere hoofdstukken diepen we dit werk uit in twee richtingen: de politieke economie die in werking treedt bij verdelingsbeslissingen in microsamenlevingen en het belang van sociale relaties en sociale netwerk posities. In hoofdstuk 3, kijken we naar de politieke economie wanneer een permanente groepsvertegenwoordiger economische middelen verdeelt onder de groepsleden. We bestuderen daarbij de strategieën van de groepsleden die de mogelijkheid hebben om te protesteren tegen de verdelingsbeslissingen van de groepsvertegenwoordiger en dit in wisselwerking met de strategieën van de vertegenwoordiger. Hiervoor maken we gebruik van een gedragsexperiment in een computerlabo. Het experiment bestaat uit een herhaald spel waarbij een permanente groepsvertegenwoordiger die de rijkste is van een economisch heterogene groep, economische middelen verdeelt onder de groepsleden. De groepsleden hebben dan de mogelijkheid om de vertegenwoordiger te straffen door middel van een meerderheidsstemming. We onderzoeken daarbij de invloed van de toegang tot informatie over de verdelingsbeslissingen en het stemgedrag.

De experimentele resultaten tonen aan dat hoe minder middelen men ontvangt van de vertegenwoordiger, hoe lager de voldoening is met het ontvangen deel. Wanneer men informatie ontvangt over de volledige verdeling, vermindert deze voldoening ook indien men minder krijgt in vergelijking met de andere groepsleden. Zoals verwacht verhoogt een lagere voldoening de bereidheid om te stemmen voor het straffen van de vertegenwoordiger. Bovendien zijn er ook belangrijke strategische elementen die het stemgedrag beïnvloeden. Wanneer het stemmen publiek is, zal men minder geneigd zijn om te stemmen tegen de vertegenwoordiger, maar dit effect verzwakt met een lagere voldoening. Hoe meer men verwacht dat twee andere groepsleden zullen stemmen voor straffen, hoe meer men geneigd zal zijn het zelfde te doen. Vrouwelijke en rijkere groepsleden zijn minder geneigd om te stemmen voor straffen tenzij zij informatie krijgen over de volledige verdeling.

Aangezien de groepsvertegenwoordiger een groot verlies lijdt waneer hij gestraft wordt, is hij geneigd om alle middelen voor zich te houden wanneer hij 
gestraft wordt. Dit is het geval tenzij de stemmingsprocedure publiek is en informatie over de volledige verdeling niet publiek gemaakt wordt. De groepsvertegenwoordiger is dan in staat om te vermijden dat er een meerderheid stemt om hem te straffen. Vele vertegenwoordigers volgen daarbij een uitsluitingstrategie. Zij zorgen ervoor dat ze de politieke steun krijgen van twee groepsleden en sluiten de derde volledig uit. In de meeste gevallen is het de armste van de groep die op deze manier uitgesloten wordt.

Om de invloed van een politieke verandering ten voordele van het armste groepslid te onderzoeken, organiseren we ook een tweede deel waarbij het armste groepslid de rol van groepsvertegenwoordiger overneemt. We zien dat de uiteindelijke verdeling minder ongelijk wordt en dat straffen veel minder frequent voorkomt. Dergelijke politieke verandering is dus niet enkel verdedigbaar omdat het de uiteindelijke verdeling rechtvaardiger maakt, maar ook in termen van het lagere efficiëntieverlies door straffen.

In hoofdstuk 4 bestuderen we de invloed van sociale netwerken op individueel verdelingsgedrag. We onderzoeken in welke mate er rekening gehouden wordt met de individuele positie in sociale netwerken wanneer economische middelen verdeeld worden. Hiervoor organiseren we een dictator spel in een Nicaraguaanse dorp aangevuld met een enquête om sociale netwerken in kaart te brengen. De resultaten geven aan dat vrijgevigheid sterk correleert met sociale netwerken en de individuele positie daarin, maar dat deze correlatie sterk afhankelijk is van het type netwerk dat we bekijken. Sociale nabijheid in algemene netwerken, vriendschapsnetwerken of familienetwerken verhoogt vrijgevigheid. Bovendien stijgt vrijgevigheid hoe meer de vrienden van de dictator relatief weinig andere vrienden hebben, hoe dichter de hulpnetwerken van de dictator, hoe kleiner de familienetwerken van de dictator of de ontvanger (indien de dictator en de ontvanger een directe familieband hebben), of hoe groter het netwerk van de ontvanger op het vlak van sociale publieke activiteiten. Ten slotte, kijken we naar de bepalende factoren van netwerkformatie. We vinden dat arme mensen, minder mobiele mensen, vrouwen of jonge mensen met een lagere waarschijnlijkheid een sociale relatie met een specifiek ander van hun dorp hebben. Als gevolg zijn deze groepen kwetsbaarder voor sociale uitsluiting omdat ze over het algemeen zich op een sociaal grotere afstand bevinden van andere mensen uit hun dorp.

Omdat deze resultaten het belang van sociale netwerken aantoonden voor individuele verdelingsbeslissingen, bestuderen we in hoofdstuk 5 hoe sociale netwerken gevormd worden en hoe economische ongelijkheid hierop een invloed uitoefent. Hiervoor organiseerden we een gedragsexperiment in een computerlabo dat bestaat uit een herhaald 'gunsten'-spel met groepen van zes 
spelers. In elke ronde krijgt een willekeurig gekozen speler de mogelijkheid om één of meer van de andere vijf groepsleden om hulp te vragen. Elke speler die om hulp gevraagd wordt beslist over de hoeveelheid hulp die hij geeft, waarna deze hulp vermenigvuldigd wordt met een efficiëntiefactor.

De resultaten bevestigen dat zowel het vragen naar hulp als het geven van hulp beïnvloed wordt door motieven van directe wederkerigheid alsook door individuele verwachtingen over toekomstige tegenprestaties. Economische ongelijkheid zorgt voor een zekere asymmetrie in de invloed die verwachte tegenprestaties en directe wederkerigheid uitoefenen. Rijke spelers geven meer hulp aan armere spelers dan wat zij krijgen van arme spelers. Dit verschil wordt groter, hoe groter de meest recente hulp die ze ontvangen hebben van arme spelers. Tegelijkertijd zijn arme spelers meer geneigd om hulp te vragen van rijke spelers. Bovendien zullen arme spelers meer hulp geven aan rijke spelers dan aan andere arme spelers. Zij doen dit omdat zij hogere tegenprestaties verwachten van rijke spelers. Het is deze asymmetrische wederkerigheid die aan de basis ligt van een zekere centralisering in de gevormde sociale netwerken in economisch ongelijke groepen. Het verklaart ook waarom er in economisch ongelijke groepen zeer hoge niveaus van hulp bereikt kunnen worden als in het begin van het spel arme spelers veel hulp geven aan andere arme spelers en aan de rijke spelers.

Als we alle analyses samenvoegen komen we tot de volgende inzichten over de bestendiging van economische ongelijkheden. Gegevens uit enquêtes en gedragsexperimenten tonen aan dat armere actoren zich in minder voordelige posities bevinden op sociaal en politiek vlak. $\mathrm{Zij}$ hebben niet alleen minder voordelige posities in sociale netwerken die hun toegang tot economische middelen bepalen. Hun zwakkere sociale inbedding maakt hen ook politiek zwakker. In de context van toegang tot middelen van hulpdonoren, kennen mensen die uitgesloten worden van deze middelen minder politieke alternatieven die de heersende politieke vertegenwoordigers zouden kunnen vervangen, wat hun toegang tot economische middelen zou kunnen verbeteren. Het versterken van hun politieke stem om dit te verhelpen kan echter een risicovolle onderneming zijn, vooral wanneer dit impliceert dat hun stem publiek gemaakt wordt. De heersende vertegenwoordigers hebben dan de mogelijkheid om strategisch te reageren. Om hun winsten te maximeren kunnen zij doelbewust deze armere actoren uitsluiten, die in vergelijking met minder armere actoren moeilijker tevreden te stemmen zijn, omdat ze aanspraak maken op een groter deel van de beschikbare economische middelen. Om de uitsluiting van deze armere actoren daadwerkelijk te verminderen dienen zij zelf politiek leidershap op te nemen. Rekening houdend met de geïdentificeerde hinderpalen voor 
dergelijke politieke verandering kan hiervoor een actievere inmenging van externe hulpdonoren nodig zijn. 


\section{Short Curriculum Vitae}

Ben D'Exelle was born on March 26, 1974 in Antwerp, Belgium. In 1997 he obtained his master's degree in Applied Economics - Commercial Engineer (University of Antwerp) with distinction, with a master thesis on reforestation and the economic rationality of poor peasants in Nicaragua. In 1998 he finished with distinction the $\mathrm{PhD}$. program of the Faculty of Applied Economics of the University of Antwerp. From October 1998 until December 2001 he worked as a resident researcher at the Research and Development Institute Nitlapán of the Central American University (UCA) in Nicaragua, where he supported the local research team to accumulate research experience and capacity.

From January 2002 until August 2008 he worked as research and teaching assistant at the Institute of Development Policy and Management, University of Antwerp. From October 2004 he started his cooperation with Prof. Arno Riedl, first as guest researcher at the Centre for Research in Experimental Economics and Political Decision-making (CREED) at the Faculty of Economics and Econometrics (University of Amsterdam); from September 2005 at the Faculty of Economics and Business Administration of Maastricht University.

Research interests: experimental economics, development economics, political economy, social networks, social exclusion, microeconomic theory and poverty. 